March 6, 2012

\title{
Integrated Warm Gas Multicontaminant Cleanup Technologies for Coal-Derived Syngas
}

\author{
Final Technical Report \\ Period of Performance: \\ June 1, 2005 to September 30, 2010
}

U.S. Department of Energy National Energy Technology Laboratory 3610 Collins Ferry Road Morgantown, WV 26505

Prepared by

Brian Turk, Raghubir Gupta, Pradeepkumar Sharma, Johnny Albritton, Aqil Jamal RTI International Post Office Box 12194 3040 Cornwallis Road Research Triangle Park, NC 27709 


\section{ACKNOWLEDGMENTS}

This project was sponsored by the National Energy Technology Laboratory (NETL) of the U.S. Department of Energy (DOE) under Cooperative Agreement No. DE-FC2605NT42459. This financial assistance from DOE/NETL is gratefully acknowledged.

To support the field demonstration and development of warm syngas cleanup for chemical applications, this project has worked in parallel toward multiple objectives for different aspects of RTI's warm syngas cleanup technologies. It would be difficult to name every individual who has contributed to this project. Nonetheless, we would like to attempt to recognize the individuals who contributed to the development of the warm $\mathrm{CO}_{2}$ capture technologies.

- DOE/NETL: Gary Stiegel, Jenny Tennant, Kanwal Mahajan, David Lyons, Joseph Strakey, and Stewart Clayton (DOE/HQ)

- Noblis: David Gray and John Plunkett

- RTI: Gary Howe, Adesh Harle, Michael Levine, Jing-Ping Shen, Maruthi Pavani, Jason Trembly, and Luke Coleman

\section{DISCLAIMER}

This report was prepared as an account of work sponsored by an agency of the United States Government. Neither the United States Government nor any agency thereof, nor any of their employees, makes any warranty, express or implied, or assumes any legal liability or responsibility for the accuracy, completeness, or usefulness of any information, apparatus, product, or process disclosed, or represents that its use would not infringe privately owned rights. Reference herein to any specific commercial product, process, or service by trade name, trademark, manufacturer, or otherwise does not necessarily constitute or imply its endorsement, recommendation, or favoring by the United State Government or any agency thereof. The views and opinions of authors expressed therein do not necessarily state or reflect those of the United States Government or any agency thereof. 


\section{CONTENTS}

$\underline{\text { Section }} \quad \underline{\text { Page }}$

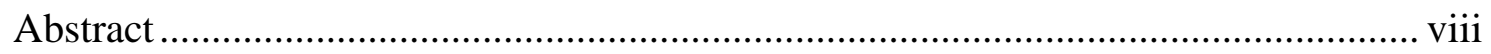

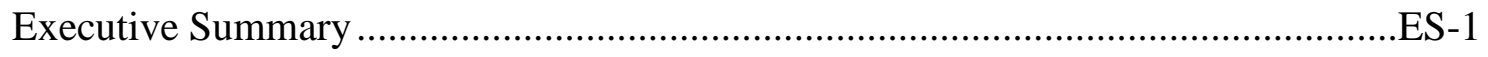

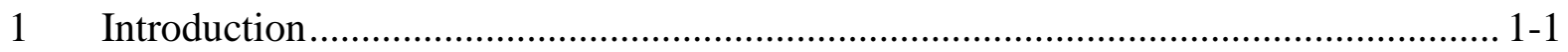

1.1 Development of Trace Contaminant Sorbents ................................................... 1-2

1.2 Development of Lithium Silicate $\mathrm{CO}_{2}$ Capture Sorbents .................................. 1-4

2 Development of Trace Contaminant Sorbents ......................................................... 2-1

2.1 Analysis of Sorbent Materials from Eastman Field Test ..................................... 2-1

2.2 Mercury Sorbent Development ................................................................... 2-5

2.2.1 Mercury Capacity..................................................................... 2-5

2.2.2 Testing for Lower Mercury Effluent Concentration ................................ 2-7

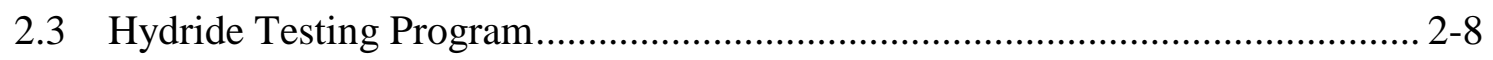

2.3.1 Candidate Hydride Material Preparation .............................................. 2-8

2.3.2 Metal Hydride Test System ………………................................... 2-8

2.3.3 Hydride QC Cartridge Sampling and Analysis ..................................... 2-11

2.3.4 Hydride Screening Study Procedure .................................................... 2-11

2.3.5 Hydride Capacity Study Procedure......................................................... 2-11

2.3.6 Metal Hydride Candidate Sorbent and QC Cartridge Analysis Procedure ................................................................................ 2-12

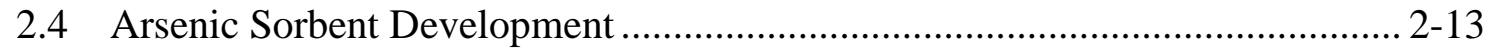

2.4.1 Arsenic Capacity ........................................................................... 2-13

2.4.2 Testing for Lower Arsenic Effluent Concentration .............................. 2-14

2.5 Hydrogen Selenide Sorbent Development ..................................................... 2-15

2.5.1 Hydrogen Selenide Sorbent Screening ………................................. 2-15

2.5.2 Hydrogen Selenide Capacity Testing............................................... 2-15

2.5.3 Testing for Lower Selenium Effluent Concentration.............................. 2-16

2.6 Phosphine Sorbent Development ............................................................. 2-17

2.6.1 Material Selection for QC Cartridge ................................................... 2-17

2.6.2 Phosphine Sorbent Screening ………………..................................... 2-17

2.6.3 Phosphine Sorbent Capacity Testing ................................................... 2-17 


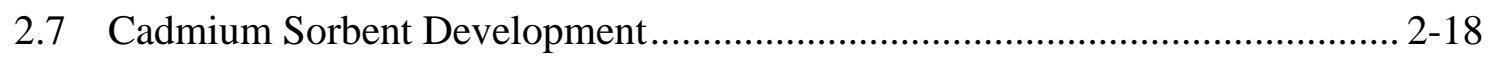

2.7.1 Cadmium Test System .................................................................... 2-18

3 Development of $\mathrm{Warm}^{\mathrm{CO}} \mathrm{CO}_{2}$ capture Technology ….................................................. 3-1

3.1 Novel R\&D Approach ............................................................................. 3-1

3.1.1 Screening Criteria for Novel Sorbent Materials .................................... 3-1

3.1.2 $\mathrm{CO}_{2}$ Recovery for Lithium Silicate Regeneration .................................. 3-2

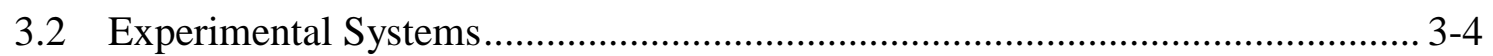

3.2.1 High-Pressure TGA ……………………….............................. 3-4

3.2.2 Automated Micro-reactor System......................................................... 3-5

3.2.3 Micro-reactor System.................................................................... 3-6

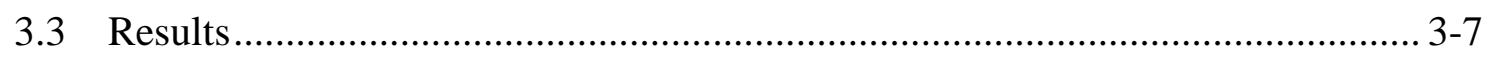

3.3.1 $\quad \mathrm{CO}_{2}$ Recovery Process ………..................................................... 3-7

3.3.2 $\quad \mathrm{CO}_{2}$ Sorbent Development...................................................... 3-12

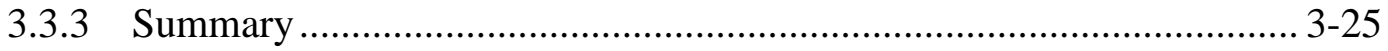

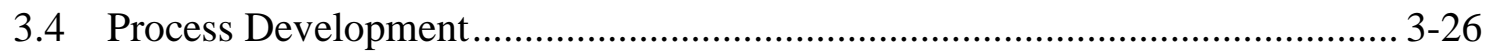

3.4.1 Experimental Testing Supporting Process Development Feasibility..... 3-26

3.4.2 Process Simulation........................................................................ 3-32

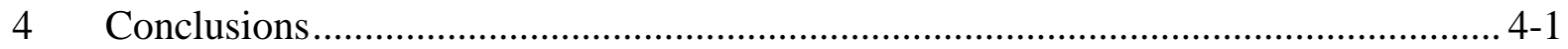

4.1 Multicontaminant Technologies for Warm Syngas Cleanup Platform................. 4-1

$4.2 \mathrm{CO}_{2}$ Technology for Warm Syngas Cleanup Platform ........................................ 4-2 


\section{LIST OF FIGURES}

Number

$\underline{\text { Page }}$

1-1 RTI's bench-scale sorbent testing system..................................................... 1-6

1-2 Profiles for adsorption process for lithium silicate for syngas containing 5,000 ppmv $\mathrm{H}_{2} \mathrm{~S}$ showing both $\mathrm{CO}_{2}$ capture and water gas shift activity........... 1-6

2-1 Block flow diagram for multicontaminant system.......................................... 2-1

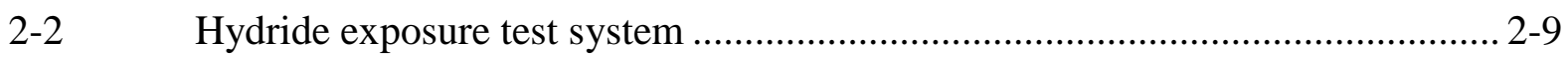

2-3 Six-port valve flow diagram on the hydride exposure test system .................... 2-10

2-4 Cadmium Exposure System ....................................................................... 2-19

3-1 Thermodynamic equilibrium curves for $\mathrm{CO}_{2}$ partial pressure with highlighted area showing materials meeting screening selection criteria............. 3-2

3-2 Processing steps in proposed $\mathrm{CO}_{2}$ recovery process........................................ 3-3

3-3 RTI high-pressure TGA (HP TGA) modified for testing $\mathrm{CO}_{2}$ sorbent

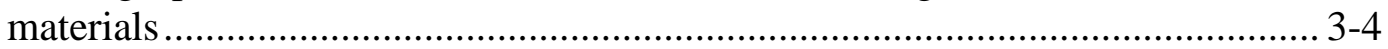

3-4 RTI's automated micro-reactor (AMR) system: (a) front view and (b) reactors ........................................................................................... 3-5

3-5 Schematic of RTI's micro-reactor system as configured for $\mathrm{CO}_{2}$ testing ........... 3-6

3-6 Adsorption profiles for $5 \mathrm{~A}$ and $13 \mathrm{X}$ zeolites at different temperatures

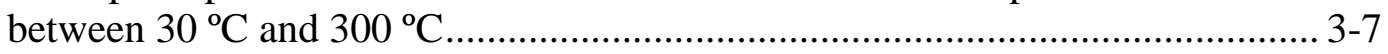

3-7 Effect of steam on $\mathrm{CO}_{2}$ adsorption for Zeolite 5A …..................................... 3-8

3-8 $\quad \mathrm{CO}_{2}$ adsorption capacities for ion-exchanged 5A zeolite samples ...................... 3-9

3-9 $\quad \mathrm{CO}_{2}$ adsorption capacities for ion-exchanged 13X zeolite samples ..................... 3-9

3-10 Effluent $\mathrm{CO}_{2}$ concentration for regeneration by concentration swing at different nitrogen flow rates.......................................................................... 3-10

3-11 Effluent $\mathrm{CO}_{2}$ concentrations during regeneration by concentration swing with $\mathrm{N}_{2} /$ steam mixtures ............................................................................... 3-11

3-12 Effluent $\mathrm{CO}_{2}$ concentration during regeneration by concentration swing at different temperatures .............................................................................. 3-12

3-13 HP-TGA test of RTI-prepared "reactive" $\mathrm{MgO}$ sample …................................ 3-13

3-14 Parametric testing of Promoter A concentration on $\mathrm{CO}_{2}$ capture performance for promoted $\mathrm{MgO}$.................................................................... 3-14

3-15 Parametric testing of Promoter B concentration for $\mathrm{CO}_{2}$ capture

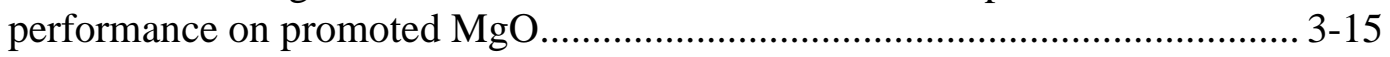

3-16 Parametric test results for $\mathrm{CO}_{2}$ capture for $\mathrm{MgO}$ samples with different

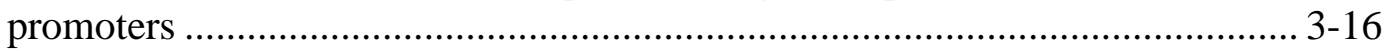

3-17 $\quad \mathrm{CO}_{2}$ capture performance for commercial samples of $\mathrm{Mg}$ compounds ............. 3-17

3-18 $\quad \mathrm{CO}_{2}$ capture performance of commercial samples of $\mathrm{Mg}$ compounds promoted with Promoter D 
3-19 Comparison of $\mathrm{MgO}$ utilization for $\mathrm{DeSO}_{\mathrm{x}}$ catalyst with and without Promoter B ....................................................................................... 3-18

3-20 $\quad \mathrm{CO}_{2}$ capacity performance for physical mixtures of promoted $\mathrm{MgO}$ and support materials.

3-21 $\quad \mathrm{CO}_{2}$ capture performance for samples with sepiolite being used as a support material

3-22 $\quad \mathrm{CO}_{2}$ capture performance for samples with alumina and bohemite being used as a support material.

3-23 Comparison of $\mathrm{CO}_{2}$ adsorption capacity for single-step formulations with magnesium aluminate calcined at different temperatures.

3-24 Comparison of $\mathrm{CO}_{2}$ adsorption capacity for formulations with magnesium aluminate calcined at different temperatures prior to being promoted

3-25 Comparison of $\mathrm{CO}_{2}$ adsorption capacity for calcium aluminate-based formulations calcined at temperatures between $400^{\circ} \mathrm{C}$ and $700{ }^{\circ} \mathrm{C}$.

3-26 Effect of syngas and steam on $\mathrm{CO}_{2}$ adsorption capacity of $\mathrm{MgO}$ sorbent promoted with Promoter B

3-27 $\quad \mathrm{CO}_{2}$ adsorption capacity at different steam concentrations for $\mathrm{MgO}$ promoted with Promoter F

3-28 Effect of $\mathrm{CO}_{2}$ partial pressure on $\mathrm{CO}_{2}$ adsorption capacity .......................... 3-27

3-29 Effect of regeneration temperature on $\mathrm{CO}_{2}$ adsorption capacity ..................... 3-28

3-30 Effects of space velocity on $\mathrm{CO}_{2}$ adsorption capacity ................................... 3-29

3-31 Effluent gas compositions for testing with and without WGS catalyst ............ 3-29

3-32 Test of new operating cycle for new process configuration ............................ 3-30

3-33 Temperature effects on $\mathrm{MgO}$-based sorbents to achieve extremely low effluent $\mathrm{CO}_{2}$ concentrations at 225 psi of $\mathrm{CO}_{2}$ partial pressure...

3-34 Calculated $\mathrm{CO}_{2}$ adsorption capacities near $100 \% \mathrm{CO}_{2}$ capture for parametric testing of adsorption temperature and $\mathrm{CO}_{2}$ partial pressure

3-35 Block flow diagram of generic IGCC system 


\section{LIST OF TABLES}

Number

$\underline{\text { Page }}$

1-1 Warm Syngas Cleanup ${ }^{1}$ - DOE Performance Goals $1-1$

1-2 Potential Species Present in Syngas for the Target Elemental

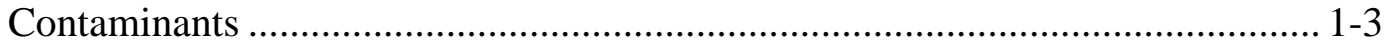

1-3 Contaminant Concentrations in Syngas ................................................. 1-3

2-1 List of Specific Materials Loaded in Vessels in Multicontaminant Skid ........... 2-1

2-2 Net Contaminant Concentrations for Commercial Sorbent A (Arsenic

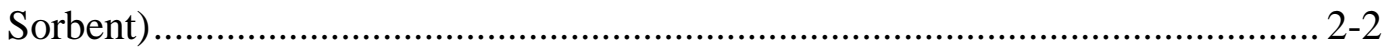

2-3 Net Contaminant Concentrations for Commercial Sulfur Guard Bed

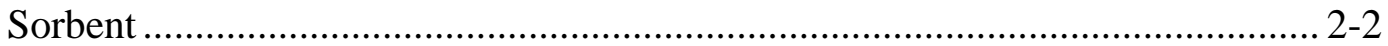

2-4 Net Contaminant Concentrations for Ammonia Sorbent (CBV-712)................. 2-3

2-5 Net Contaminant Concentrations for Impregnated Carbon (Hg Sorbent) ........... 2-3

2-6 Net Contaminant Concentrations for RTI-3 Sorbent ..................................... 2-3

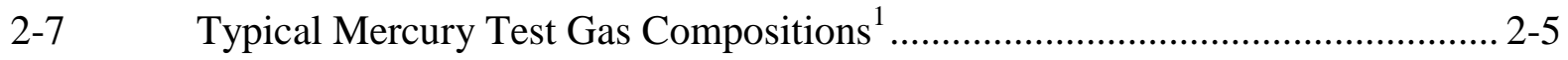

2-8 Summary of Mercury Capacity Testing ...................................................... 2-6

2-9 Mercury Capacity at below 5 ppbw Hg Effluent ............................................ 2-8

2-10 Typical Hydride Test Gas Compositions ${ }^{1}$...................................................... 2-9

2-11 Hydride Quality Control Cartridge Configuration ............................................ 2-11

2-12 Summary of Arsine Capacity Testing .................................................... 2-14

2-13 Modified As Testing for 5 ppbv Effluent Concentration................................. 2-15

2-14 Results from Hydrogen Selenide Screening ............................................ 2-15

2-15 Summary of Hydrogen Selenide Capacity Testing ........................................ 2-16

2-16 Modified Se Testing for 200 ppbv Effluent Concentration ............................. 2-16

2-17 Results from Phosphine Screening Studies................................................. 2-17

2-18 Summary of Phosphine Capacity Testing .................................................. 2-18

3-1 Problems and Solutions Encountered with HP-TGA Testing........................... 3-5

3-2 $\quad \mathrm{CO}_{2}$ Test Results from Micro-Reactor System ........................................... 3-12

4-1 Warm Syngas Cleanup ${ }^{1}$-DOE Performance Goals ....................................... 4-1 


\begin{abstract}
One of the key obstacles for the introduction of commercial gasification technology for the production of power with Integrated Gasification Combined Cycle (IGCC) plants or the production of value added chemicals, transportation fuels, and hydrogen has been the cost of these systems. This situation is particularly challenging because the United States has ample coal resources available as raw materials and effective use of these raw materials could help us meet our energy and transportation fuel needs while significantly reducing our need to import oil. One component of the cost of these systems that faces strong challenges for continuous improvement is removing the undesirable components present in the syngas.

The need to limit the increase in cost of electricity to $<35 \%$ for new coal-based power plants which include $\mathrm{CO}_{2}$ capture and sequestration addresses both the growing social concern for global climate change resulting from the emission of greenhouse gas and in particular $\mathrm{CO}_{2}$ and the need to control cost increases to power production necessary to meet this social objective. Similar improvements to technologies for trace contaminants are getting similar pressure to reduce environmental emissions and reduce production costs for the syngas to enable production of chemicals from coal that is cost competitive with oil and natural gas.

RTI, with DOE/NETL support, has been developing sorbent technologies that enable capture of trace contaminants and $\mathrm{CO}_{2}$ at temperatures above $400{ }^{\circ} \mathrm{F}$ that achieve better capture performance, lower costs and higher thermal efficiency. This report describes the specific work of sorbent development for mercury $(\mathrm{Hg})$, arsenic (As), selenium $(\mathrm{Se})$, cadmium $(\mathrm{Cd})$, and phosphorous $(\mathrm{P})$ and $\mathrm{CO}_{2}$ removal. Because the typical concentrations of $\mathrm{Hg}, \mathrm{As}, \mathrm{Se}, \mathrm{Cd}$, and $\mathrm{P}$ are less than $10 \mathrm{ppmv}$, the focus has been on single-use sorbents with sufficient capacity to ensure replacement costs are cost effective. The research in this report describes the development efforts which expand this sorbent development effort to include $\mathrm{Se}, \mathrm{Cd}$, and $\mathrm{P}$ as well as $\mathrm{Hg}$ and As. Additional research has focused on improving removal performance with the goal of achieving effluent concentrations that are suitable for chemical production applications.

By contrast, sorbent development for $\mathrm{CO}_{2}$ capture has focused on regenerable sorbents that capture the $\mathrm{CO}_{2}$ byproduct at higher $\mathrm{CO}_{2}$ pressures. Previous research on $\mathrm{CO}_{2}$ sorbents has demonstrated that the most challenging aspect of developing $\mathrm{CO}_{2}$ sorbents is regeneration. The research documented in this report investigates options to improve regeneration of the $\mathrm{CO}_{2}$ capture sorbents. This research includes effort on addressing existing regeneration limitations for sorbents previously developed and new approaches that focus initially on the regeneration performance of the sorbent.
\end{abstract}




\section{EXECUTIVE SUMMARY}

The primary objective of this project has been to develop syngas cleanup technologies that operate at temperatures $>400^{\circ} \mathrm{F}$ with specific goals of reducing the cost of gasification technologies, improving the performance of the cleaning processes, and improving the thermal efficiency of syngas cleaning. The key driver for this research is the need to drive down the cost of commercial applications of coal gasification to make it competitive. This research has also focused on expanding RTI's syngas cleaning platform to address:

- A larger portfolio of contaminants, namely selenium (Se), cadmium (Cd), and phosphorous $(\mathrm{P})$ as well as mercury $(\mathrm{Hg})$ and arsenic (As)

- More stringent effluent concentrations that support chemical production as well as more stringent emission regulations

- The challenges of developing a cost effective $\mathrm{CO}_{2}$ capture and sequestration process.

This research has resulted in two sorbent development programs. The first has worked towards the development of single-use sorbents for which their concentration in syngas is $<10$ ppmv. At these concentrations, the utilization of the sorbent's capacity to capture contaminants can be slow enough that replacement costs are acceptable. To help expedite identification and development of sorbents for these applications, preferential selection criteria for candidate sorbent materials included commercially available materials and materials that demonstrated removal potential for multiple contaminants. In addition, the sorbent materials that were exposed to real coal-derived syngas during the Eastman field test (see Final Report for ) were submitted for additional analysis for the contaminants in the expanded contaminant portfolio for this project to provide actual exposure information at operating conditions.

These criteria were selected to enable rapid transfer successful sorbent development and demonstration to actual commercial application. Available commercial materials were preferred because existing commercial production expertise would shorten or completely eliminate scale up production of this material for actual commercial application. The ability to effectively simultaneously remove multiple contaminants helps intensify the syngas cleaning process resulting in lower capital and operating costs which can accelerate implementation of a technology. 
Three specialized laboratory reactor systems were used to screen and evaluate sorbent contaminant capacity. Testing in the laboratory reactor systems used a simulated syngas mixture for testing. The advantage of a simulated syngas mixture was the ability to carefully control the composition of the syngas and the concentration of the contaminants. This provided greater ability to investigate synergistic interactions between the primary syngas components, syngas and sorbent materials. However, the key disadvantage was the chemical composition of the contaminant was fixed. The selection of the contaminant chemical composition was selected based on the best available information, which is the thermodynamic equilibrium predictions based on chemical stability. Based on these thermodynamic predictions, the chemical composition of the contaminants was $\mathrm{Hg}$ vapor, arsine $\left(\mathrm{AsH}_{3}\right)$, hydrogen selenide $\left(\mathrm{H}_{2} \mathrm{Se}\right), \mathrm{Cd}$ vapor and phosphine $\left(\mathrm{PH}_{3}\right)$ for $\mathrm{Hg}, \mathrm{As}, \mathrm{Se}, \mathrm{Cd}$ and $\mathrm{P}$, respectively.

For the contaminants As, Se and $\mathrm{P}$, at least one, but generally several sorbent materials were identified that had effective capture capacities of $>3 \mathrm{wt} \%$. Modification of the testing protocol also enabled demonstrating that most promising sorbents could also effectively capture these contaminants at the DOE targets for these contaminants for chemical production. Another positive result from this development program was that several sorbent materials were identified that could effectively remove more than one contaminant. Unfortunately, there was not sorbent that effectively removed all of the targeted contaminants.

Mercury sorbent development attempted to address the limited capacity for $\mathrm{Hg}$ at operating temperatures $>400^{\circ} \mathrm{F}$. The results from analysis of the sorbent materials from the Eastman field test provided clues for a $\mathrm{Hg}$ sorbent with about 2 times the capacity for the of the mercury sorbent tested at Eastman. Additional research will be necessary to effectively integrate this new sorbent into the syngas cleanup technology platform.

The challenge for the $\mathrm{Cd}$ sorbent development task was generating a simulated syngas stream with a known and consistent concentration of $\mathrm{Cd}$ vapor. The approach attempted in this project involved using the vapor pressure of a heated sample of $\mathrm{Cd}$ metal to generate the $\mathrm{Cd}$ vapor. Unfortunately even at the outlet of the $\mathrm{Cd}$ vapor generator, the concentration of $\mathrm{Cd}$ vapor was significantly less than predicted based on thermodynamics and was not consistent. These results coupled with the $\mathrm{Cd}$ concentrations in the coal-derived syngas at Eastman warrant additional investigation of the importance of $\mathrm{Cd}$ as a contaminant in coal-derived syngas.

The second sorbent development program was devoted to regenerable sorbents for $\mathrm{CO}_{2}$ capture. This program looked at a zeolite based $\mathrm{CO}_{2}$ recovery process that exploited previous development of a lithium silicate-based sorbent material. The advantages of the Lithium silicate 
material were exceptional $\mathrm{CO}_{2}$ capture performance from syngas mixtures even in the presence of $\mathrm{H}_{2} \mathrm{~S}$. The challenge was regeneration of this sorbent. In this project a number of zeolite materials were found that could effectively capture $\mathrm{CO}_{2}$ at lower partial pressure and temperature and produce a pressurized $\mathrm{CO}_{2}$ byproduct using a temperature swing desorption process. The problem was the effluent $\mathrm{CO}_{2}$ concentration during regeneration of the lithium silicate-based sorbent was not sufficient to effectively use the zeolite sorbent for $\mathrm{CO}_{2}$ recovery.

Using a modified screening process, which focused on high pressure regeneration, a novel magnesium oxide- (MgO-) based sorbent was identified. This sorbent had $\mathrm{CO}_{2}$ capacities of $>40 \mathrm{wt} \%$ and could produce higher pressure $\mathrm{CO}_{2}$ byproduct stream with a thermal swing. Process development of this process demonstrated that a pressure swing regeneration of this material was more acceptable than a thermal swing. However, even with a pressure swing, the $\mathrm{CO}_{2}$ partial pressure was still very low and steam was needed. Techno-economic analysis of the process did not demonstrate significant thermal efficiency improvement over a conventional Selexol-based $\mathrm{CO}_{2}$ capture process. 



\section{SECTION 1 \\ INTRODUCTION}

Although the large abundance and low cost of coal compared to other fossil fuels make coal an attractive fuel source, the use of gasification technology for the conversion of this fuel source into power through integrated gasification combined cycle (IGCC) systems or valueadded chemicals - ranging from hydrogen to transportation fuels - has been limited. One limitation has been a cost-effective means of removing contaminants to meet specifications required for either power or chemical production. To address this limitation, RTI, with funding from the Department of Energy National Energy Technology Laboratory (DOE/NETL), has been actively developing a full syngas cleaning technology platform that operates at temperatures greater than $400{ }^{\circ} \mathrm{F}$ to optimize the overall thermal efficiency, reduce capital and operating costs, and enable tailoring contaminant removal performance for power and chemical applications.

Key components of this technology platform include the high-temperature desulfurization process (HTDP), the direct sulfur recovery process (DSRP), and sorbents for removal of trace components like hydrochloric acid $(\mathrm{HCl})$, ammonia $\left(\mathrm{NH}_{3}\right)$, mercury $(\mathrm{Hg})$, and arsenic (As). Pilot plant operation at Eastman Chemical Company in Kingsport, Tennessee with real coal-derived syngas successfully showed the technical capabilities of HTDP, DSRP, and sorbents for As and $\mathrm{Hg}$. Independent techno-economic studies by Nexant and Noblis have used these pilot plant data to demonstrate that warm syngas cleanup both improves thermal efficiency and reduces capital cost of an IGCC system. Documentation of this technology development and the Eastman pilot plant testing can be found in a Final Topical Report entitled Novel Technologies for Gaseous Contaminants Control, submitted under DOE Contract No. DE-AC26-99FT40675.

This development and the Eastman pilot plant testing were exclusively focused on existing cleanup requirements for IGCC applications. In addition, the different technologies in the warm syngas cleaning platform were at different stages of development. To continue commercialization of this technology, the focus for the warm gas cleaning platform and this project were directed toward meeting syngas contaminant removal requirements for chemical production applications established by DOE/NETL and shown in Table 1-1. In addition to the requirements in Table 1-1, the project also focused on accelerating development of sorbent-based removal of trace contaminants and
Table 1-1. Warm Syngas Cleanup ${ }^{1}-$ DOE Performance Goals

\begin{tabular}{cc}
\hline Contaminant & $\begin{array}{c}\text { Maximum } \\
\text { after Cleanup }\end{array}$ \\
\hline $\mathrm{S}$ (total) & $50 \mathrm{ppb}$ \\
$\mathrm{NH}_{3}$ & $10 \mathrm{ppm}$ \\
$\mathrm{HCl}$ & $10 \mathrm{ppb}$ \\
$\mathrm{Hg}$ & $5 \mathrm{ppbw}$ \\
$\mathrm{Se}$ & $0.2 \mathrm{ppm}$ \\
$\mathrm{As}$ & $5 \mathrm{ppb}$ \\
$\mathrm{Cd}$ & $30 \mathrm{ppb}$ \\
$\mathrm{P}$ & $20 \mathrm{ppb}$ \\
$\mathrm{CO}_{2}$ & $>90 \%$ \\
\hline
\end{tabular}

${ }^{1}$ At pressure $\geq 600 \mathrm{psi}$; temperatures $\geq 400^{\circ} \mathrm{F}$ 
sorbent-based $\mathrm{CO}_{2}$ capture at temperatures above $400{ }^{\circ} \mathrm{F}$. The goal was to ensure that these technologies would be available to help meet regulations being developed for new IGCC plants being built.

Development of these sorbent-based technologies for trace contaminant removal and $\mathrm{CO}_{2}$ capture required very different developmental approaches to meet the specific removal constraints. An example of these differences is contaminant concentration in the syngas. Contaminants like $\mathrm{Hg}$, As, selenium (Se), and cadmium $(\mathrm{Cd})$ are typically present in concentrations of less than 1 ppmv. By contrast, $\mathrm{CO}_{2}$ is typically present at $>5 \mathrm{vol} \%(50,000$ ppmv). The cost-competitive solution for a sorbent-based approach for the high $\mathrm{CO}_{2}$ concentrations requires a regenerable sorbent that permits multiple regenerations to reduce sorbent costs. For the trace contaminants, a single-use sorbent will be acceptable because the low concentration of the contaminant permits long periods of operation prior to the need to replace the sorbent. Therefore, distinct tasks were developed and implemented for sorbents for trace contaminant removal and high-temperature $\mathrm{CO}_{2}$ capture.

\subsection{Development of Trace Contaminant Sorbents}

The previous development efforts for trace contaminants in DOE Contract No. DE-AC26-99FT40675 focused specifically on $\mathrm{Hg}$ and As with a goal of $90 \%$ capture of these contaminants. In this project, the list of contaminants has been expanded to include $\mathrm{Se}, \mathrm{Cd}$, and $P$. The analytic processes and equipment were also modified as necessary to ensure that the effluent concentrations of the contaminants could meet the specifications in Table 1-1 and enable chemical production with the clean syngas.

Table 1-1 provides a firm limit on the acceptable concentration for each target element for a clean syngas that is suitable for chemical production applications. However, Table 1-1 does not provide two key pieces of information about the concentration of contaminants in the original raw syngas. These are the specific composition of the contaminant species in the raw syngas and the concentration of these species. The complex interaction of the gasification reaction network, thermodynamic equilibrium constraints, and the high-temperature and high-pressure operating conditions makes evaluation of both the contaminant composition and the concentrations extremely challenging. At this time, the best information available is derived based on thermodynamic calculations to identify thermodynamically stable contaminant species and estimations of concentration based on the elemental analysis of typical coal feed stocks.

A summary of the available information on the stable thermodynamic contaminant species and estimated concentrations are provided in Tables 1-2 and 1-3, respectively. Based on 
the information in Table 1-2, specific contaminant compounds were selected to effectively simulate contaminant-laden syngas. Similarly, the information in Table 1-3 was used to identify a typical concentration of these contaminants in the raw syngas mixture.

Table 1-2. Potential Species Present in Syngas for the Target Elemental Contaminants

\begin{tabular}{cl}
\hline Element & \multicolumn{1}{c}{ Species } \\
\hline $\mathrm{S}$ & $\mathbf{H}_{2} \mathbf{S}, \mathbf{C O S}, \mathrm{CS}_{2}$ \\
$\mathrm{~N}$ & $\mathrm{NH}_{3}, \mathrm{HCN}$ \\
$\mathrm{Cl}$ & $\mathbf{H C l}$, metal chlorides \\
$\mathrm{Hg}$ & $\mathbf{H g}(\mathbf{g})^{1,2}, \mathrm{Hg}\left(\mathrm{CH}_{3}\right)_{2}{ }^{1}$ \\
$\mathrm{As}$ & $\mathrm{As}_{2}(\mathrm{~g})^{1,2}, \mathrm{As}_{4}\left(\mathrm{~g}^{1,2}, \mathbf{A s H}_{3}(\mathbf{g})^{1,2}, \mathrm{AsS}(\mathrm{g})^{2}\right.$, and other FeAs species \\
$\mathrm{Se}$ & $\mathbf{H}_{2} \mathrm{Se} \mathrm{(g)}{ }^{1,2}$ \\
$\mathrm{Cd}$ & $\mathrm{Cd}(\mathbf{g})^{1}, \mathrm{CdS}(\text { condensed })^{1}, \mathrm{CdCl}_{2}(\mathrm{~g})^{1}$ \\
\hline
\end{tabular}

${ }^{1}$ Equilibrium calculations by Diaz-Somoano (2003) at 572 to $932{ }^{\circ} \mathrm{F}$

${ }^{2}$ Equilibrium calculations by Helble (1996) at 621 to $1341^{\circ} \mathrm{F}$

Bolded items identify the species chosen for simulated syngas testing.

Table 1-3. Contaminant Concentrations in Syngas

\begin{tabular}{|c|c|c|}
\hline Species & Range of Concentrations in Coal & Range of Concentrations in Syngas \\
\hline $\mathrm{S}$ & $0.3-3.6 w t^{1}$ & $750-7000$ ppmv as $\mathrm{H}_{2} \mathrm{~S}$ and $25-200$ ppmv as $\mathrm{COS}_{2}$ \\
\hline $\mathrm{N}$ & $1.1-1.6 \mathrm{wt} \%^{1}$ & $50-800$ ppmv as $\mathrm{NH}_{2}$ \\
\hline $\mathrm{Cl}$ & $0.0032-0.37 w t \%^{3}$ & $170-830$ ppmv as $\mathrm{HCl}_{2}$ \\
\hline $\mathrm{Hg}$ & $0.02-1 \mu \mathrm{g} / \mathrm{g}^{3}$ & $1.3-63 \mathrm{ppbv}^{4}$ \\
\hline As & $0.5-80 \mu \mathrm{g} / \mathrm{g}^{3}$ & $84-1300 \mathrm{ppbv}^{4}$ \\
\hline $\mathrm{Se}$ & $0.2-1.6 \mu \mathrm{g} / \mathrm{g}^{3}$ & $32-2600$ ppbv $^{4}$ \\
\hline $\mathrm{Cd}$ & $0.1-3 \mu \mathrm{g} / \mathrm{g}^{3}$ & $11-340 \mathrm{ppbv}^{4}$ \\
\hline
\end{tabular}

1 Determined in Canadian feed-coals (Goodarzi, 2002)

2 Data survey of four types of gasifiers conducted by Bakker (1998)

3 Typical concentrations in the world's coal as examined by Swaine (1990)

${ }^{4}$ Calculated concentrations based on elemental concentration in coal and assuming complete vaporization

Material testing to identify and develop promising sorbents involved the use of specialized testing systems. For $\mathrm{Hg}$, this testing system was developed as part of DOE Contract No. DE-AC26-99FT40675. A complete description of the Hg removal testing system, validation testing, sorbent screening, and initial capacity testing are included in the final report for the same DOE contract. The testing system developed for $\mathrm{AsH}_{3}$ under that contract was modified to enable testing with other hydride contaminants $\left(\mathrm{H}_{2} \mathrm{Se}\right.$ and $\left.\mathrm{PH}_{3}\right)$. Details on this system are provided in Section 2.3 in this report. Because the predicted stable thermodynamic for $\mathrm{Cd}$ was $\mathrm{Cd}$ vapor, a specialized testing system that attempted to generate $\mathrm{Cd}$ vapor from a gas flow through a temperature controlled bed of metallic Cd is described in Section 2.7. 
In spite of the differences in the testing systems developed for each contaminant, the two consistent approaches for sorbent development were to preferentially look for commercial materials and maximize the value of a particular sorbent evaluating the potential for removing multiple contaminants. Preference was given to commercial materials, as these materials are generally able to rapidly move from laboratory testing to demonstration because no production scale-up issues are anticipated for a commercial material.

In an effort to maximize the information extracted from testing of trace contaminant sorbents during the Eastman Pilot Plant testing, analysis of the spent sorbent materials was expanded beyond $\mathrm{As}$ and $\mathrm{Hg}$, which were required for the original project, to include $\mathrm{Se}, \mathrm{Cd}$, and P. The results from this analysis are discussed in Section 2.1.

\subsection{Development of Lithium Silicate $\mathrm{CO}_{2}$ Capture Sorbents}

Funding under DOE Contract No. DE-AC26-99FT40675 also supported development of lithium silicate-based sorbents for high-temperature $\mathrm{CO}_{2}$ capture from syngas. Lithium silicate was identified as an effective material to capture $\mathrm{CO}_{2}$ using atmospheric thermogravimetric analysis (TGA) screening. TGA testing demonstrated that lithium silicate could effectively remove $\mathrm{CO}_{2}$ from nitrogen and simulated syngas streams. Lithium silicate's ability to capture $\mathrm{CO}_{2}$ was based on the reaction below:

$$
\mathrm{Li}_{4} \mathrm{SiO}_{4}(\mathrm{~s})+\mathrm{CO}_{2}(\mathrm{~g}) \leftrightarrow \mathrm{Li}_{2} \mathrm{CO}_{3}(\mathrm{~s})+\mathrm{Li}_{2} \mathrm{SiO}_{3}(\mathrm{~s})
$$

The reaction between lithium silicate and $\mathrm{CO}_{2}$ is exothermic, with a reaction enthalpy of $\Delta \mathrm{H}^{\circ}{ }_{298 \mathrm{~K}}$ of $-142 \mathrm{~kJ} / \mathrm{mol}$. Because reaction [1] is reversible, the sorbent releases $\mathrm{CO}_{2}$ during regeneration. During TGA testing, the capacity and activity for $\mathrm{CO}_{2}$ removal of the lithium silicate sorbent remained constant over multiple cycles based on either temperature or concentration swing regenerations.

To exploit this performance of lithium silicate materials, research and development (R\&D) efforts focused on developing lithium silicate-based sorbents, including both fixed- and fluidized-bed formulations. The key challenge with the fluidized-bed formulation was that the lithium silicate became soft enough to enable the particles to agglomerate during the $\mathrm{CO}_{2}$ capture and regeneration cycles. As a consequence, the fluidized-bed sorbent would fuse into a large solid mass that could not be fluidized. After multiple unsuccessful attempts to find a solution to this challenge, R\&D efforts to develop a fluidized-bed sorbent formulation were halted, and efforts instead were concentrated on developing a fixed-bed sorbent formulation. 
The challenge that thwarted efforts to develop a fluidized-bed sorbent formulation actually assisted the development of a fixed-bed formulation because the softening and fusing of the lithium silicate material effectively strengthened the sorbent formulation with each cycle. $R \& D$ efforts for a fixed-bed sorbent led to a promising formulation with sufficient physical strength, $\mathrm{CO}_{2}$ capacity, and $\mathrm{CO}_{2}$ reactivity.

Extensive testing of this fixed-bed sorbent formulation was conducted in RTI's benchscale sorbent testing system, shown in Figure 1-1 on the following page. The sorbent was shown to effectively remove $\mathrm{CO}_{2}$ from simulated syngas mixtures during $19 \mathrm{CO}_{2}$ adsorption and regeneration cycles. One significant advantage of this lithium silicate-based sorbent was that its $\mathrm{CO}_{2}$ capture performance was enhanced in simulated syngas mixtures with sulfur species like hydrogen sulfide $\left(\mathrm{H}_{2} \mathrm{~S}\right)$ and carbonyl sulfide (COS). Furthermore, the lithium silicate sorbent also had some water gas shift activity. As shown in Figure 1-2, both the $\mathrm{CO}_{2}$ and $\mathrm{CO}$ effluent concentrations at the start of the test were very low, and when the sorbent's $\mathrm{CO}_{2}$ capacity was extinguished (at approximately 10 minutes), both the $\mathrm{CO}_{2}$ and $\mathrm{CO}$ reached steady-state compositions different from those at the inlet of the reactor.

Based on the adsorption performance, lithium silicate-based sorbent appeared to be an ideal candidate for high-temperature $\mathrm{CO}_{2}$ capture. Unfortunately, regeneration performance of this sorbent was not as promising. During atmospheric TGA testing, lithium silicate sorbent formulations could be easily regenerated with either a temperature swing or an inert gas. In RTI's bench-scale sorbent testing system, temperature swing regeneration could cause the thermal decomposition of lithium carbonate according to reaction [1], but the temperature required to fully regenerate the sorbent was $>700{ }^{\circ} \mathrm{C}$. This combination of high heat of reaction for thermal decomposition $(142 \mathrm{~kJ} / \mathrm{mol})$ and high temperature for regeneration is not available in an IGCC system. In addition, the ability to transfer this heat at such a high temperature presents a technical challenge. Thus, temperature swing regeneration of lithium silicate-based sorbents is impractical. 


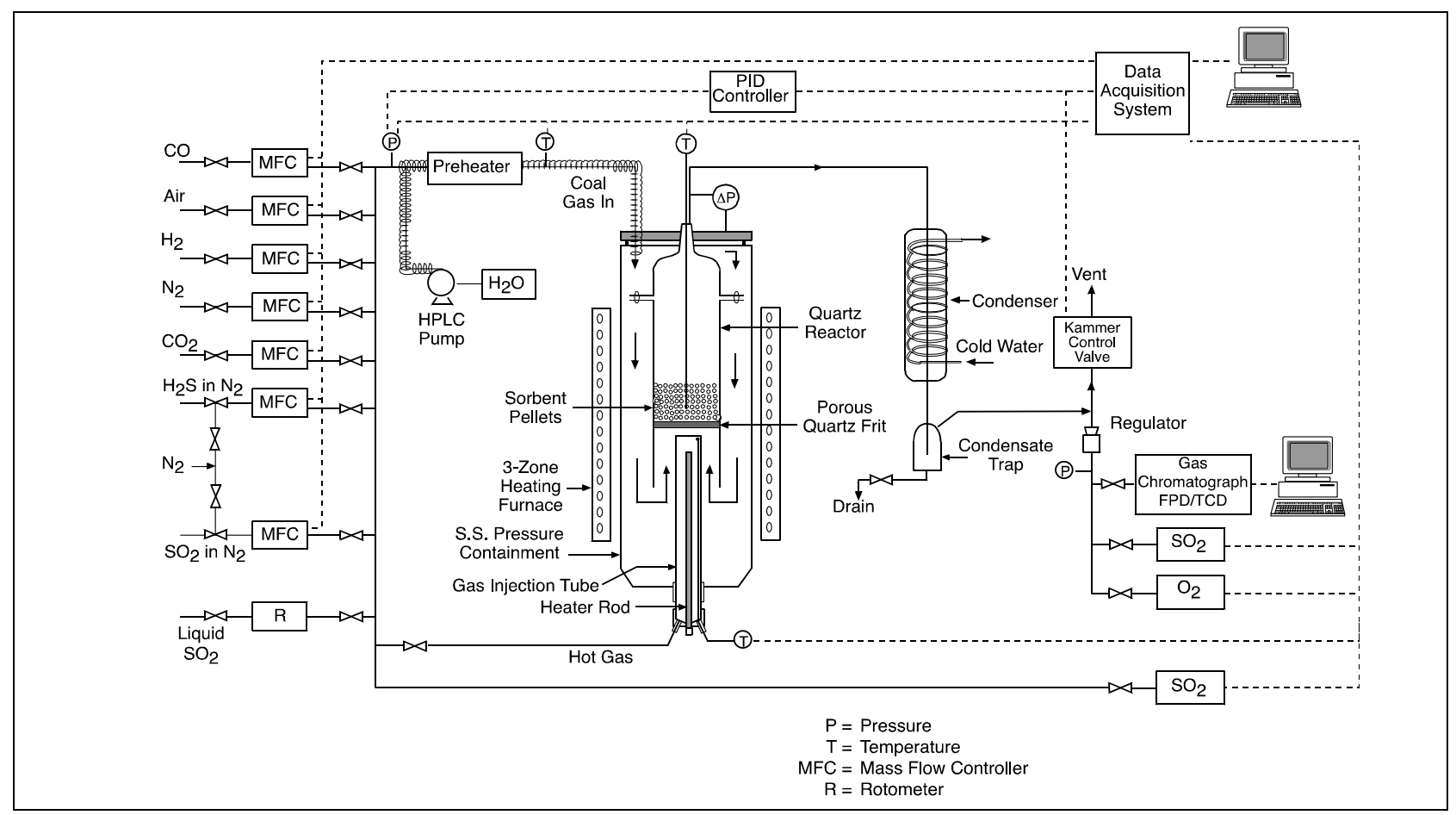

Figure 1-1. RTI's bench-scale sorbent testing system

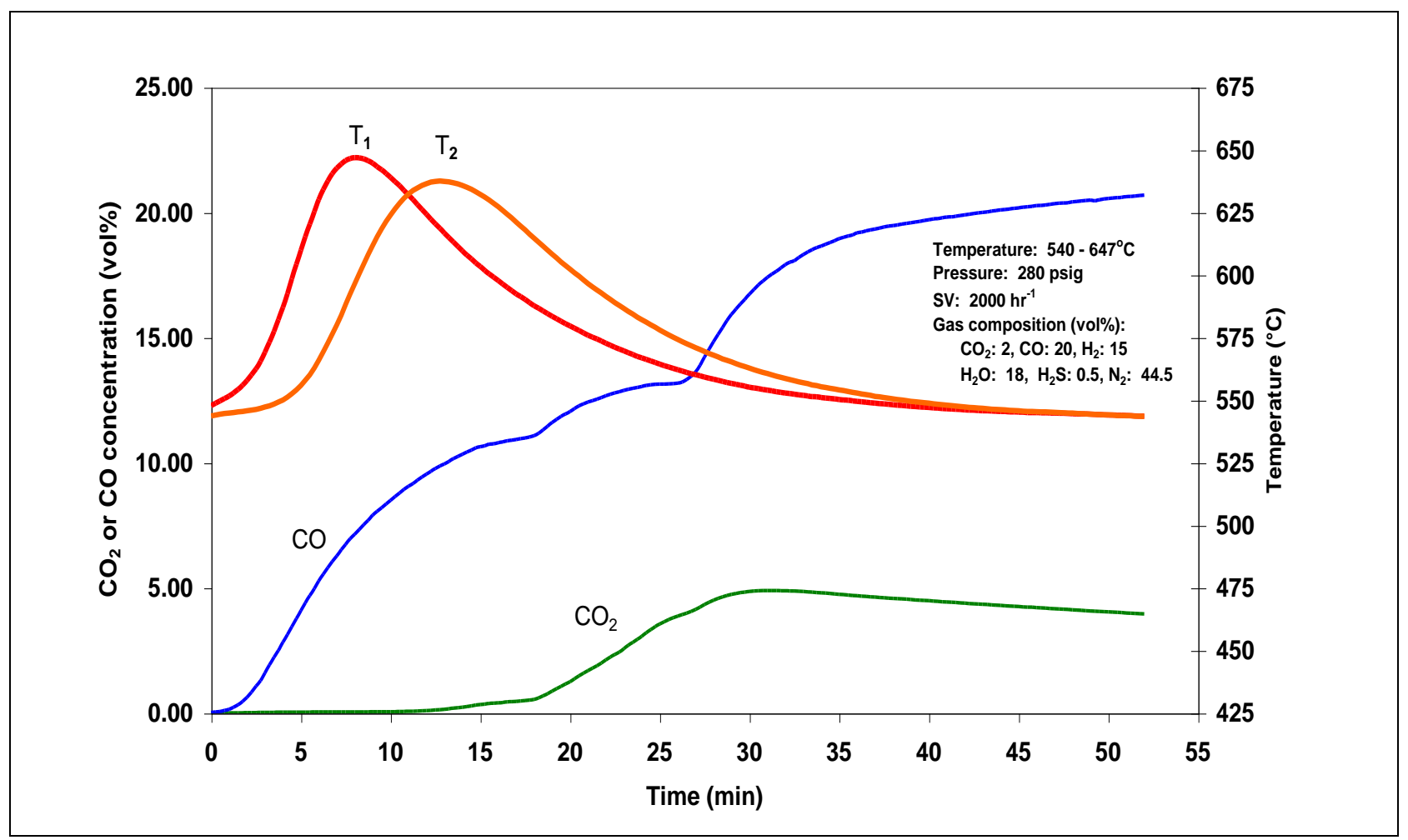

Figure 1-2. Profiles for adsorption process for lithium silicate for syngas containing 5,000 ppmv $\mathrm{H}_{2} \mathrm{~S}$ showing both $\mathrm{CO}_{2}$ capture and water gas shift activity 
The alternative option was to use a concentration swing to remove the $\mathrm{CO}_{2}$ from the sorbent during regeneration. In TGA testing, the standard inert used was helium (He). Testing in RTI's bench-scale reactor system demonstrated that nitrogen $\left(\mathrm{N}_{2}\right)$ could also be used. Because using either $\mathrm{He}$ or $\mathrm{N}_{2}$ as the inert to regenerate the sorbent resulted in a mixed gas product stream containing $\mathrm{CO}_{2}$ with significant amounts of $\mathrm{He}$ or $\mathrm{N}_{2}$, regeneration using a concentration swing based on these gases was not practical for generating a high-purity sequestration-ready $\mathrm{CO}_{2}$ product.

The only promising gas that could be used was steam, which can be effectively separated yielding a relatively pure $\mathrm{CO}_{2}$ stream for sequestration by condensation. Although operating RTI's bench-scale sorbent testing system with $100 \%$ steam was not possible, mixtures with up to $50 \%$ steam in $\mathrm{N}_{2}$ were tested and clearly showed that steam could be used as an inert to regenerate lithium silicate-based sorbents. However, these laboratory data showed that steam-to$\mathrm{CO}_{2}$ ratios of $>20$ would be required to regenerate the lithium silicate-based sorbents. Preliminary techno-economic analysis showed that, for regeneration with steam-to- $\mathrm{CO}_{2}$ ratios of $>20$, the energy penalty and amount of steam consumed by the regeneration would be economically prohibitive. Based on this analysis, the cost and energy requirements for regeneration of lithium silicate-based sorbent were determined to be prohibitive. 



\section{SECTION 2 \\ DEVELOPMENT OF TRACE CONTAMINANT SORBENTS}

\subsection{Analysis of Sorbent Materials from Eastman Field Test}

As part of the Eastman field test for DOE Contract No. DE-AC26-99FT40675, sorbents for mercury, arsenic, and ammonia were exposed to a coal-derived syngas stream at $200{ }^{\circ} \mathrm{C}$ and about $850 \mathrm{psig}$ for roughly 500 hours. A simple process flow diagram of the multicontaminant skid for the exposure of these sorbents to coal-derived syngas is shown in Figure 2-1. Table 2-1 provides a list of the sorbents used in the multicontaminant skid. Preand post-test analyses of the mercury and arsenic sorbents were completed for mercury and arsenic and included in the final report for DOE Contract No. DE-AC26-99FT40675.

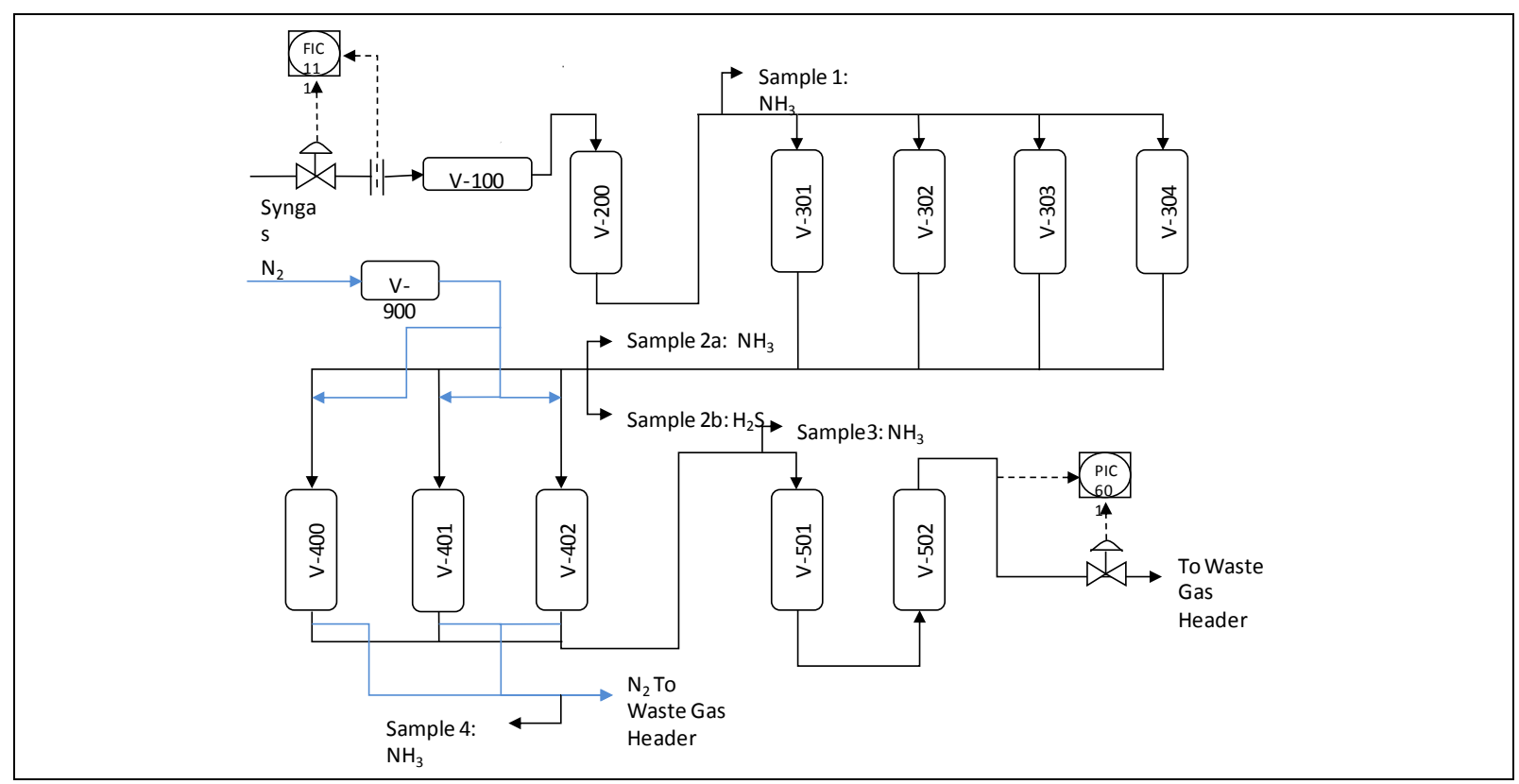

Figure 2-1. Block flow diagram for multicontaminant system

Table 2-1. List of Specific Materials Loaded in Vessels in Multicontaminant Skid

\begin{tabular}{lll}
\hline \multicolumn{1}{c}{ Vessel } & \multicolumn{1}{c}{ Sorbent } & \multicolumn{1}{c}{ Function } \\
\hline V-100 & Lithium silicate & High-temperature $\mathrm{CO}_{2}$ removal \\
V-200 & Commercial Sorbent A & Arsenic removal \\
V-301, V-302, V-303, V-304 & G-72D & Bulk sulfur removal \\
V-400, V-401, V-402 & CBV-712 & Ammonia removal \\
V-501 & G-72D & Polishing sulfur removal \\
V-502 & Impregnated carbon & Mercury removal \\
\hline
\end{tabular}

However, during this field test, the sorbents from this multicontaminant skid were successfully exposed to the full contaminant matrix present in a coal-derived syngas for 500 hours. To fully explore the effects of contaminant-laden syngas on different sorbent 
materials in the multicontaminant skid, all sorbents, which included the ammonia and commercial desulfurization sorbent in addition to the As and $\mathrm{Hg}$ sorbents, were analyzed for not only $\mathrm{Hg}$ and As, but also Se, Cd, and P. Because the sorbents were also carefully removed from the reactor vessels to preserve their relative position in the reactor vessel, analysis of the sorbent samples could provide information about the effect of the contaminant on the sorbent as the syngas moved through the sorbent bed. Samples of the RTI-3 sorbent removed from the high temperature desulfurization system after different operating periods were also included with the other sorbents for analyses. The results for the analyses of these sorbents are shown in Tables 2-2 through 2-6.

Table 2-2. Net Contaminant Concentrations for Commercial Sorbent A (Arsenic Sorbent)

\begin{tabular}{cccccc}
\hline & \multicolumn{5}{c}{ Net element concentration in sorbent $^{\mathbf{1}}(\boldsymbol{\mu g} \mathbf{g} \mathbf{g})$} \\
\cline { 2 - 5 } Bed Position & Arsenic $^{\mathbf{2}}$ & Selenium $^{\mathbf{2}}$ & Cadmium $^{\mathbf{2}}$ & Phosphorous $^{\mathbf{2}}$ & Mercury $^{\mathbf{3}}$ \\
\hline 1 (top) & 12700 & 1670 & $<1.25$ & $<1.25$ & 0.701 \\
5 & 939 & 2.02 & $<1.25$ & $<1.25$ & 0.159 \\
9 & $<1.25$ & $<1.25$ & $<1.25$ & 12.7 & 0.043 \\
13 & 1.66 & $<1.25$ & $<1.25$ & $<1.25$ & 0.032 \\
17 & 237 & 7.09 & $<1.25$ & 1.77 & 0.035 \\
21 & 27.4 & $<1.25$ & $<1.25$ & $<1.25$ & $<0.020$ \\
25 (bottom) & 249 & 14.6 & $<1.25$ & $<1.25$ & 0.044 \\
\hline
\end{tabular}

${ }^{1}$ Net concentration refers to the difference in concentration between the post- and pre-sorbent samples.

${ }^{2}$ Elements recovered using Hydrogen fluoride (HF) dissolution and concentrations determined by inductively coupled plasma optical emission spectroscopy (ICP-OES).

${ }^{3}$ Mercury concentration determined by DMA- 80 .

Table 2-3. Net Contaminant Concentrations for Commercial Sulfur Guard Bed Sorbent

\begin{tabular}{cccccc}
\hline & \multicolumn{5}{c}{ Net Element Concentration in Sorbent $^{\mathbf{1}}(\boldsymbol{\mu g} \mathbf{g} \mathbf{g})$} \\
\cline { 2 - 6 } Bed Position & Arsenic $^{2}$ & Selenium $^{2}$ & Cadmium $^{2}$ & Phosphorous $^{2}$ & Mercury $^{3}$ \\
\hline 1 (top) & 5.11 & $<1.25$ & $<1.25$ & 2.31 & 0.054 \\
4 & 5.58 & $<1.25$ & $<1.25$ & 3.14 & 0.075 \\
8 & 8.94 & $<1.25$ & $<1.25$ & 3.33 & 0.145 \\
12 & 7.25 & $<1.25$ & 4.10 & $<1.25$ & 0.060 \\
16 & 3.56 & $<1.25$ & $<1.25$ & 3.73 & 0.022 \\
20 & 4.41 & $<1.25$ & $<1.25$ & 3.60 & 0.151 \\
24 (bottom) & 4.35 & $<1.25$ & $<1.25$ & 3.66 & 0.146 \\
\hline
\end{tabular}

${ }^{1}$ Net concentration refers to the difference in concentration between the post- and pre-sorbent samples.

${ }^{2}$ Elements recovered using HF dissolution and concentrations determined by ICP-OES.

${ }^{3}$ Mercury concentration determined by DMA- 80 . 
Table 2-4. Net Contaminant Concentrations for Ammonia Sorbent (CBV-712)

\begin{tabular}{cccccc}
\hline & \multicolumn{5}{c}{ Net Element Concentration in Sorbent $^{\mathbf{1}}(\boldsymbol{\mu g} \mathbf{g} \mathbf{g})$} \\
\cline { 2 - 6 } Bed Position & Arsenic $^{\mathbf{2}}$ & Selenium $^{2}$ & Cadmium $^{2}$ & Phosphorous $^{2}$ & Mercury $^{\mathbf{3}}$ \\
\hline 1 (top) & 4.82 & $<1.25$ & $<1.25$ & $<1.25$ & $<0.020$ \\
3 & 4.93 & $<1.25$ & $<1.25$ & $<1.25$ & $<0.020$ \\
6 & 4.72 & $<1.25$ & $<1.25$ & $<1.25$ & $<0.020$ \\
9 & 4.76 & $<1.25$ & $<1.25$ & $<1.25$ & $<0.020$ \\
12 & 2.15 & $<1.25$ & $<1.25$ & $<1.25$ & $<0.020$ \\
15 (bottom) & 2.32 & $<1.25$ & $<1.25$ & $<1.25$ & $<0.020$ \\
\hline
\end{tabular}

${ }^{1}$ Net concentration refers to the difference in concentration between the post- and pre-sorbent samples.

${ }^{2}$ Elements recovered using HF dissolution and concentrations determined by ICP-OES.

${ }^{3}$ Mercury concentration determined by DMA- 80 .

Table 2-5. Net Contaminant Concentrations for Impregnated Carbon (Hg Sorbent)

\begin{tabular}{|c|c|c|c|c|c|}
\hline \multirow[b]{2}{*}{ Bed Position } & \multicolumn{5}{|c|}{ Net Element Concentration in Sorbent ${ }^{1}(\mu \mathrm{g} / \mathrm{g})$} \\
\hline & Arsenic $^{2}$ & Selenium $^{2}$ & Cadmium $^{2}$ & Phosphorous $^{2}$ & Mercury $^{3}$ \\
\hline 2 (top) & 181 & $<1.25$ & $<1.25$ & 41.0 & $<0.020$ \\
\hline 4 & 205 & $<1.25$ & $<1.25$ & $<1.25$ & $<0.020$ \\
\hline 7 & 138 & $<1.25$ & $<1.25$ & 21.5 & $<0.020$ \\
\hline 10 & 109 & $<1.25$ & $<1.25$ & $<1.25$ & $<0.020$ \\
\hline 13 & 102 & $<1.25$ & $<1.25$ & $<1.25$ & $<0.020$ \\
\hline 14 (bottom) & 124 & $<1.25$ & $<1.25$ & $<1.25$ & $<0.020$ \\
\hline
\end{tabular}

${ }^{1}$ Net concentration refers to the difference in concentration between the post- and pre-sorbent samples.

${ }^{2}$ Elements recovered using HF dissolution and concentrations determined by ICP-OES.

${ }^{3}$ Mercury concentration determined by DMA-80.

Table 2-6. Net Contaminant Concentrations for RTI-3 Sorbent

\begin{tabular}{cccccc}
\hline & \multicolumn{5}{c}{ Net Element Concentration in Sorbent $\mathbf{~}(\boldsymbol{\mu g} / \mathbf{g})$} \\
\cline { 2 - 5 } Sample Date & Arsenic $^{\mathbf{2}}$ & Selenium $^{\mathbf{2}}$ & Cadmium $^{\mathbf{2}}$ & Phosphorous $^{\mathbf{2}}$ & Mercury $^{\mathbf{3}}$ \\
\hline 9/15/06 & 167 & 2.72 & $<1.25$ & $<1.25$ & $<0.020$ \\
$9 / 20 / 06$ & 525 & 22.6 & $<1.25$ & $<1.25$ & $<0.020$ \\
$10 / 26 / 06$ & 713 & 53.8 & $<1.25$ & $<1.25$ & $<0.020$ \\
$4 / 19 / 07$ & 1480 & 96.7 & $<1.25$ & $<1.25$ & $<0.020$ \\
$(1,500 \mathrm{~h})$ & & & & $<1.25$ & $<0.020$ \\
$2 / 25 / 08$ & 686 & 47.5 & $<1.25$ & & \\
$(3,000 \mathrm{~h})$ & & & & & \\
\hline
\end{tabular}

${ }^{1}$ Net concentration refers to the difference in concentration between the post- and pre-sorbent samples.

${ }^{2}$ Elements recovered using HF dissolution and concentrations determined by ICP-OES.

${ }^{3}$ Mercury concentration determined by DMA- 80 .

The analyses for the RTI-3 sorbent shows significant concentration increases for As and $\mathrm{Se}$, but changes to the concentrations for $\mathrm{Cd}, \mathrm{P}$, and $\mathrm{Hg}$ remain below detection limits. These results are consistent with the results collected by URS Corporation during analysis of the syngas before and after the high-temperature desulfurization system during the field test (see final report for DOE Contract No. DE-AC26-99FT40675). Based on the 
concentrations data collected by URS, the RTI-3 sorbent was removing about $97 \%$ of the As and $97 \%$ of the Se. Based on the URS's measurements of $\mathrm{Hg}$ concentration in the syngas, the $\mathrm{Hg}$ removed by RTI-3 was less than the experimental errors associated with $\mathrm{Hg}$ measurement. Although URS did attempt to measure the Cd concentration in the syngas, the results were consistently below the detection limit. URS did not perform any analysis to determine $\mathrm{P}$ concentration in the syngas.

The analyses for the different sorbents from the multicontaminant skid show some very interesting results. The absence of any increase or accumulation of $\mathrm{Cd}$ on any of the sorbents is consistent with URS's analysis of the syngas, which demonstrated that the Cd concentration in the syngas was below the detection limit. Commercial Sorbent A demonstrated significant concentration increases for $\mathrm{As}, \mathrm{Se}$, and $\mathrm{Hg}$. The concentration of all three of these contaminants decreases rapidly along the length of the bed. Because the syngas was exposed to Commercial Sorbent A first, the expectation was that this sorbent would capture the As. The fact that the sorbent also captured $\mathrm{Se}$ and $\mathrm{Hg}$ was a positive observation.

Results for the commercial sulfur guard bed sorbent show an increase in the concentration of As, $\mathrm{Hg}$, and P. Furthermore, the concentration profile for these contaminants was relatively constant across the entire length of the sorbent bed. This would suggest that the concentration of these contaminants was large enough to completely saturate the capacity of the sorbent. This was not expected, as the commercial sulfur guard bed sorbent was downstream of the bed containing Commercial Sorbent A. The high level of removal in the sorbent bed with Commercial Sorbent A should have significantly reduced the contaminant concentration in the syngas. The absence of any increase in the concentration of Se across the entire length of the sorbent bed with the commercial sulfur guard bed confirms that Commercial Sorbent A does remove the Se concentration in the syngas to essentially zero. However, Commercial Sorbent A does not seem to reduce the concentration of $\mathrm{As}$ and $\mathrm{Hg}$ to near zero.

The ammonia and $\mathrm{Hg}$ sorbent beds, which are the two subsequent beds through which the syngas passed, show no significant change in concentration for $\mathrm{Se}, \mathrm{Cd}$, and $\mathrm{Hg}$. Both of these sorbents show a relatively consistent concentration increase in As along the length of the bed. The interesting feature is that the increase in As concentration in the $\mathrm{Hg}$ sorbent bed is greater than that of the ammonia sorbent, even though the $\mathrm{Hg}$ sorbent bed is downstream of the ammonia sorbent bed. During laboratory tests of the impregnated carbon with As, this sorbent showed very high capacity for arsine $(>5 \mathrm{wt} \%)$. One potential 
conclusion that can be drawn from the As concentration profile for the $\mathrm{Hg}$ sorbent bed is that As is present in the syngas as more than just an arsine species.

These results were extremely valuable in providing pertinent information about

- contaminant removal potential for a variety of different sorbents,

- demonstration and potential synergistic benefits of multicontaminant removal, and

- information about the actual chemical composition of the contaminant species present in coal-derived syngas.

\subsection{Mercury Sorbent Development}

\subsubsection{Mercury Capacity}

The field test results described in the previous section and the results from the previous laboratory testing program for $\mathrm{Hg}$ sorbent from warm syngas (see final report for DOE Contract No. DE-AC26-99FT40675) provide a strong foundation from which to continue $\mathrm{Hg}$ sorbent development. One of the key developmental goals for $\mathrm{Hg}$ sorbents for warm syngas applications is to increase $\mathrm{Hg}$ capacity in syngas at temperatures greater than $200{ }^{\circ} \mathrm{C}$. Using the specialized testing system developed in DOE Contract No. DE-AC2699FT40675, a series of potential sorbent candidates was tested to evaluate $\mathrm{Hg}$ capacity in simulated syngas mixtures at greater than $200^{\circ} \mathrm{C}$. The composition of these different syngas mixtures is provided in Table 2-7. The testing results are shown in Table 2-8.

Table 2-7. Typical Mercury Test Gas Compositions ${ }^{1}$

\begin{tabular}{lccccc}
\hline & \multicolumn{5}{c}{ Composition (nominal vol\%) } \\
\cline { 2 - 6 } \multicolumn{1}{c}{ Test Gas Designation } & $\mathbf{C O}_{\mathbf{2}}$ & $\mathbf{C O}$ & $\mathbf{H}_{\mathbf{2}}$ & $\mathbf{H}_{\mathbf{2}} \mathbf{S}$ & Steam \\
\hline Clean syngas & 51.5 & 27.0 & 19.0 & 0.0 & 2.5 \\
Dirty syngas & 51.0 & 27.0 & 19.0 & 0.5 & 2.5 \\
$\mathrm{CO}_{2} / \mathrm{N}_{2}$ & 11.2 & 0.0 & 0.0 & 0.0 & 0.0 \\
\hline
\end{tabular}

${ }^{1}$ Theoretical amount of mercury vapor in test gas stream was 280 ppbv.

Of all the materials tested in Table 2-8 below, only two showed higher $\mathrm{Hg}$ capacity than the impregnated carbon identified from the earlier testing program. One of these materials was a palladium- (Pd-) based sorbent developed by DOE/NETL's internal research program. This material demonstrated a $\mathrm{Hg}$ capacity of $0.353 \mathrm{wt} \%$ in dirty syngas (contains $0.5 \mathrm{vol} \% \mathrm{H}_{2} \mathrm{~S}$ ). 
Table 2-8. Summary of Mercury Capacity Testing

\begin{tabular}{|c|c|c|c|c|c|}
\hline Set \# & Sorbent & $\begin{array}{l}\text { Exposure } \\
\text { Temp. }\left({ }^{\circ} \mathrm{C}\right)\end{array}$ & Matrix & $\begin{array}{c}\text { Capacity } \\
\text { (wt. \%) }\end{array}$ & $\begin{array}{c}\text { Removal } \\
(\%)\end{array}$ \\
\hline 21 & UND/EERC F2ZO & 200 & Dirty syngas & 0.0033 & 94.3 \\
\hline 26 & UND/EERC F2ZO & 200 & Clean syngas & 0.0014 & 67.5 \\
\hline 22 & UND/EERC F2BO & 200 & Dirty syngas & NC & - \\
\hline 23 & UND/EERC F5BO & 200 & Dirty syngas & $\mathrm{NC}$ & - \\
\hline 24 & CuO-Carbon & 200 & Dirty syngas & 0.0018 & 99.6 \\
\hline 25 & Cu-O-MnO-Carbon & 200 & Dirty syngas & 0.0005 & 93.2 \\
\hline 28 & $\mathrm{Pd}-\mathrm{Al}_{2} \mathrm{O}_{3}$ & 200 & Dirty syngas & 0.353 & 89.2 \\
\hline 29 & Commercial Sorbent A & 200 & Dirty syngas & $\mathrm{NC}$ & - \\
\hline 30 & Commercial Sorbent A & 200 & Clean syngas & $\mathrm{NC}$ & - \\
\hline 34 & Impregnated Carbon (Eastman) & 200 & Clean syngas & 0.010 & 98.9 \\
\hline 39 & Impregnated Carbon (Commercial) & 200 & Clean syngas & 0.17 & 90.0 \\
\hline 41 & lodated Charcoal & 200 & Clean syngas & $<0.04$ & - \\
\hline 42 & Sud-Chemie Sample D & 200 & Clean syngas & NC & - \\
\hline 43 & Sud-Chemie Sample D & 200 & Dirty syngas & 0.0031 & 87.5 \\
\hline 54 & S-Carbon/Sud-Chemie Sample G & 200 & $\mathrm{CO}_{2} / \mathrm{N}_{2}$ & NC & - \\
\hline 57 & S-Carbon/Sud-Chemie Sample G & 200 & Clean syngas & NC & - \\
\hline 58 & Se-Commercial Sorbent A & 200 & Clean syngas & 0.0069 & 96.5 \\
\hline 62 & As-Commercial Sorbent A & 200 & Clean syngas & NC & - \\
\hline 65 & $\mathrm{SeO}_{2}-\mathrm{SiO}_{2}-\mathrm{Al}_{2} \mathrm{O}_{3}$ & 30 & Clean syngas & 3.32 & 91.0 \\
\hline 66 & Ga-As Plates & 200 & Clean syngas & NC & - \\
\hline 67 & $\mathrm{SeO}_{2}-\mathrm{SiO}_{2}-\mathrm{Al}_{2} \mathrm{O}_{3} /$ Commercial Sorbent $\mathrm{A}$ & 200 & Clean syngas & NC & - \\
\hline 69 & gamma- $\mathrm{Al}_{2} \mathrm{O}_{3}$ & 200 & Clean syngas & NC & - \\
\hline
\end{tabular}

$\mathrm{NC}=$ Not calculated. Analysis results from initial QC cartridge samples indicated that effluent concentration exceeded performance goal for cleaned syngas.

The second promising sorbent material was developed based on the results from analyses of the multicontaminant from the Eastman field test. One of the unexpected results from these analyses was the accumulation of $\mathrm{Hg}$ in the sorbent bed with Commercial Sorbent A. This was unexpected, because Commercial Sorbent A had failed to demonstrate sufficient $\mathrm{Hg}$ capture during its initial screening test. To confirm these results, the actual $\mathrm{Hg}$ capacity of this material was measured in both clean (sulfur-free) and dirty (contains 0.5 vol\% $\mathrm{H}_{2} \mathrm{~S}$ ) syngas mixtures. The results confirmed that the $\mathrm{Hg}$ capacity of Commercial Sorbent A was below the detection limit.

Because the simulated syngas mixtures did not increase the $\mathrm{Hg}$ capacity of Commercial Sorbent A, the other contaminants present in coal-derived syngas must be affecting its $\mathrm{Hg}$ capacity. Based on the analyses of Commercial Sorbent A, the two most promising contaminant candidates were As and Se. In a test with Commercial Sorbent A that had been exposed to As, no increase in $\mathrm{Hg}$ capacity was observed. Testing of Se sorbents at $200{ }^{\circ} \mathrm{C}$ is challenging because of the tendency for Se loss as Se vapor, which is then carried out of the reactor. To overcome this limitation, a Se-based sorbent was tested at 
room temperature (where Se vapor loss is not a problem). During this test, the Se-based sorbent had a $\mathrm{Hg}$ capacity of about $3.32 \mathrm{wt} \%$.

To demonstrate the potential of Se for $\mathrm{Hg}$ capture at $200{ }^{\circ} \mathrm{C}$, a test was conducted with a mixed sorbent bed. This mixed sorbent bed consisted of a top layer of Se-based sorbent and a lower layer of Commercial Sorbent A. Commercial Sorbent A was chosen because the Eastman field test results showed almost complete retention of the Se. Although the results show that this sorbent combination did not reduce the effluent $\mathrm{Hg}$ concentration to less than $10 \%$ of its inlet concentration, it did remove $60 \%$ to $70 \%$ of the $\mathrm{Hg}$ for 4,560 minutes prior to terminating the test. This is equivalent to capturing approximately $0.5 \mathrm{wt} \%$ $\mathrm{Hg}$ in the Se-based sorbent.

One challenge in conducting the Eastman field test was procuring sufficient impregnated carbon for the $\mathrm{Hg}$ sorbent bed. At the time of the test, scale-up of this material was still being undertaken. Results from an initial scale-up batch prepared showed that the $\mathrm{Hg}$ capacity of this material (Set 34) was not the original test sample. Subsequent scale-up efforts were completed on this sorbent for other applications. Tests of a sample from a commercial batch of this sorbent have shown that this sorbent (see Set 39) can now be successfully produced for commercial applications.

\subsubsection{Testing for Lower Mercury Effluent Concentration}

With the focus of developing warm syngas cleaning technologies for chemical applications, acceptable levels of $\mathrm{Hg}$ concentration in the clean syngas were reduced to 5 ppbw for $\mathrm{Hg}$. The sensitivity of the original test procedures developed with this mercury testing system had a detection limit equivalent to a concentration of $34 \mathrm{ppbw}$ in the effluent syngas. Several modifications that were implemented reduced the detection limit for $\mathrm{Hg}$ sufficiently to demonstrate the ability to reduce $\mathrm{Hg}$ concentration in the syngas. The new testing protocol was used to demonstrate that the leading $\mathrm{Hg}$ sorbent was capable of meeting this Hg target.

In Table 2-9, the results from this test show that the impregnated carbon was able to reduce the inlet $\mathrm{Hg}$ concentration from $2016 \mathrm{ppbw}$ in the pretreated simulated syngas to below 5 ppbw in the effluent syngas mixture. The $\mathrm{Hg}$ capacity for this sorbent at an effluent $\mathrm{Hg}$ concentration of $<5$ ppbw was $0.14 \mathrm{wt} \%$. 
Table 2-9. Mercury Capacity at below 5 ppbw Hg Effluent

\begin{tabular}{cccccc}
\hline Set \# & Sorbent & $\begin{array}{c}\text { Exposure } \\
\text { Temp. }\left({ }^{\circ} \mathbf{C}\right)\end{array}$ & Matrix & $\begin{array}{c}\text { Capacity } \\
(\text { wt. \%) }\end{array}$ & $\begin{array}{c}\text { Removal } \\
(\%)\end{array}$ \\
\hline 70 & Impregnated carbon (Commercial) & 200 & $\begin{array}{c}\text { Clean } \\
\text { syngas }\end{array}$ & 0.14 & 100 \\
\hline
\end{tabular}

\subsection{Hydride Testing Program}

In contrast to the mercury and cadmium contaminants, the primary contaminants for $\mathrm{As}, \mathrm{Se}$, and $\mathrm{P}$ are the hydride species, which are arsine $\left(\mathrm{AsH}_{3}\right)$, hydrogen selenide $\left(\mathrm{H}_{2} \mathrm{Se}\right)$, and phosphine $\left(\mathrm{PH}_{3}\right)$. All of these hydride species are gases, which require a different testing system than for $\mathrm{Hg}$. The toxic nature of the hydrides also requires similar specialized testing procedures to maintain a safe work environment. Because of these similarities, the same test system could be used with little modification for all three contaminants. To handle the volume of material required for the sorbent development program, two identical systems were built. A description of this testing system and procedures are provided below.

\subsubsection{Candidate Hydride Material Preparation}

Candidate materials for hydride removal were tested as received, except when the size of the material was reduced by grinding in a mortar and pestle to accommodate the exposure system reactor. The ground material was then sized using a No. 45 (Tyler equivalent 42 mesh) and No. 170 (Tyler equivalent mesh 170) standard test sieve before testing.

\subsubsection{Metal Hydride Test System}

A schematic of the hydride exposure system is shown in Figure 2-2. The main system components included the hydride gas mixture; a six-port, two-position valve (VICI, Inc.); an exposure chamber; and the backup QC cartridge sample. The hydride source gas mixture was supplied from a certified, compressed gas mixture containing nominal $50 \mathrm{ppm}$ of the hydride in $\mathrm{H}_{2}$ (Scott Specialty Gases, Inc.). The source gas was metered at $20 \mathrm{~mL} / \mathrm{min}$ using a variable restrictor flow controller. Other simulated syngas components (CO and $\mathrm{CO}_{2}$ ) were supplied by a second compressed gas mixture.

Flow from this mixture, metered at $80 \mathrm{~mL} / \mathrm{min}$ with an upstream reference flow controller (Condyne, Inc.), was either blended directly with the hydride gas mixture stream or directed through two water-filled impingers maintained at room temperature and then blended with the hydride gas mixture before entering the six-port valve. Typical test gas compositions generated for the hydride exposure tests using this arrangement are shown in 
Table 2-10. Dry nitrogen metered at $10 \mathrm{~mL} / \mathrm{min}$ was supplied to the standby side of the valve to provide a sweep gas for purging the system during standby periods.

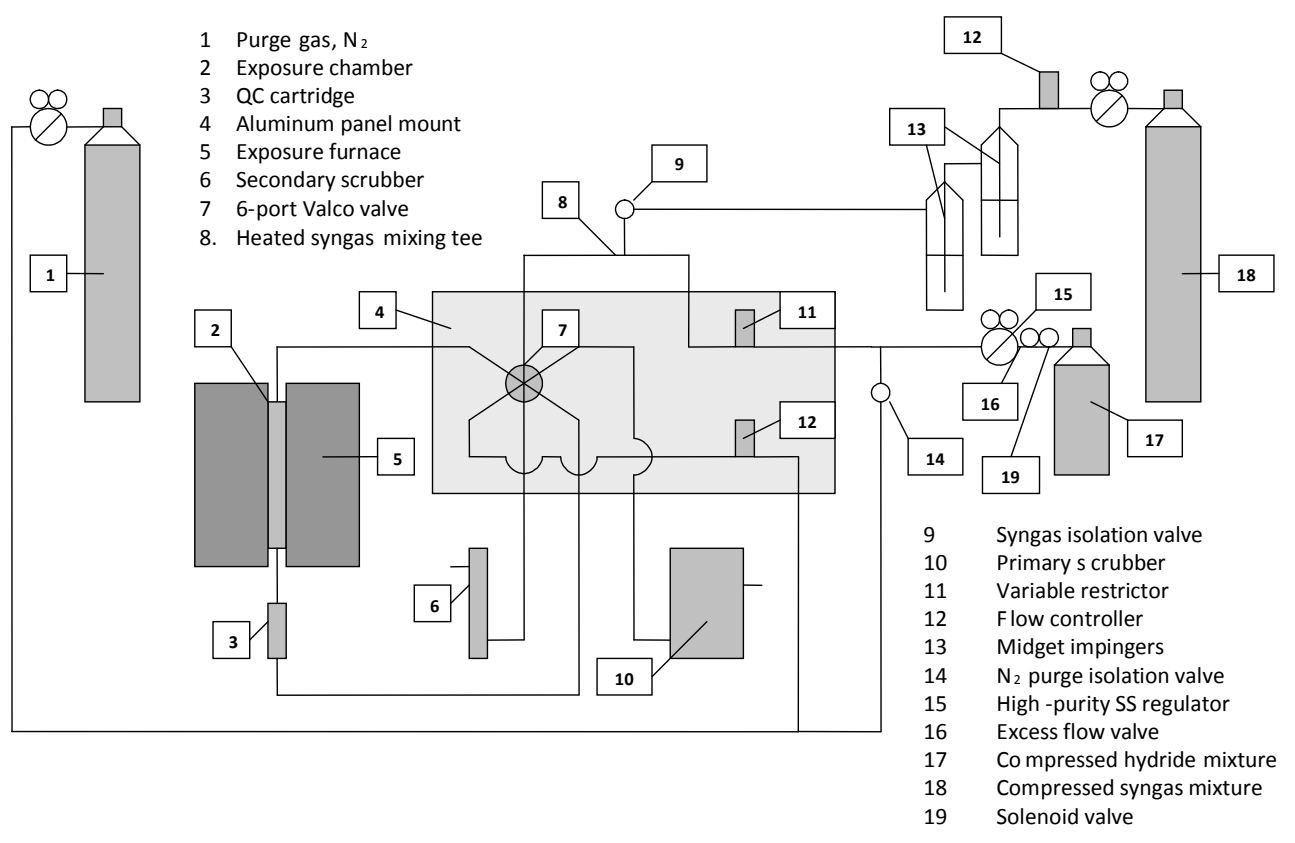

Figure 2-2. Hydride exposure test system

Table 2-10. Typical Hydride Test Gas Compositions ${ }^{1}$

\begin{tabular}{lccccc}
\hline & \multicolumn{5}{c}{ Composition (nominal vol\%) } \\
\cline { 2 - 6 } \multicolumn{1}{c}{ Test Gas Designation } & CO2 & CO & $\mathbf{H}_{\mathbf{2}}$ & $\mathbf{H}_{\mathbf{2}} \mathbf{S}$ & Steam \\
\hline Clean syngas & 51.5 & 27.0 & 19.0 & 0.0 & 2.5 \\
Dirty syngas & 51.0 & 27.0 & 19.0 & 0.5 & 2.5 \\
Modified dirty syngas & 11.2 & 38.5 & 47.0 & 0.8 & 2.5 \\
\hline
\end{tabular}

${ }^{1}$ Theoretical amount of hydride in test gas stream was $10 \mathrm{ppm}$.

The six-port valve, configured with 0.125 -in. ports, allowed the system to be placed in either exposure mode or standby mode without changing plumbing connections. Flow diagrams for the exposure and standby modes are shown in Figure 2-3. The valve was maintained at nominal $100{ }^{\circ} \mathrm{C}$ using a heated enclosure. All transfer lines leading into and out of the valve were constructed from 0.125-in.-O.D. stainless steel tubing. Like the valve, these lines were kept at nominal $100{ }^{\circ} \mathrm{C}$ using heat tapes. 


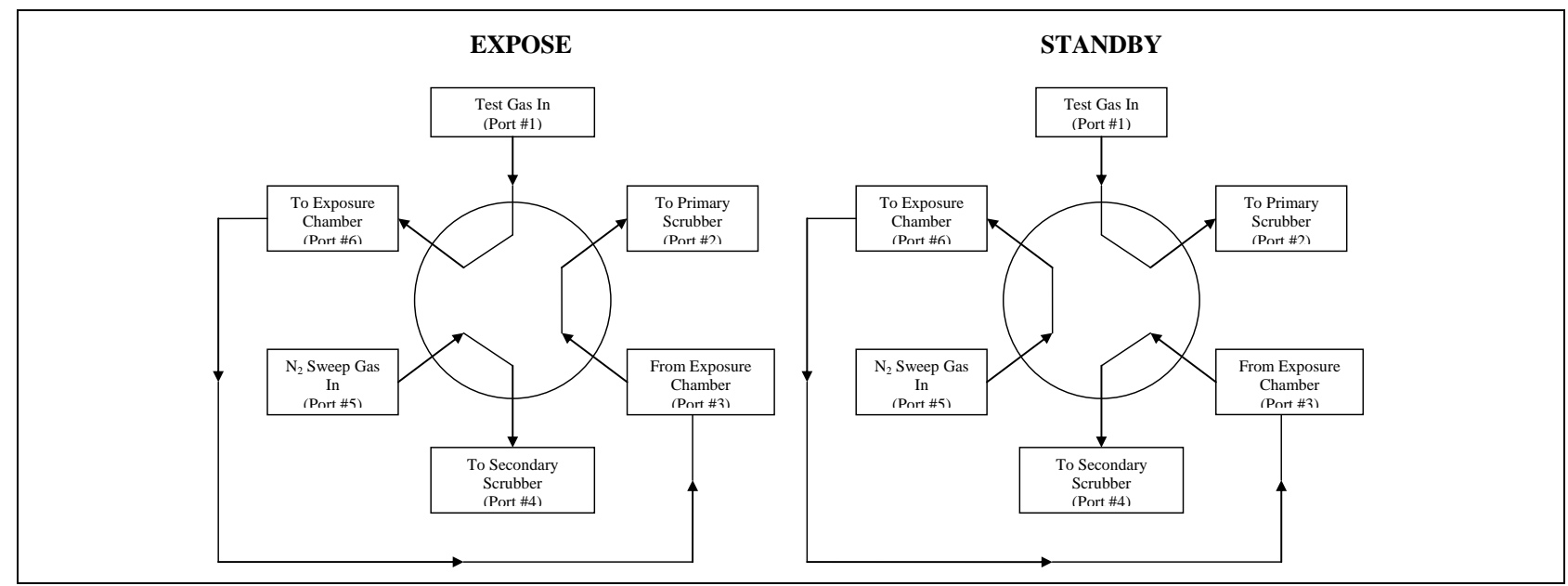

Figure 2-3. Six-port valve flow diagram on the hydride exposure test system

The exposure chamber holding the fixed bed of candidate sorbent during hydride exposures was constructed from stainless steel tubing (0.250 in. O.D. $\times 12$ in. L). A tube furnace was used to maintain the chamber at the desired exposure temperature. Both tube furnace and exposure chamber were oriented vertically so that the simulated syngas containing the target hydride entered the top and exited the bottom of the chamber. Candidate sorbent beds were prepared by positioning a single quartz wool plug in the upper region of the chamber and adding enough sorbent on top of the quartz wool to produce a total bed length of 1 in. For most sorbents tested, this resulted in about $0.3-0.4 \mathrm{~g}$ of material, depending on the bulk density of the material.

To prepare the system for exposure tests, the six-port valve was placed in the standby position, and the flow of simulated syngas was started. The syngas flow was adjusted to $80 \mathrm{~mL} / \mathrm{min}$, as measured at the outlet of the primary scrubber. The flow of hydride/hydrogen was then started and adjusted to $20 \mathrm{~mL} / \mathrm{min}$, resulting in a total flow of $100 \mathrm{~mL} / \mathrm{min}$ measured at the primary scrubber outlet. To start an exposure test, a backup QC cartridge sample was connected to the outlet of the exposure chamber containing the candidate sorbent, and this assembly was installed in the exposure test system. While the six-port valve remained in the standby position, the exposure chamber and QC cartridge were preheated for $30 \mathrm{~min}$. Dry nitrogen supplied to the standby side of the valve was used to purge room air from the exposure chamber and QC cartridge while these components were being heated. After 30 minutes, the six-port valve position was switched from standby to exposure mode to direct the hydride-containing syngas flow through the exposure chamber and QC cartridge. The flow was measured at the primary scrubber outlet periodically during the exposure. 
For safety reasons, the flows of simulated syngas and hydride/hydrogen were stopped at the end of each day. Dry nitrogen metered at $10 \mathrm{~mL} / \mathrm{min}$ was introduced to the exposure side of the valve, and this flow, along with the house nitrogen supplied to the standby side of the valve, was used to keep all components of the system purged during overnight standby periods.

\subsubsection{Hydride QC Cartridge Sampling and Analysis}

The QC cartridge was constructed from 0.375 in. $\mathrm{O} . \mathrm{D} \times 2$ in $\mathrm{L}$ stainless steel tubing. Each QC cartridge was prepared immediately before use by positioning a quartz wool plug at the bottom of the cartridge, and then an appropriate amount of QC sorbent material was added to produce a sorbent bed length of approximately 1 in. The QC cartridge was sampled in the vertical position and preheated to a target operating temperature by heat tape before QC sample collection began. The QC cartridge sorbent and target operating temperature for each metal hydride studied are shown in Table 2-11.

Table 2-11. Hydride Quality Control Cartridge Configuration

\begin{tabular}{lcc}
\hline \multicolumn{1}{c}{ Hydride } & Sorbent Material & Operating Temperature ${ }^{\circ} \mathbf{C}$ \\
\hline Arsine & Carulite & 200 \\
Hydrogen selenide & Impregnated carbon & 60 \\
Phosphine & $\mathrm{CuO}-\mathrm{Al}_{2} \mathrm{O}_{3}$ & 60 \\
\hline
\end{tabular}

After a 30-minute sampling period, the six-port valve position was changed from exposure to standby, and the QC cartridge was cooled while being purged with nitrogen. Once purged, the QC sorbent was transferred from the cartridge to a 1-dram glass vial and stored in the glass vials at room temperature until analyzed.

\subsubsection{Hydride Screening Study Procedure}

To determine whether candidate sorbent materials retained the metal hydride, shortterm screening studies were conducted by contacting the sorbent with the test gas containing the hydride in humidified, simulated syngas. The experimental exposure temperature ranged from 200 to $250{ }^{\circ} \mathrm{C}$, and the typical exposure time was 30 minutes. After the 30 -minute exposure, the system was purged with nitrogen, and the exposed candidate sorbent and QC sorbent were removed and transferred to separate 1-dram glass vials.

\subsubsection{Hydride Capacity Study Procedure}

Long-term metal hydride capacity studies were conducted at exposure temperatures between 30 and $430{ }^{\circ} \mathrm{C}$. The capacity tests were started by installing the exposure chamber and a fresh QC cartridge in the exposure system and exposing the material to arsine- 
containing syngas for 30 minutes. After this exposure time, the QC cartridge was cooled and removed using the nitrogen purge procedure previously described. The tube furnace, however, was allowed to remain around the exposure chamber at the target exposure temperature while the QC cartridge was cooled. (The candidate material was purged with dry nitrogen while heated during the 10-minute QC cartridge cooling period due to the fact that the six-port valve was maintained in the standby position.)

After the QC sorbent was removed, the empty QC cartridge (containing quartz wool only) was reinstalled in the exposure system and preheated. After approximately 10 minutes, the six-port valve position was changed from standby to exposure mode to expose the candidate sorbent to additional amounts of metal hydride. At the end of an exposure day, the six-port valve was switched to standby, and the syngas and hydride/hydrogen flows were stopped. The candidate sorbent was purged with dry nitrogen and maintained at the exposure temperature while in exposure mode during the overnight standby periods.

Additional QC cartridge samples were usually collected once per day to monitor for metal hydride breakthrough. Capacity test exposures were allowed to continue, with nominal exposure periods of approximately 8 hours per day, until the effluent concentration determined by QC cartridge measurements was $\leq 90 \%$ of the feed concentration or sorbent capacity exceeded $5 \mathrm{wt} \%$. At this point, a final backup QC cartridge was collected and the exposure test stopped. The exposed sorbent material and the sorbent from the final QC cartridge were transferred to separate 1-dram glass vials and were stored at room temperature until analyzed.

\subsubsection{Metal Hydride Candidate Sorbent and QC Cartridge Analysis Procedure}

To determine the amount of targeted metal hydride species retained on the candidate sorbent and QC cartridge materials, the entire sample amount was transferred from the 1dram vial to a $50-\mathrm{mL}$ centrifuge tube, and 10 drops of deionized water were added to the centrifuge tube, along with $2 \mathrm{~mL}$ of Unisolv and $0.5 \mathrm{~mL}$ of nitric acid. After digesting with heat, the final volume was adjusted with deionized water and the resulting solution was analyzed by inductively coupled plasma atomic emission spectroscopy (ICP-AES) to determine the amount of metal retained on the QC sample. 


\subsection{Arsenic Sorbent Development}

\subsubsection{Arsenic Capacity}

As with the $\mathrm{Hg}$ sorbents, one of the primary considerations for evaluating materials for As removal was their capacity. Preliminary economic analysis indicated that sorbents with a minimum As capacity of $2.35 \mathrm{wt} \%$ would be economically feasible. In order to facilitate commercialization of the promising sorbents, testing preference was given to existing commercial sorbents and sorbent that demonstrated the ability to capture multiple contaminants simultaneously. Results from testing a wide range of potential materials are provided in Table 2-12. Table 2-12 has a total of six materials that demonstrate an As capacity of $>2.35 \mathrm{wt} \%$. Almost all of these materials also demonstrate an As capacity $>5$ wt $\%$.

To effectively identify the most promising sorbent candidates, additional testing of the sorbents was conducted to evaluate the reactivity of the sorbent with clean and dirty syngas. This reactivity toward syngas could be used to assist in rating the pool of promising sorbent, with the highest-ranking sorbents being the least reactive toward syngas. The test results showed that no sorbent material was without reactivity toward syngas. However, most of the activity occurred at the start, probably associated with either reduction or sulfidation of the different sorbent chemical components. Based on the As capacity and reactivity testing, the two most promising As candidates were the impregnated carbon and Commercial Sorbent A, respectively.

Because the Eastman field test of the high-temperature desulfurization system demonstrated that the RTI-3 sorbent had a significant capacity for As, additional testing was conducted to investigate the As capacity for this material. An RTI-3 sorbent sample removed after 1,500 hours of operation in coal-derived syngas was placed in the hydride test system and exposed to a simulated syngas mixture with 10 ppmv of arsine. The results show that the As concentration of RTI-3 at an effluent arsenic concentration of about $1400 \mathrm{ppbv}$ was $0.56 \mathrm{wt} \%$ (or $5600 \mathrm{ppmw}$ ). Furthermore, the increase in effluent As concentration was relatively slow, indicating that RTI-3 could continue to remove significant amounts of the arsine in the syngas even at about $0.6 \mathrm{wt} \%$ loading. 
Table 2-12. Summary of Arsine Capacity Testing

\begin{tabular}{clcccc}
\hline Set \# & \multicolumn{1}{c}{ Sorbent } & $\begin{array}{c}\text { Exposure } \\
\text { Temp. }\left({ }^{\circ} \mathbf{C}\right)\end{array}$ & Matrix & $\begin{array}{c}\text { Capacity } \\
(\text { wt. } \%)\end{array}$ & $\begin{array}{c}\text { Removal } \\
(\%)\end{array}$ \\
\hline $250-3$ & Impregnated Carbon (Research) & 250 & Dirty syngas & $>1.48$ & 100 \\
$200-1$ & Impregnated Carbon (Research) & 200 & Dirty syngas & $>7.96$ & 100 \\
$200-2$ & Commercial Sorbent A & 200 & Dirty syngas & 2.98 & 90.1 \\
$200-3$ & Sud-Chemie Sample A & 200 & Dirty syngas & $>5.93$ & 100 \\
$200-7$ & Commercial Sorbent C & 200 & Dirty syngas & $>5.87$ & 95.0 \\
$200-8$ & Sud-Chemie Sample B & 200 & Dirty syngas & $>5.75$ & 99.6 \\
$200-9$ & Pd-Al $_{2} \mathrm{O}_{3}(\mathrm{NETL})$ & 200 & Dirty syngas & $>7.16^{1}$ & 97.1 \\
$200-10$ & RTI-3 & 200 & Dirty syngas & $0.031^{1}$ & 92.4 \\
$200-11$ & Impregnated Carbon (Commercial) & 200 & Dirty syngas & $>5.76$ & 99.9 \\
$200-12$ & lodated Carbon & 200 & Dirty syngas & $>8.07$ & 99.7 \\
$200-14$ & Impregnated Carbon (Eastman) & 200 & Dirty syngas & $>7.73$ & 98.6 \\
$430-1$ & RTI-3 (1500 hr Absorber) & 430 & Dirty syngas & $0.566^{1}$ & 86.2 \\
\hline
\end{tabular}

${ }^{1}$ Low material balance for this exposure

One of the more promising materials was the Pd-based sorbent provided by DOE/NETL and developed by their in-house research team. Although this material had a very high As capacity, the results from the capacity test are unique. During the first 4,000 minutes of As exposure, this Pd-based sorbent reduced the arsine concentration to essentially zero. However, at subsequently longer exposure periods, the effluent As concentration would exceed to inlet concentration for a brief period prior to dropping back down to near zero. Because of the uniqueness of this result, the test was continued until several of these brief periods of a high effluent As concentration could be observed. The objective of extending this test was to establish that the sampling and analytical procedures were not responsible for the unique performance.

Final analysis of the sorbent material demonstrated that the sorbent had only $5.5 \mathrm{wt} \%$ of As, when the expected amount based on the breakthrough profile should have been about $17 \mathrm{wt} \%$. One potential explanation was that As was leaking out of the sorbent in the nitrogen flow used in hot overnight standby mode. Although testing of this hypothesis did demonstrate that a certain amount of As was removed with the nitrogen during the overnight standby mode, the amount of As removed was not sufficient to explain the large difference between the actual As concentration on the sorbent and the estimated concentration. The DOE/NETL research team was provided with a detailed report of testing with their Pd-based sorbents to help them continue development of these sorbent materials.

\subsubsection{Testing for Lower Arsenic Effluent Concentration}

Based on the shift in focus of this project to extend the warm syngas cleanup for chemical production applications, the target As concentration in the clean syngas was 
lowered to $5 \mathrm{ppbv}$. The sensitivity of the original test procedure and analytical method would have been equivalent to about $250 \mathrm{ppbv}$. These sampling procedures and analytical methods were modified to enable achieving a detection limit below 5 ppbv in spite of the high inlet concentration $(10,000 \mathrm{ppbv})$. The results of testing the two primary sorbent candidates with these new modified sampling and analytical methods are shown in Table 2-13. Neither of the two leading sorbent candidates was able to achieve the target As effluent concentration. These results along with the results from the Eastman field test with multicontaminant skid indicate that additional research is necessary to adequately identify an As sorbent for chemical production applications with coal-derived syngas.

Table 2-13. Modified As Testing for 5 ppbv Effluent Concentration

\begin{tabular}{clcccc}
\hline Set \# & \multicolumn{1}{c}{ Sorbent } & $\begin{array}{c}\text { Exposure } \\
\text { Temp. }\left({ }^{\circ} \mathbf{C}\right)\end{array}$ & Matrix & $\begin{array}{c}\text { Inlet } \\
\text { concentration } \\
\text { (ppbv) }\end{array}$ & $\begin{array}{c}\text { Outlet } \\
\text { concentration } \\
\text { (ppbv) }\end{array}$ \\
\hline $200-15$ & $\begin{array}{l}\text { Commercial Sorbent A } \\
\text { Impregnated Carbon }\end{array}$ & 200 & Dirty syngas & 10,000 & 48.7 \\
$200-16$ & $\begin{array}{l}\text { (Eastman) } \\
\text { Impregnated Carbon }\end{array}$ & 200 & $\begin{array}{c}\text { Dirty syngas } \\
\text { Low H } \mathrm{S} \\
\text { syngas }\end{array}$ & 10,000 & 76.9 \\
\hline
\end{tabular}

\subsection{Hydrogen Selenide Sorbent Development}

\subsubsection{Hydrogen Selenide Sorbent Screening}

The selection process for potential sorbents for hydrogen selenide focused initially on available commercial sorbents and especially those materials that had demonstrated potential for capturing more than one contaminant. The results of these initial screening tests are provided in Table 2-14. The results show that sorbent materials that have been tested for warm syngas cleanup for ammonia, $\mathrm{HCl}$, Table 2-14. Results from Hydrogen Selenide Screening

\begin{tabular}{lc}
\hline \multicolumn{1}{c}{ Sorbent Material } & Recovery $(\%)$ \\
\hline $\mathrm{RTI}-3$ & 85.6 \\
Commercial Sorbent A & 76.5 \\
Trona T-50 & 12.7 \\
$\mathrm{RTI}-9 \mathrm{E}\left(\mathrm{Li}_{2} \mathrm{SiO}_{3}\right)$ & 9.43 \\
Sud-Chemie Sample G & 84.4 \\
$\mathrm{CBV}-712$ & 4.07 \\
Impregnated Carbon & 52.7 \\
$\mathrm{Fe}_{3} \mathrm{O}_{4}-\mathrm{Al}_{2} \mathrm{O}_{3}$ & 66.4 \\
$\mathrm{Commercial}$ Sorbent D & 78.6 \\
\hline
\end{tabular}
and $\mathrm{CO}_{2}$ as part of the warm syngas cleanup platform showed very limited removal of $\mathrm{H}_{2} \mathrm{Se}$. Other materials like Commercial Sorbent A and RTI-3 showed much higher removal of $\mathrm{H}_{2} \mathrm{Se}$.

\subsubsection{Hydrogen Selenide Capacity Testing}

The promising sorbents identified during these screening tests were used to select a list of materials for capacity testing. Results for these capacity tests are shown in Table 215. A number of materials, which include Commercial Sorbent $\mathrm{A}, \mathrm{NiO}-\mathrm{Al}_{2} \mathrm{O}_{3}$, and $\mathrm{Fe}_{3} \mathrm{O}_{4^{-}}$ 
$\mathrm{Al}_{2} \mathrm{O}_{3}$, had Se capacities of greater than $4.0 \mathrm{wt} \%$. The results confirm the results obtained with Se capture on Commercial Sorbent A from the Eastman field test with the multicontaminant skid.

Table 2-15. Summary of Hydrogen Selenide Capacity Testing

\begin{tabular}{clcccc}
\hline Set \# & \multicolumn{1}{c}{ Sorbent } & $\begin{array}{c}\text { Exposure } \\
\text { Temp. }\left({ }^{\circ} \mathbf{C}\right)\end{array}$ & Matrix & $\begin{array}{c}\text { Capacity } \\
(\text { wt. \%) }\end{array}$ & $\begin{array}{c}\text { Removal } \\
(\%)\end{array}$ \\
\hline $200-1$ & RTI-3 & 200 & Dirty syngas & 0.100 & 94.0 \\
$200-2$ & Impregnated Carbon (Research) & 200 & Dirty syngas & $\mathrm{NC}$ & - \\
$200-3$ & Commercial Sorbent A $_{200-4}$ & 200 & Dirty syngas & $>5.23$ & 96.1 \\
$200-7$ & $\mathrm{Fe}_{3} \mathrm{O}_{4}-\mathrm{Al}_{2} \mathrm{O}_{3}$ & 200 & Dirty syngas & $>4.71^{1}$ & 93.0 \\
$430-1$ & $\mathrm{NiO}-\mathrm{NiAl}_{2} \mathrm{O}_{4}$ & 200 & Dirty syngas & $>5.77$ & 100 \\
\hline
\end{tabular}

$\mathrm{NC}=$ Not calculated. Analysis results from initial QC cartridge samples indicated effluent concentration exceeded performance goal for cleaned syngas.

${ }^{1}$ Low material balance for this exposure

Interestingly, RTI-3 and the impregnated carbon did not show very large Se capacities. One potential explanation for the low removal by the RTI-3 sorbent was the $200{ }^{\circ} \mathrm{C}$ test temperature. A second test was performed with RTI-3, but at $430{ }^{\circ} \mathrm{C}$, which is similar to the typical operating temperature of the high-temperature desulfurization system. The results show that the Se capacity did increase, but not significantly. The relative rate of increase on the effluent concentration as Se capacity increased was slow, indicating a long and slow breakthrough profile.

\subsubsection{Testing for Lower Selenium Effluent Concentration}

The target concentration for Se for chemical production is $200 \mathrm{ppbv}$. The initial configuration for the sampling and analytical procedures had a detection limit that was equivalent to about $240 \mathrm{ppbv}$. Several slight modifications were made to improve this detection limit. The results of a test with Commercial Sorbent A are shown in Table 2-16. During this test, Commercial Sorbent A effectively reduced an inlet concentration of $10,000 \mathrm{ppbv}$ of $\mathrm{H}_{2} \mathrm{Se}$ to about $25 \mathrm{ppbv}$ at the start of the experiment. At the end of the test, the Se loading on the sorbent was $3.42 \mathrm{wt} \%$, but the effluent Se concentration was only 153 ppbv.

Table 2-16. Modified Se Testing for 200 ppbv Effluent Concentration

\begin{tabular}{cccccc}
\hline Set \# & Sorbent & $\begin{array}{c}\text { Exposure } \\
\text { Temp. }\left({ }^{\circ} \mathbf{C}\right)\end{array}$ & Matrix & $\begin{array}{c}\text { Capacity } \\
\text { (wt. \%) }\end{array}$ & $\begin{array}{c}\text { Removal } \\
(\%)\end{array}$ \\
\hline $200-8$ & Commercial Sorbent A & 200 & Dirty syngas & 3.42 & 98.5 \\
\hline
\end{tabular}




\subsection{Phosphine Sorbent Development}

\subsubsection{Material Selection for QC Cartridge}

One of the key modifications of the hydride testing system required to enable testing sorbents for phosphine removal was identification of a suitable material for the QC cartridges. Identification of a suitable material was also a very challenging task. Multiple materials were rapidly identified that would capture phosphine. The problem was that these materials inevitably had high inherent concentrations of $\mathrm{P}$. These high $\mathrm{P}$ backgrounds made accurate and consistent measurement of small differences in $\mathrm{P}$ concentration difficult to impossible. Attempts to prewash charcoal samples demonstrated that the $\mathrm{P}$ content of these materials could be reduced to acceptable background concentrations for analysis for low levels of phosphine capture, but this washing step changed the phosphine capture properties, and the change was not consistent even for identical washing conditions. After screening a number of materials, a copper-based material prepared by RTI with a low phosphorous background demonstrated retention of high concentrations of phosphine even in a simulated syngas containing $0.5 \mathrm{vol} \% \mathrm{H}_{2} \mathrm{~S}$. This copper-based material was used as the sorbent for the QC cartridges for phosphine testing.

\subsubsection{Phosphine Sorbent Screening}

The standard approach of preferentially screening commercial materials and materials with known multicontaminant capture capabilities was implemented for screening of potential phosphine sorbent materials. Because of the high inherent concentrations of $\mathrm{P}$ in the materials, the typical screening test was extended from 30 minutes to 120 minutes. This additional exposure time ensured that significant capture of $\mathrm{P}$ by a material could be effectively identified in spite of

Table 2-17. Results from Phosphine Screening Studies

\begin{tabular}{lc}
\hline Sorbent Material & Recovery (\%) \\
\hline Commercial Sorbent A & 30.3 \\
CBV-712 & 13.0 \\
Sud-Chemie Sample G & 65.2 \\
Commercial Sorbent D & 87.1 \\
Sud-Chemie Sample N & 62.9 \\
RTI-8 & 83.2 \\
Sud-Chemie Sample M & 79.4 \\
Sud-Chemie Sample L & 81.9 \\
Sud-Chemie Sample E & 89.0 \\
Sud-Chemie Sample F & 85.8 \\
Sud-Chemie Sample A & 81.3 \\
Commercial Sorbent E & 94.8 \\
\hline
\end{tabular}
high $\mathrm{P}$ background concentrations. The results from these screening tests are provided in Table 2-17, which shows that four materials demonstrated greater than $85 \%$ retention of the $\mathrm{P}$.

\subsubsection{Phosphine Sorbent Capacity Testing}

Results from the phosphine screening tests were used to select candidate sorbents for capacity testing. The standard phosphine concentration used for these capacity tests was 
10 ppmv. However, for two specialized tests, the phosphine concentration in the simulated syngas was 1 ppmv rather than $10 \mathrm{ppmv}$. The results for capacity testing for phosphine are provided in Table 2-18. Based on these results, at least one material exists that can provide phosphine removal at $200{ }^{\circ} \mathrm{C}$ in dirty syngas at a $\mathrm{P}$ capacity of $>3 \mathrm{wt} \%$.

Table 2-18. Summary of Phosphine Capacity Testing

\begin{tabular}{|c|c|c|c|c|c|}
\hline Set \# & Sorbent & $\begin{array}{l}\text { Exposure } \\
\text { Temp. }\left({ }^{\circ} \mathrm{C}\right)\end{array}$ & Matrix & $\begin{array}{l}\text { Capacity } \\
\text { (wt. \%) }\end{array}$ & $\begin{array}{c}\text { Removal } \\
(\%)\end{array}$ \\
\hline $200-1$ & $\mathrm{CuO}-\mathrm{Al}_{2} \mathrm{O}_{3}$ & 200 & Dirty syngas $^{1}$ & $>0.091$ & 100 \\
\hline $200-2$ & Commercial Sorbent D & 200 & Dirty syngas $^{1}$ & $>0.259$ & 88.3 \\
\hline $200-3$ & RTI-8 & 200 & Dirty syngas & 0.40 & 43.7 \\
\hline $200-4$ & Commercial Sorbent D & 200 & Dirty syngas $^{2}$ & 3.73 & 88.6 \\
\hline $200-5$ & RTI-3 & 200 & Dirty syngas & $\mathrm{NC}$ & - \\
\hline $200-6$ & Commercial Sorbent A & 200 & Dirty syngas & NC & - \\
\hline $200-7$ & Impregnated Carbon & 200 & Dirty syngas & $\mathrm{NC}$ & - \\
\hline
\end{tabular}

$\mathrm{NC}=$ Not calculated. Analysis results from initial QC cartridge samples indicated that effluent concentration exceeded performance goal for cleaned syngas.

${ }^{1}$ Phosphine challenge concentration was $1 \mathrm{ppm}$ instead of $10 \mathrm{ppm}$.

${ }^{2}$ Modified syngas matrix used for a portion of this exposure. Backup QC cartridge results indicated periodic spikes in the phosphine effluent concentration.

\subsection{Cadmium Sorbent Development}

\subsubsection{Cadmium Test System}

Based on thermodynamic calculations, the most stable $\mathrm{Cd}$ species in warm syngas is metallic $\mathrm{Cd}$ vapor. To effectively generate a simulated syngas mixture with $\mathrm{Cd}$ vapor, the design of the $\mathrm{Cd}$ test system needed to include a $\mathrm{Cd}$ vapor generator. The simplest design concept for this $\mathrm{Cd}$ vapor generator was to use a furnace to maintain a bed of $\mathrm{Cd}$ metal at a fixed temperature to generate a known vapor pressure of $\mathrm{Cd}$ and to continuously remove this $\mathrm{Cd}$ vapor with a sweep gas of $\mathrm{CO}_{2}$.

A schematic of the cadmium exposure system is shown in Figure 2-4. The main components of the system included a cadmium vapor generator tube maintained at a constant temperature in a horizontally mounted tube furnace, an exposure chamber maintained at a constant temperature in a vertically mounted tube furnace, and a QC cartridge sample. The $\mathrm{Cd}$ vapor generator tube consisted of a bed of cadmium metal held at the center of a 0.25 in O.D. by 12 in. long stainless steel tube by two quarts wool plugs. The system was designed so that when heated, the $\mathrm{Cd}$ metal would vaporize and be carried downstream by a flow of $\mathrm{CO}_{2}$ metered at $50 \mathrm{~mL} / \mathrm{min}$ with an electronic mass flow controller. The cadmium vapor was then blended with a $60-\mathrm{mL} / \mathrm{min}$ flow of simulated 
syngas supplied by a compressed gas mixture before entering the exposure chamber containing the candidate sorbent.

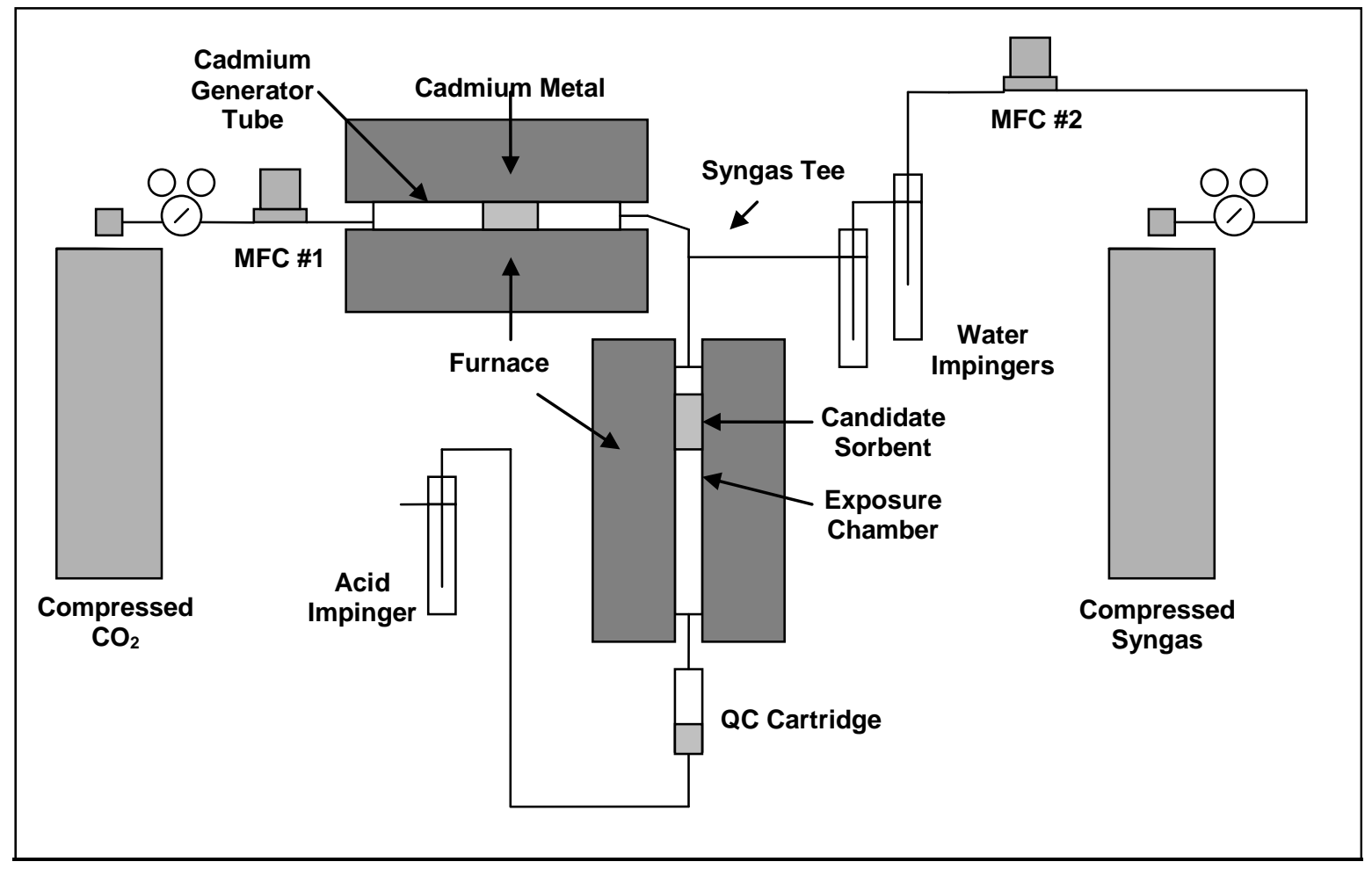

Figure 2-4. Cadmium Exposure System

Once the Cd exposure system was assembled, preliminary tests were conducted to demonstrate that the simulated syngas mixture did contain a known amount of $\mathrm{Cd}$ and that the concentration of $\mathrm{Cd}$ in the syngas was consistent. To effectively capture the $\mathrm{Cd}$ vapor, the syngas was forced through an impinger filled with an acidic solution. In the first tests, no $\mathrm{Cd}$ vapor was detected. Because of the potential for the system to accumulate $\mathrm{Cd}$ prior to becoming saturated, the acid impinger was moved directly to the outlet of the Cd vapor generator. Even at the outlet of the Cd vapor generator, no Cd vapor was detected.

A series of parametric tests was conducted to assist in defining the specific operating conditions necessary for consistently generating $\mathrm{Cd}$ vapor stream of known concentration. This series of parametric tests investigated

- operating temperatures up to a temperature within $10^{\circ} \mathrm{C}$ of the melting point of $\mathrm{Cd}$, replacing the original $\mathrm{Cd}$ metal with a fresh sample,

- using nitrogen as a sweep gas rather than $\mathrm{CO}_{2}$, and

- pre-reduction treatments for the $\mathrm{Cd}$ metal to reduce or remove any potential surface oxide layer. 
Although this parametric testing did manage to generate some $\mathrm{Cd}$ vapor, the concentration was significantly less than expected based on vapor pressure calculations and was not consistent.

Based on these results and the results from the Eastman field test, there is little evidence to suggest that $\mathrm{CD}$ vapor is a significant contaminant in coal-derived syngas. 


\section{SECTION 3 \\ DEVELOPMENT OF WARM $\mathrm{CO}_{2}$ CAPTURE TECHNOLOGY}

\subsection{Novel R\&D Approach}

\subsubsection{Screening Criteria for Novel Sorbent Materials}

Lithium silicate-based sorbents consistently demonstrated exceptional performance toward $\mathrm{CO}_{2}$ capture from syngas. The challenge was specifically the regeneration. One of the primary reasons for this challenge is the low equilibrium partial pressure of $\mathrm{CO}_{2}$ for lithium silicate at temperatures from $300{ }^{\circ} \mathrm{C}$ to $600{ }^{\circ} \mathrm{C}$. However, this low $\mathrm{CO}_{2}$ equilibrium partial pressure also makes lithium silicate a good sorbent for removing $\mathrm{CO}_{2}$.

From this analysis, the ideal $\mathrm{CO}_{2}$ sorbent for high-temperature application would be a material with a low equilibrium partial pressure between $200^{\circ} \mathrm{C}$ and $400{ }^{\circ} \mathrm{C}$ and a significantly higher $\mathrm{CO}_{2}$ equilibrium partial pressure at temperatures from $300^{\circ} \mathrm{C}$ to $500{ }^{\circ} \mathrm{C}$. For a fully shifted syngas stream in standard reference IGCC plants, the $\mathrm{CO}_{2}$ partial pressure is approximately 300 psi. To achieve DOE's target $\mathrm{CO}_{2}$ capture of $90 \%$, the $\mathrm{CO}_{2}$ partial pressure in the syngas must be reduced to roughly $30 \mathrm{psi}$. Alternatively, to effectively regenerate at system pressure, the equilibrium $\mathrm{CO}_{2}$ partial pressure for regeneration would need to be $>300$ psi.

Using available thermodynamic properties, the equilibrium $\mathrm{CO}_{2}$ partial pressure for a variety of different solids was calculated. Results of this effort, plotted in Figure 3-1, show that a number of different materials have equilibrium $\mathrm{CO}_{2}$ partial pressure curves that fit the desired profile for an effective $\mathrm{CO}_{2}$ sorbent. And, with this approach, the $\mathrm{CO}_{2}$ product can be generated at high pressure, reducing the parasitic energy load for compression associated with capture and sequestration of $\mathrm{CO}_{2}$.

Screening materials to demonstrate their ability to capture $\mathrm{CO}_{2}$ at appropriate conditions requires testing at pressure. Unfortunately, the atmospheric TGA that was used in the original screening of sorbent materials would not be effective for testing at pressure. Therefore, our highpressure TGA system was modified to enable sorbent screening. Because loading and unloading the high-pressure TGA was relatively time consuming, two additional high-pressure reactor systems were modified to assist in material screening tests. A description of these testing systems is provided in Section 3.2, Experimental Systems. 


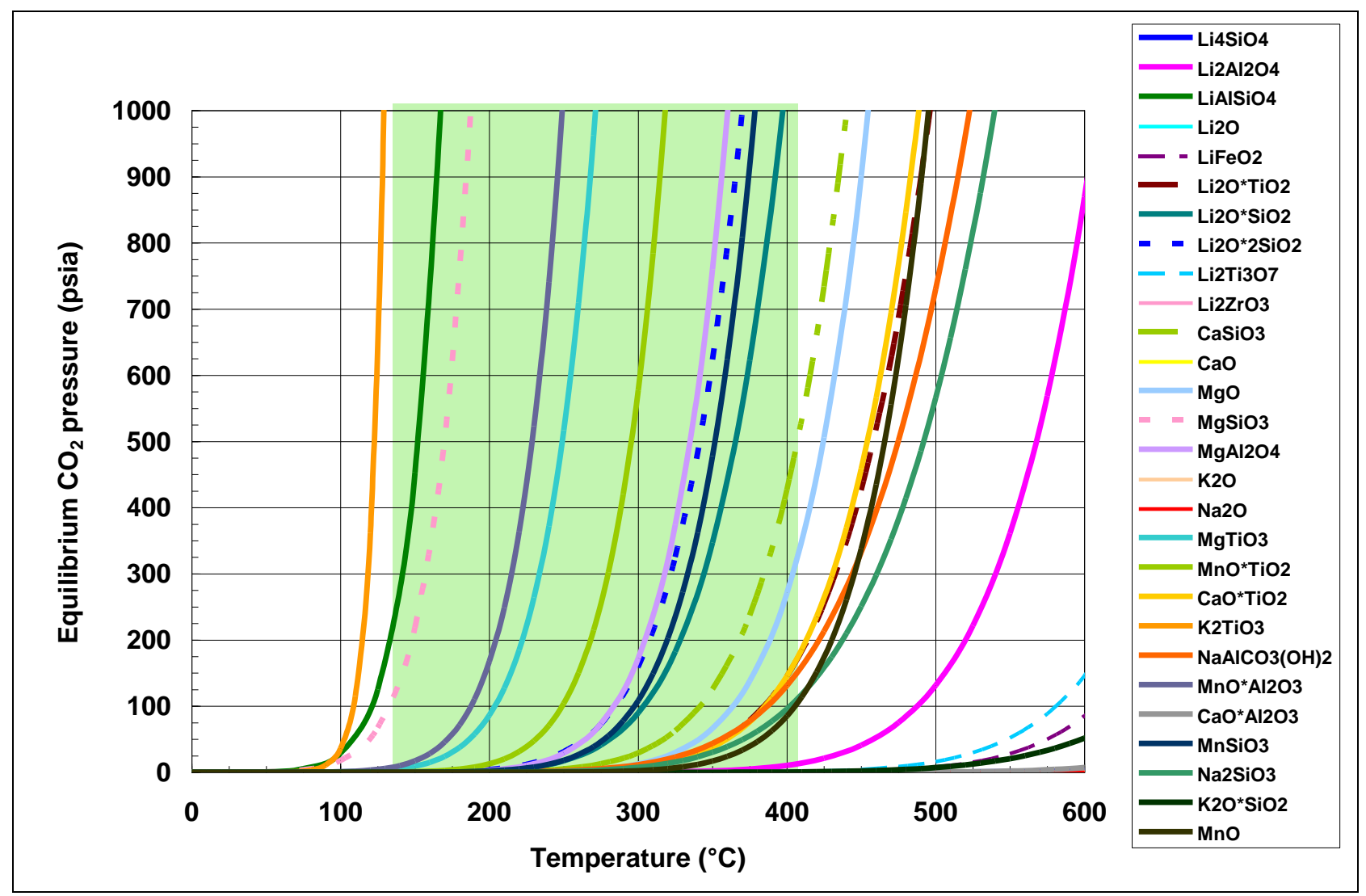

Figure 3-1. Thermodynamic equilibrium curves for $\mathrm{CO}_{2}$ partial pressure with highlighted area showing materials meeting screening selection criteria

\subsection{2 $\quad \mathrm{CO}_{2}$ Recovery for Lithium Silicate Regeneration}

The existing body of data available for our lithium silicate-based sorbents had already demonstrated $\mathrm{CO}_{2}$ adsorption performance from hot syngas during multicycle testing. The specific strengths of this adsorption performance were fast $\mathrm{CO}_{2}$ adsorption kinetics, which allowed $>90 \%$ removal, no reduction in $\mathrm{CO}_{2}$ adsorption performance in the presence of high sulfur concentrations between 0.5 and 1 vol\%, and performance stability over multiple adsorption and regeneration cycles.

The challenge lay in regeneration of the lithium silicate sorbent. Temperature swing was impractical because the very high temperature required consumes the high value heat and presents significant technical challenges in transferring the reaction enthalpy into the sorbent bed. Regeneration by concentration swing, although repetitively demonstrated in our bench-scale sorbent testing system, required too much steam for producing a high-purity $\mathrm{CO}_{2}$ product or resulted in a dilute $\mathrm{CO}_{2}$ product that cannot be used for sequestration. 
A potential solution is to implement a $\mathrm{CO}_{2}$ recovery process in which a second sorbent is used to effectively recover the dilute $\mathrm{CO}_{2}$ from the regeneration effluent. This $\mathrm{CO}_{2}$ recovery process was conceptualized based on the adsorption properties of zeolite materials. In this process, the dilute low-pressure effluent from lithium silicate regeneration is contacted with a sorbent. This sorbent selectively adsorbs the $\mathrm{CO}_{2}$ at low temperature $\left(<100^{\circ} \mathrm{C}\right)$. When saturated with $\mathrm{CO}_{2}$, the sorbent is then pressurized with $\mathrm{CO}_{2}$. After pressurization, the sorbent is heated. This heating results in a decrease in the adsorption capacity of the sorbent, which releases $\mathrm{CO}_{2}$. The sorbent is then depressurized and cooled. At this point, the sorbent has been regenerated. The specific steps involved in the proposed $\mathrm{CO}_{2}$ recovery process are shown in Figure 3-2.

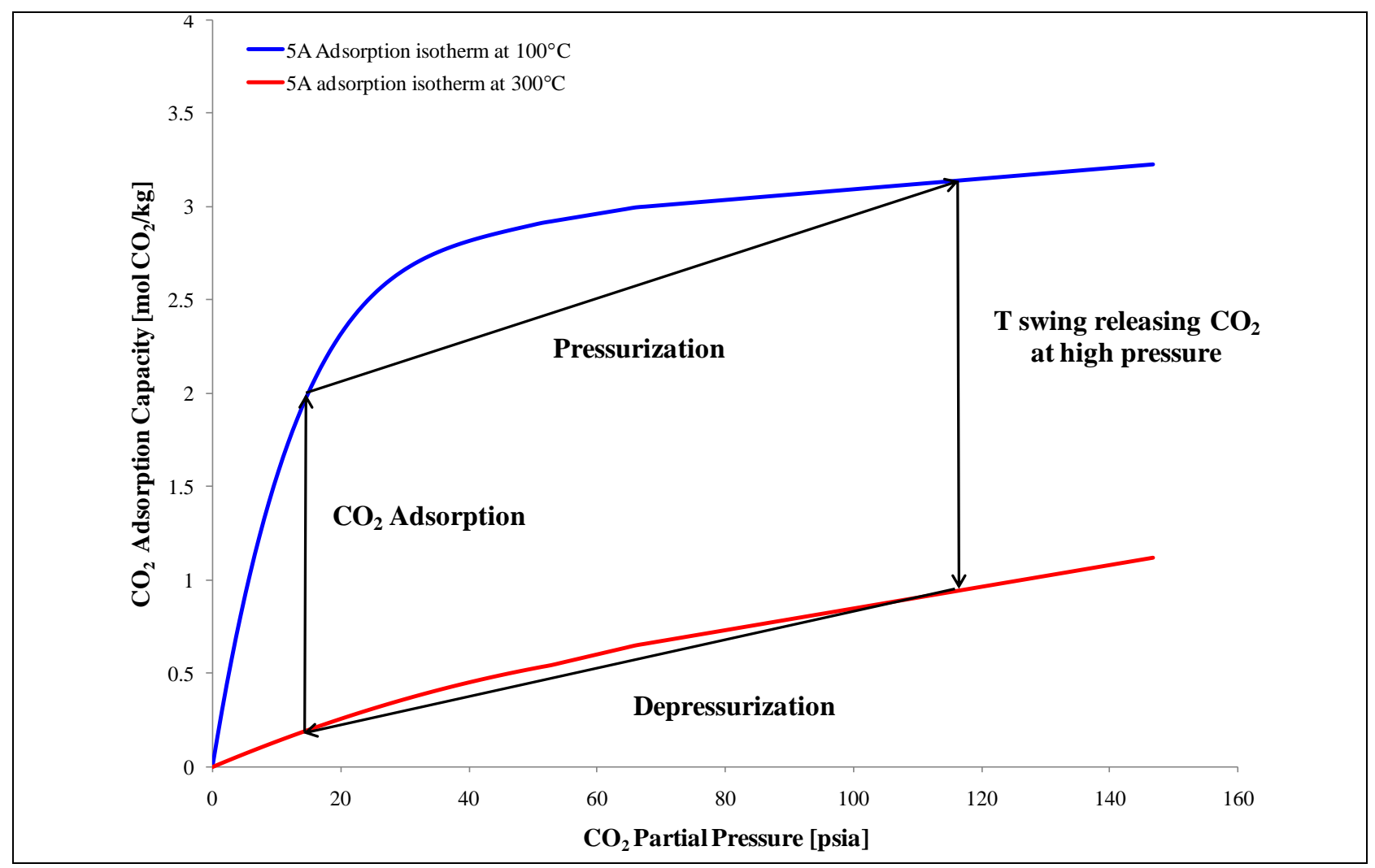

Figure 3-2. Processing steps in proposed $\mathrm{CO}_{2}$ recovery process

Key performance criteria for the sorbent for the $\mathrm{CO}_{2}$ recovery process are

- High $\mathrm{CO}_{2}$ capacity at low $\mathrm{CO}_{2}$ partial pressures

- High $\mathrm{CO}_{2}$ capacity at low temperatures

- Low $\mathrm{CO}_{2}$ capacity at higher temperatures $\left(200{ }^{\circ} \mathrm{C}-300^{\circ} \mathrm{C}\right)$

- Selective adsorption of $\mathrm{CO}_{2}$ over water. 
To effectively conduct $\mathrm{R} \& \mathrm{D}$ on this $\mathrm{CO}_{2}$ recovery process, testing focused on evaluating the optimal regeneration conditions for the lithium silicate-based sorbent and developing the adsorption isotherms for promising zeolite materials over a temperature range of $100{ }^{\circ} \mathrm{C}$ to $300{ }^{\circ} \mathrm{C}$

\subsection{Experimental Systems}

High-pressure sorbent testing systems were required to effectively test at temperature and pressure conditions that would meet the target criteria for regeneration. Three existing reactor systems were modified for the specific purpose of testing sorbent materials for this project.

\subsubsection{High-Pressure TGA}

TGAs monitor the weight change of a solid sample in response to changes in gas composition and temperature. Specialized highpressure TGAs (HP-TGAs) measure weight changes under high-pressure conditions. The CAHN TG-151 available at RTI has a reactor system suitable for testing at up to $800{ }^{\circ} \mathrm{C}$ and 600 psig. This TGA is pictured in Figure 3-3.

Specific $\mathrm{CO}_{2}$ removal conditions were selected based on a typical General Electric syngas composition that has been shifted under

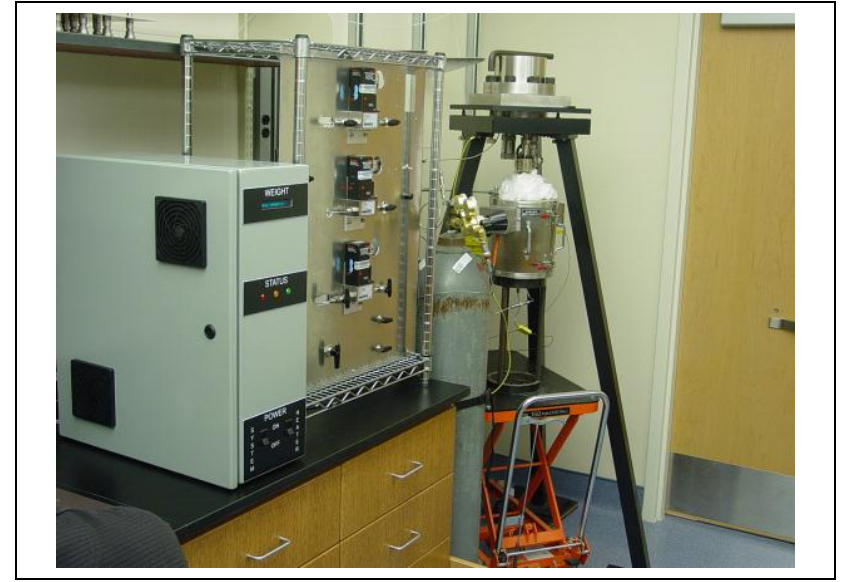

Figure 3-3. RTI high-pressure TGA (HP TGA) modified for testing $\mathrm{CO}_{2}$ sorbent materials optimal conditions to enable capture of $>90 \%$ of the $\mathrm{CO}_{2}$ from the syngas. Under these conditions, the $\mathrm{CO}_{2}$ partial pressure should be approximately 300 psi. To achieve $90 \%$ removal of this $\mathrm{CO}_{2}$, the effluent syngas stream must contain $<30$ psig of $\mathrm{CO}_{2}$. For regeneration, the sorbent must be able to release the $\mathrm{CO}_{2}$ to achieve $\mathrm{a} \mathrm{CO}_{2}$ partial pressure of $>100 \mathrm{psig}$. One of the key parametric variables in regeneration is reaction temperature.

RTI's CAHN TGA was modified to facilitate materials screening tests under these conditions. These modifications also addressed technical challenges encountered during commissioning and initial operation. Table 3-1 lists the challenges encountered along with the solutions implemented. 
Table 3-1. Problems and Solutions Encountered with HP-TGA Testing

\begin{tabular}{|c|c|}
\hline Problem & Solution \\
\hline Control system crashing & $\begin{array}{l}\text { The original control board was found to be faulty. A new control system was } \\
\text { designed, installed, and validated. }\end{array}$ \\
\hline Mass signal noise $( \pm 15 \mathrm{mg})$ & $\begin{array}{l}\text { The noise in the mass signal was caused by the back pressure control valve. New } \\
\text { control parameters were installed in the control software, reducing a significant } \\
\text { portion of the noise. }\end{array}$ \\
\hline Buoyancy $\left(\mathrm{He}-\mathrm{CO}_{2}\right)$ & $\begin{array}{l}\text { The mass of the sample decreased }(40 \%) \text { upon the introduction of } \mathrm{CO}_{2} \text { into } \mathrm{He} \text {. } \\
\text { The large buoyancy difference between the } \mathrm{He} \text { and } \mathrm{He} / \mathrm{CO}_{2} \text { gas mixtures was } \\
\text { determined to have caused the inconsistency. Helium was replaced with argon, } \\
\text { reducing the buoyancy effect caused by gas composition. }\end{array}$ \\
\hline Buoyancy (temperature) & $\begin{array}{l}\text { The mass of the sample was found to linearly increase with temperature during the } \\
\text { regeneration cycle. This increase is due to the decrease in the surrounding gas } \\
\text { density with temperature. To reduce this effect, additional weight was added to the } \\
\text { sample holder, reducing the buoyancy effect of the gas. }\end{array}$ \\
\hline
\end{tabular}

\subsubsection{Automated Micro-reactor System}

Although the HP-TGA proved successful for screening at optimal conditions for a regenerable $\mathrm{CO}_{2}$ sorbent, a number of limitations inherent with the HP-TGA reduced its practical value as an effective screening tool. The two most important limitations were (1) the time required to effectively load and unload sorbent samples and (2) the specific data collected to monitor sorbent performance was weight change of the sorbent. To facilitate screening materials and promote the development of promising materials identified during screening, an existing reactor system equipped with two fully automated reactors was modified for screening and testing $\mathrm{CO}_{2}$ sorbents. This system is shown in Figure 3-4.
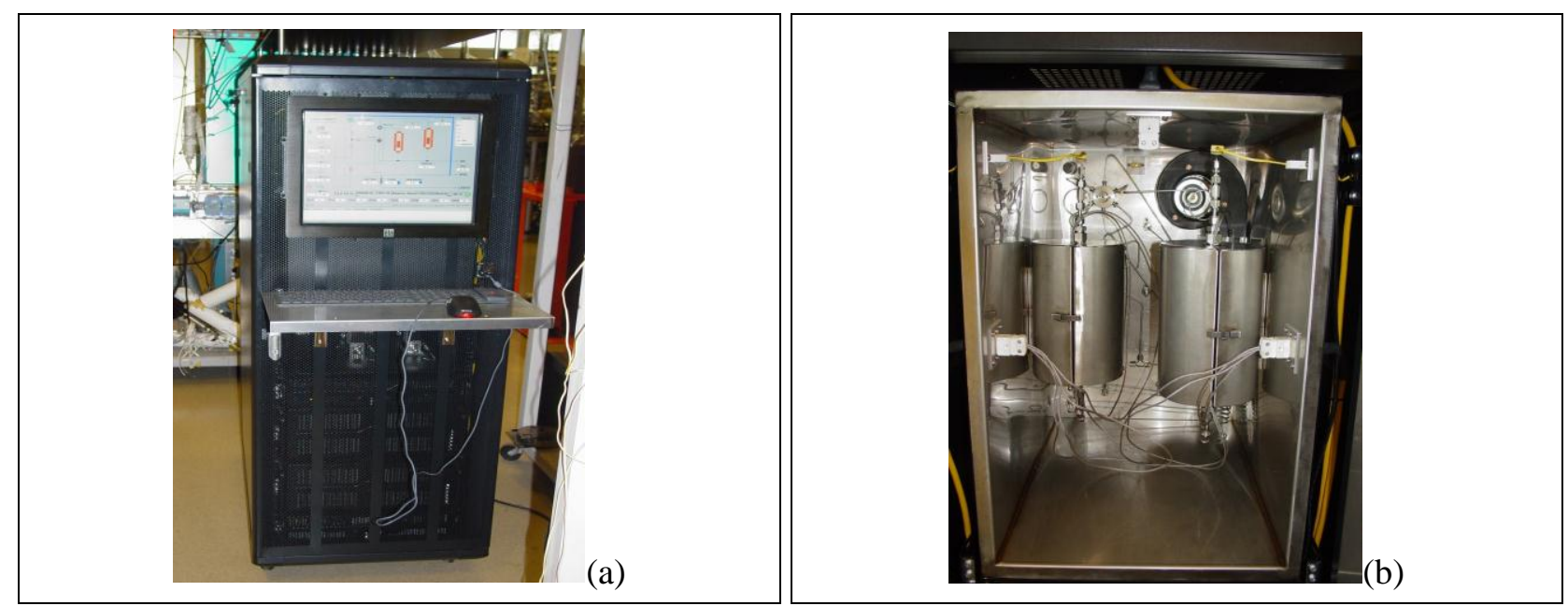

Figure 3-4. RTI's automated micro-reactor (AMR) system: (a) front view and (b) reactors

Because this system was automated and had two reactors, up to four cycles $\left(\mathrm{CO}_{2}\right.$ adsorption and regeneration) could be completed for two samples in a 24 -h period, significantly 
increasing the number of samples that could be tested. The reactors, shown in Figure 3-4(b), consisted of approximately 6 -inch lengths of $1 / 2$-inch stainless steel tubing. The volume of sorbent that could effectively be contained in these reactors was about $4 \mathrm{~g}$. The system was capable of testing at a total pressure of $350 \mathrm{psig}$, temperatures up to $600{ }^{\circ} \mathrm{C}$, and space velocities up to $9,000 \mathrm{~h}^{-1}$ (at standard temperature and pressure [STP]). Test gases consisted of a $\mathrm{CO}_{2} / \mathrm{N}_{2}$ mixture for adsorption and $\mathrm{N}_{2}$ for regeneration. The $\mathrm{CO}_{2}$ concentration in effluent gas was monitored with a continuous $\mathrm{CO}_{2}$ analyzer.

\subsubsection{Micro-reactor System}

The schematic for RTI's micro-reactor system is shown in Figure 3-5. The reactor for this system consists of a 16-in length of $1 / 2$-in SS tube that can hold between 1 and $10 \mathrm{~g}$ of sorbent material. The operating limits for this system are $700{ }^{\circ} \mathrm{C}$ and $500 \mathrm{psig}$. This gas feed system for this micro-reactor system was designed to enable testing of $\mathrm{CO}_{2}$ adsorption in simulated syngas mixtures containing up to $60 \mathrm{vol} \%$ steam. As with the automated micro-reactor system, the CO and $\mathrm{CO}_{2}$ reactor effluents were monitored with a continuous analyzer.

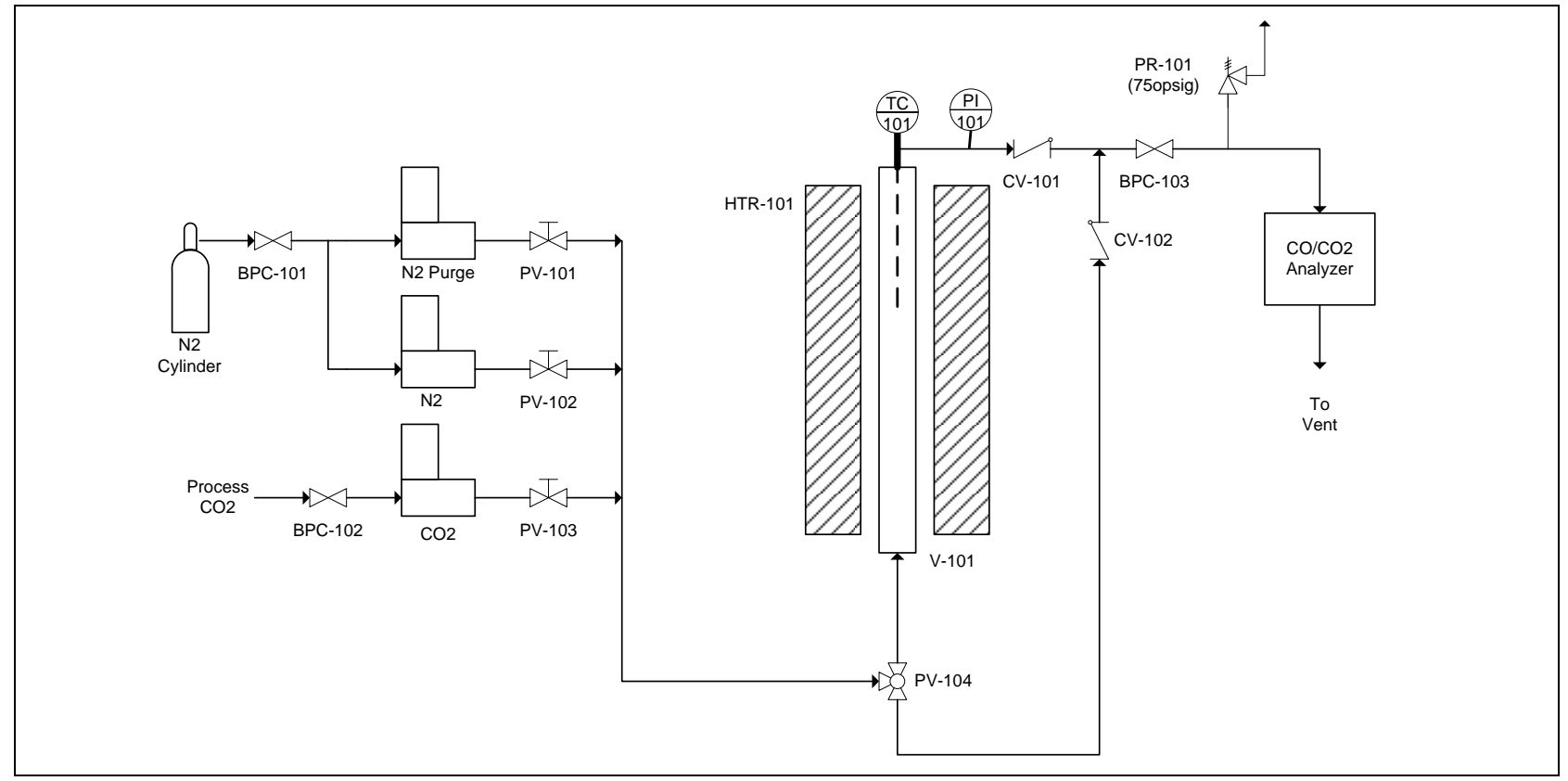

Figure 3-5. Schematic of RTl's micro-reactor system as configured for $\mathrm{CO}_{2}$ testing 


\subsection{Results}

\subsection{1 $\quad \mathrm{CO}_{2}$ Recovery Process}

\subsubsection{Zeolite Evaluation and Sorbent Development}

An initial evaluation of potential sorbents that would meet the specifications required for a $\mathrm{CO}_{2}$ recovery process indicated that the most promising sorbents were zeolites. A number of commercial samples of $5 \mathrm{~A}$ and $13 \mathrm{X}$ zeolites were procured. Based on the recommendation of the zeolite vendor, a modified 13X (13X Z10 10ND) was also procured. The vendor indicated that their evaluation had shown this modified $13 \mathrm{X}$ zeolite had better $\mathrm{CO}_{2}$ adsorption properties (over a wide range of $\mathrm{CO}_{2}$ partial pressures).

Because a full adsorption isotherm was beneficial for the evaluation of these materials, the results from two different testing systems were combined to produce a full $\mathrm{CO}_{2}$ isotherm from no $\mathrm{CO}_{2}$ partial pressure $(0 \mathrm{psi})$ to about $130 \mathrm{psi}$ of $\mathrm{CO}_{2}$ partial pressure. The atmospheric TGA was effectively used for adsorption below $14.7 \mathrm{psi}$ of $\mathrm{CO}_{2}$ partial pressure. The microreactor system was used to obtain the adsorption results at $>14.7 \mathrm{psi}$ of $\mathrm{CO}_{2}$ partial pressure. Results from this testing are shown in Figure 3-6. Although both systems could provide results at

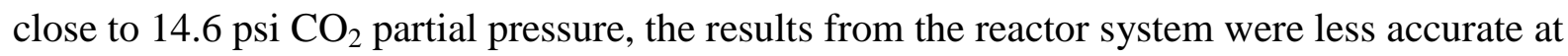
this low $\mathrm{CO}_{2}$ partial pressure, which explains the discontinuity in Figure 3-6 at $14.6 \mathrm{psi}^{\mathrm{CO}_{2}}$ partial pressure.

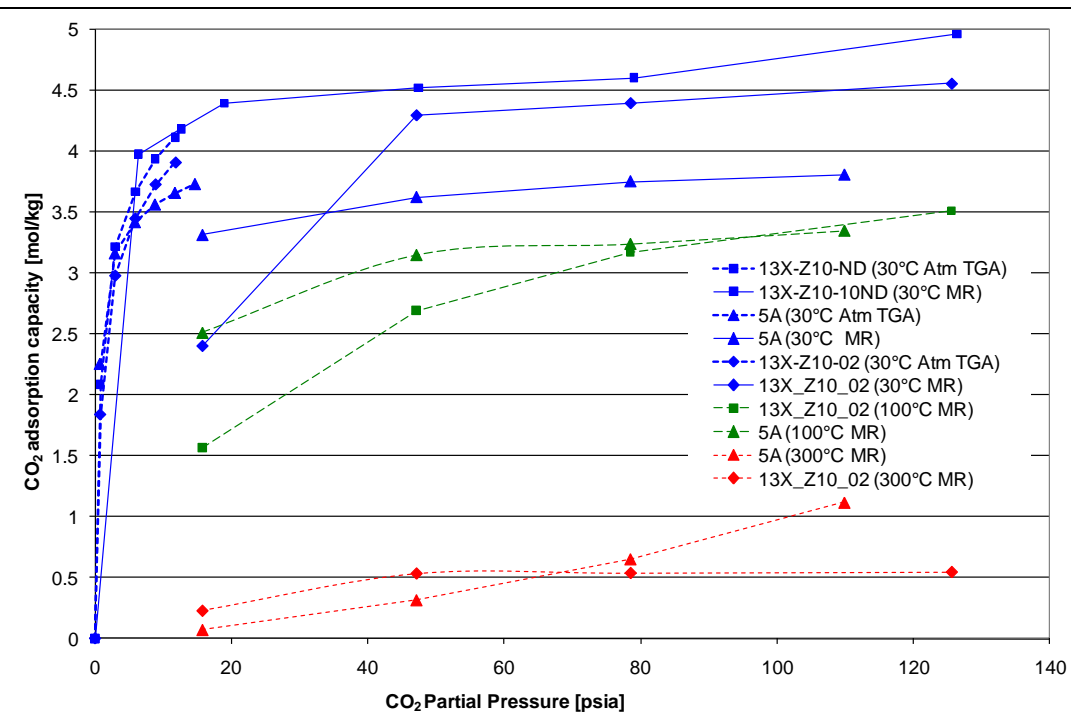

Figure 3-6. Adsorption profiles for 5A and 13X zeolites at different temperatures between $30 \stackrel{\circ}{-C}$ and $300 \stackrel{\circ}{\circ}$ 
As shown in Figure 3-6, at about $30{ }^{\circ} \mathrm{C}$, the $\mathrm{CO}_{2}$ adsorption ranged from about $3.5 \mathrm{~mol}$ of $\mathrm{CO}_{2} / \mathrm{kg}$ of adsorbent for the $5 \mathrm{~A}$ zeolite to about $4.5 \mathrm{~mol}$ of $\mathrm{CO}_{2} / \mathrm{kg}$ of adsorbent for the $13 \mathrm{X}$ zeolite. At $300{ }^{\circ} \mathrm{C}$, the $\mathrm{CO}_{2}$ adsorption capacity for both zeolite materials decreased significantly and was roughly between 0.5 and $1 \mathrm{~mol}$ of $\mathrm{CO}_{2} / \mathrm{kg}$ of adsorbent. The results for the $13 \mathrm{X}$ zeolite at $100{ }^{\circ} \mathrm{C}$ show a $\mathrm{CO}_{2}$ adsorption capacity of between 2.5 and $3 \mathrm{~mol}$ of $\mathrm{CO}_{2} / \mathrm{kg}$ of adsorbent. These results show that, if the $\mathrm{CO}_{2}$ partial pressure in the off-gas from the lithium silicate regeneration is about 14.7 psia, the proposed $\mathrm{CO}_{2}$ recovery process could be technically feasible.

The zeolites were tested with a mixture of $\mathrm{CO}_{2}$ and steam to determine the selectivity of the zeolite material for $\mathrm{CO}_{2}$ adsorption. These results, shown in Figure 3-7, indicate that the 5A zeolite material was more selective for $\mathrm{CO}_{2}$ and that no significant difference in the $\mathrm{CO}_{2}$ adsorption capacity was observed when steam was introduced. Therefore, if steam is used as an inert purge in the regeneration of lithium silicate, the $\mathrm{CO}_{2}$ concentration in the regeneration off gas stream can be increased by condensation of the steam. These results could be used to expand the potential operating window for the $\mathrm{CO}_{2}$ recovery process.

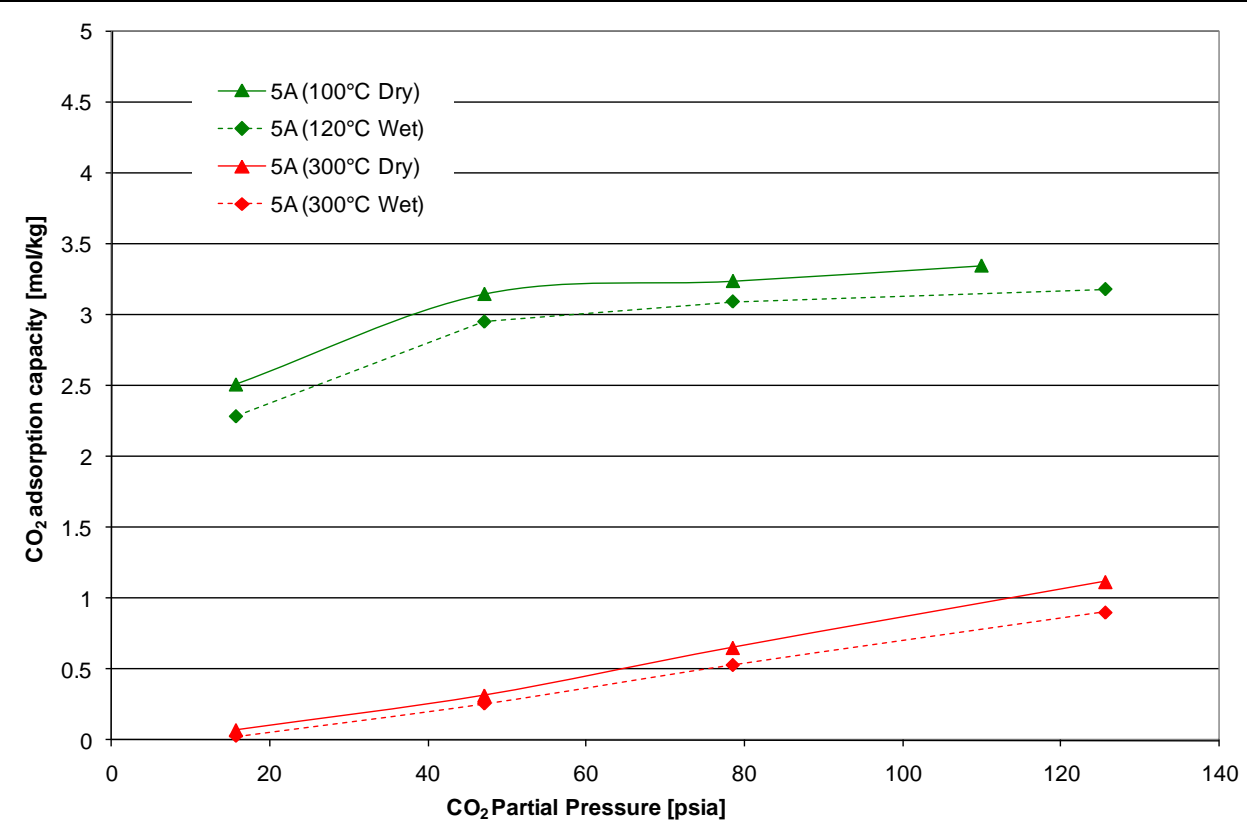

Figure 3-7. Effect of steam on $\mathrm{CO}_{2}$ adsorption for Zeolite 5A

Because achieving the highest $\mathrm{CO}_{2}$ adsorption capacity at the lowest partial pressure of $\mathrm{CO}_{2}$ was an important feature for these zeolite materials in the $\mathrm{CO}_{2}$ recovery process, the potential for improving the commercial zeolite adsorbents was investigated by modifying the zeolites by ion exchange. The $\mathrm{CO}_{2}$ adsorption profiles for these modified sorbents are shown in Figures 3-8 and 3-9. For the 5A zeolites, two of the exchanged zeolites (B and D) showed 
significantly lower $\mathrm{CO}_{2}$ adsorption capacity. The $\mathrm{CO}_{2}$ adsorption capacity for the other two exchanged zeolites (A and C) was essentially identical to the original 5A zeolite.

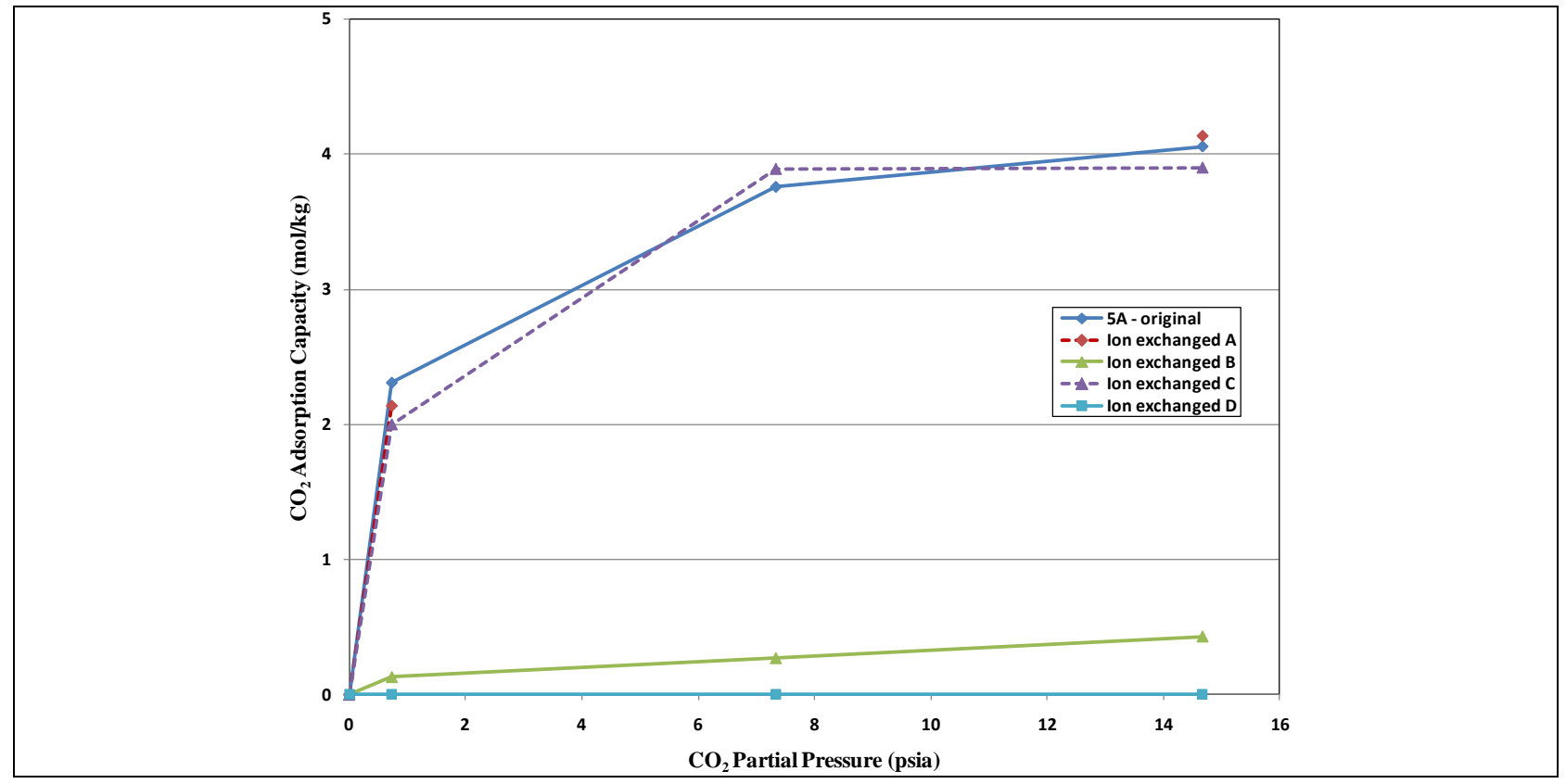

Figure 3-8. $\quad \mathrm{CO}_{2}$ adsorption capacities for ion-exchanged $5 \mathrm{~A}$ zeolite samples

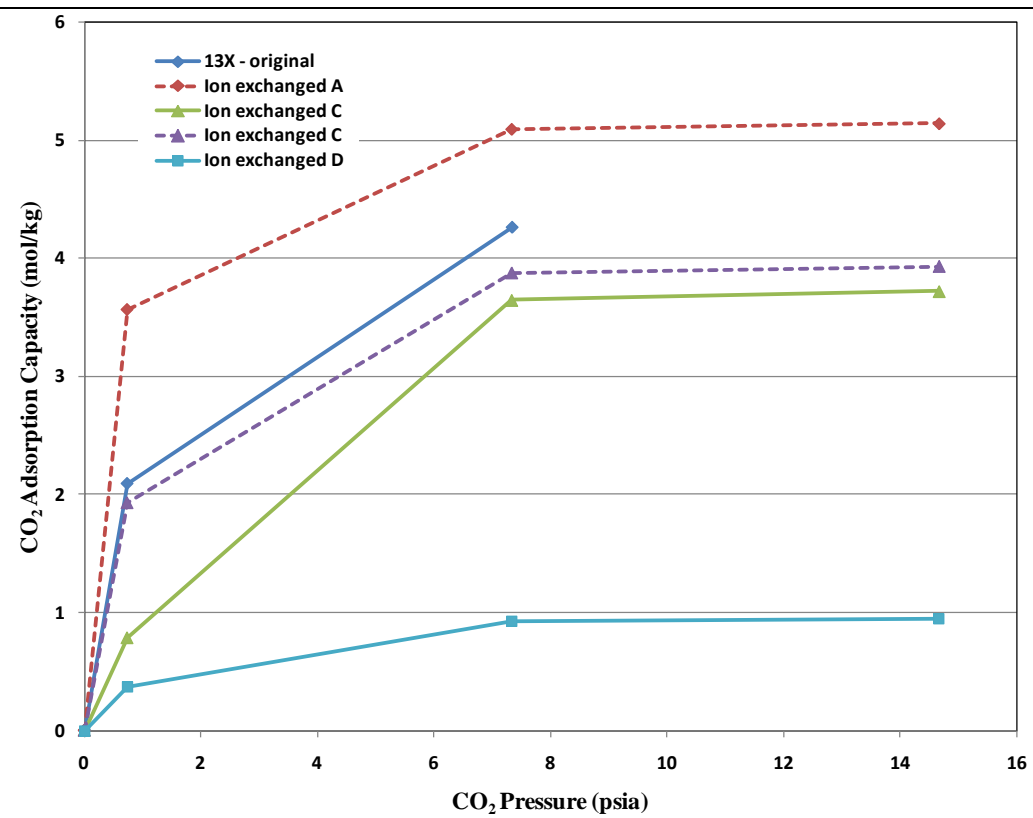

Figure 3-9. $\mathrm{CO}_{2}$ adsorption capacities for ion-exchanged $13 \mathrm{X}$ zeolite samples

For the $13 \mathrm{X}$ zeolites, the ion-exchanged sample $\mathrm{A}$ had a higher $\mathrm{CO}_{2}$ adsorption capacity than the original $13 \mathrm{X}$, whereas exchanged zeolite $\mathrm{D}$ had a much lower $\mathrm{CO}_{2}$ capacity than the 
original 13X. Based on physical analysis of these materials, a correlation between the surface area, pore volume, and $\mathrm{CO}_{2}$ adsorption capacity was identified.

\subsubsection{Lithium Silicate Regeneration}

In parallel with the work on the zeolite materials, lithium silicate sorbent testing was conducted to evaluate the ability to generate a suitable regeneration off-gas for the $\mathrm{CO}_{2}$ recovery process. The primary objective was to obtain as high a $\mathrm{CO}_{2}$ partial pressure in the regeneration off-gas as possible. The key operation parameters investigated were inert purge flow rate, using mixtures of $\mathrm{N}_{2}$ /steam as an inert, and the regeneration temperature.

The results from concentration swing-based regenerations with $\mathrm{N}_{2}$ and $\mathrm{N}_{2} /$ steam mixtures at $600{ }^{\circ} \mathrm{C}$ are shown in Figures 3-10 and 3-11. The three most predominant results shown are (1) the $\mathrm{CO}_{2}$ concentration in off-gas is very low ( $\left.<1 \mathrm{vol} \%\right)$, (2) the $\mathrm{CO}_{2}$ concentration in the off-gas is inversely proportional to flow, and (3) the time required for regeneration decreases significantly with increasing flow rate. The only effect of adding $15 \mathrm{vol} \%$ steam to the purge gas was a slight $(<10 \%)$ increase in the $\mathrm{CO}_{2}$ concentration in the off-gas. Thus, the shortest regeneration times occur at the highest purge rates and produce the lowest concentration of $\mathrm{CO}_{2}$. These results confirm the result from previous testing that extremely high steam-to- $\mathrm{CO}_{2}$ ratios would be required to effectively regenerate lithium silicate sorbents and produce a high-purity $\mathrm{CO}_{2}$ byproduct.

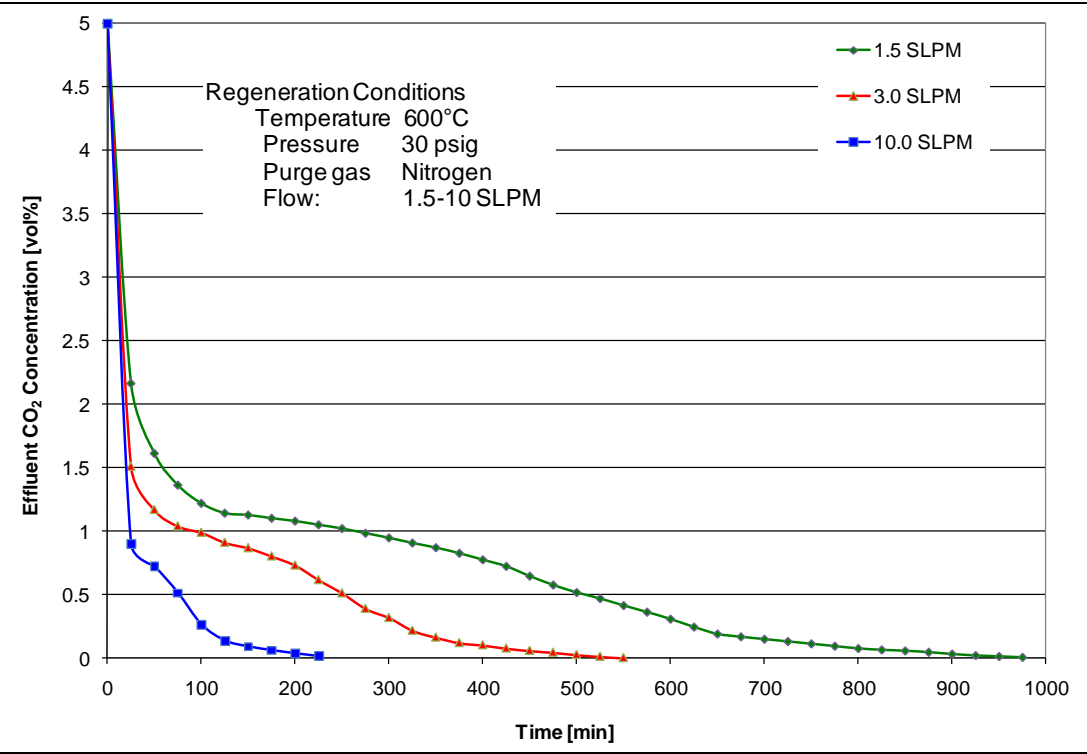

Figure 3-10. Effluent $\mathrm{CO}_{2}$ concentration for regeneration by concentration swing at different nitrogen flow rates 


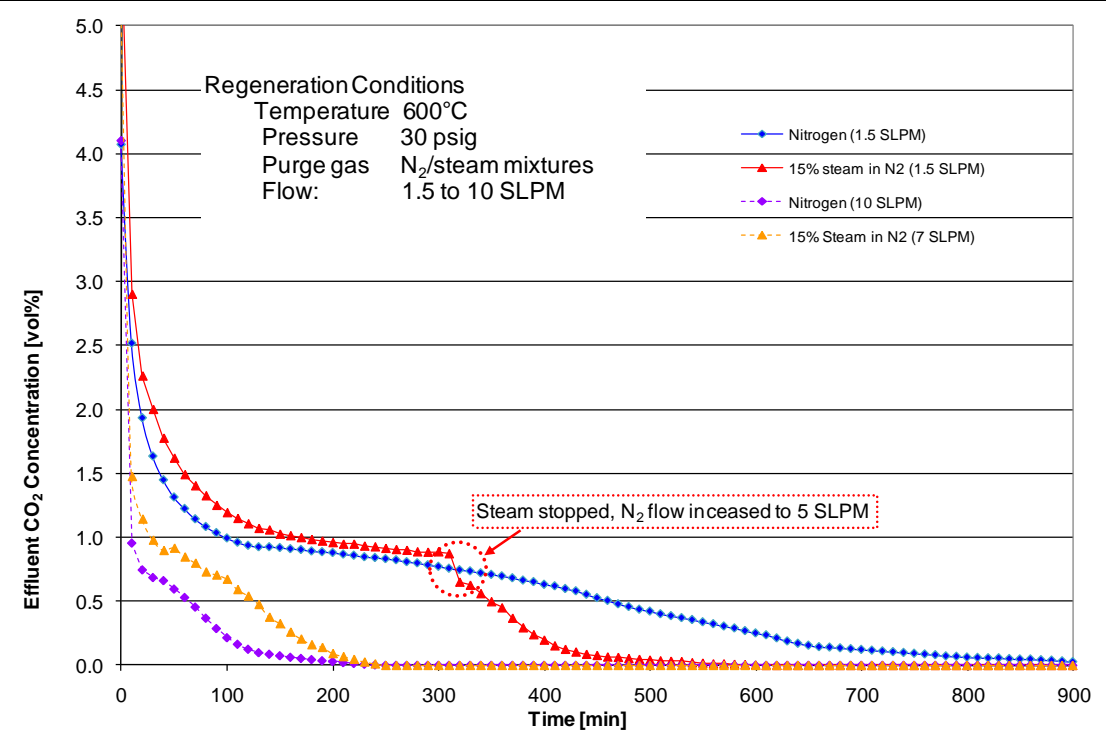

Figure 3-11. Effluent $\mathrm{CO}_{2}$ concentrations during regeneration by concentration swing with $\mathrm{N}_{2} /$ steam mixtures

The results in Figures 3-10 and 3-11 were surprising because the $\mathrm{CO}_{2}$ concentrations in the off-gas were significantly lower than expected based on thermodynamic equilibrium calculations. The regeneration profiles shown in Figures 5-5 and 5-6 suggest that mass transfer is limiting the regeneration. A theoretical explanation for this mass transfer limitation is that the promoter used to enhance the $\mathrm{CO}_{2}$ capacity of the lithium silicate sorbents is responsible for mass transfer within the lithium silicate structure. For $\mathrm{CO}_{2}$ capture, the promoter helps maximize the $\mathrm{CO}_{2}$ capacity. However, during regeneration, transfer of the $\mathrm{CO}_{2}$ from within the lithium silicate structure to the surface is facilitated by the promoter and can only proceed at a fixed rate.

Figure 3-12 shows results of several tests conducted at higher regeneration temperatures. The higher temperatures did result in higher $\mathrm{CO}_{2}$ concentrations in the off-gas, but, even at a temperature of $750{ }^{\circ} \mathrm{C}$, the $\mathrm{CO}_{2}$ concentration in the off-gas was still only a fraction of the concentration necessary for effective integration with the zeolite-based $\mathrm{CO}_{2}$ recovery process.

The general conclusion from testing conducted for the $\mathrm{CO}_{2}$ recovery process was that zeolites could potentially be used for a $\mathrm{CO}_{2}$ recovery process, but that generating an acceptable off-gas from concentration swing regeneration of lithium silicate was not practical using temperature or inert purge rates. For this reason, further testing and development for the $\mathrm{CO}_{2}$ recovery process was discontinued. 


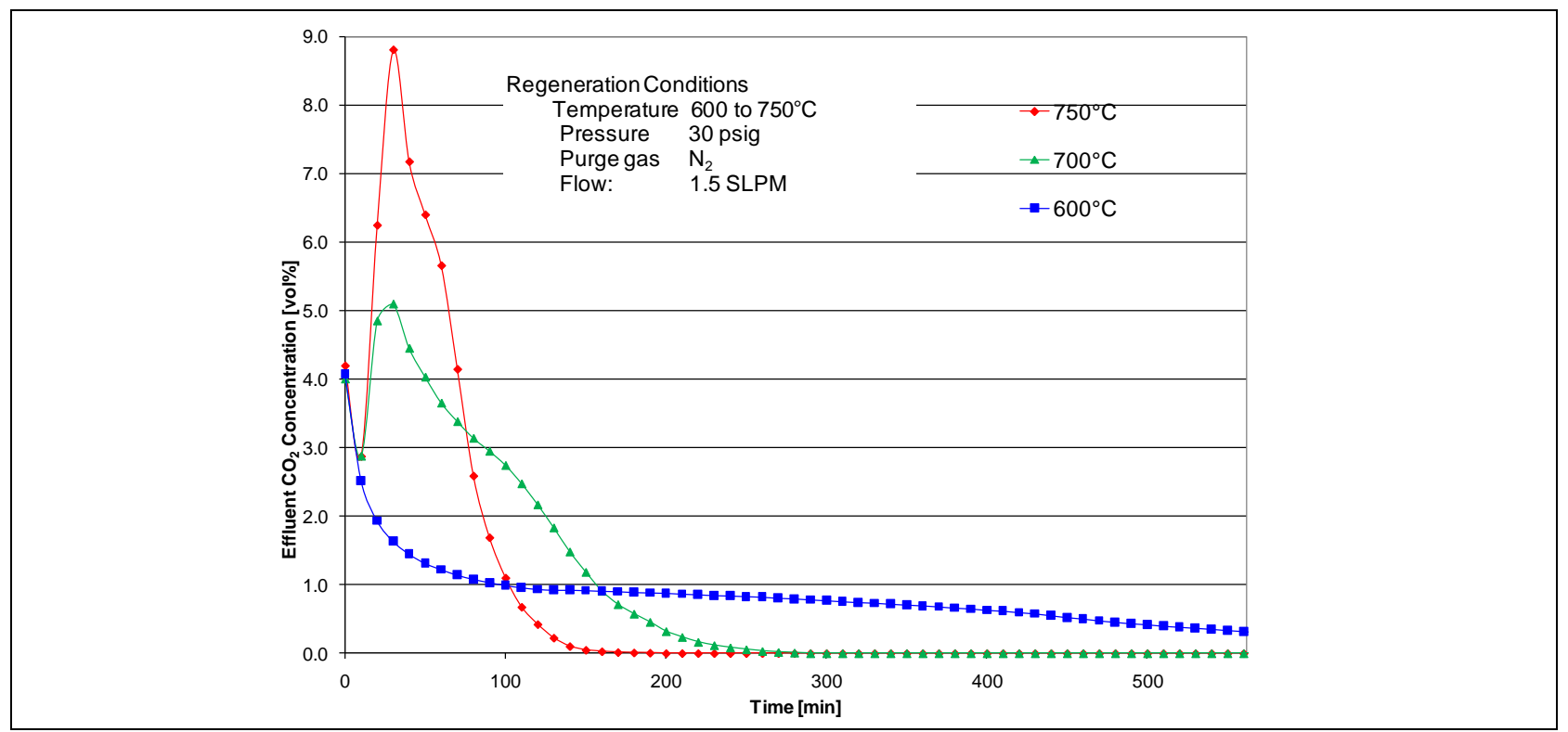

Figure 3-12. Effluent $\mathrm{CO}_{2}$ concentration during regeneration by concentration swing at different temperatures

\subsection{2 $\quad \mathrm{CO}_{2}$ Sorbent Development}

\subsubsection{Material Screening}

A number of different materials were prepared and tested in either the HP-TGA or the AMR system. Table 3-2 presents results for some of the most promising materials. An Mg-Li-based material showed the most promising performance. Using the AMR system, testing of this material was expanded from the standard 3-cycle test to an 11cycle test. During this test, this material showed consistent adsorption and regeneration performance producing a $\mathrm{CO}_{2}$ byproduct during regeneration at pressures as high as $45 \mathrm{psig}$. This limit was

Table 3-2. $\quad \mathrm{CO}_{2}$ Test Results from MicroReactor System

\begin{tabular}{|c|c|c|}
\hline Material & $\begin{array}{c}\text { Temperature } \\
\left({ }^{\circ} \mathrm{C}\right)\end{array}$ & $\begin{array}{c}\mathrm{CO}_{2} \text { Adsorption } \\
\text { (wt\%) }\end{array}$ \\
\hline $\mathrm{CaSiO}_{3}$ & 200 & 0.23 \\
\hline $\mathrm{CaSiO}_{3}$ & 300 & 0.03 \\
\hline $\mathrm{MgTiO}_{3}$ & 250 & 0.41 \\
\hline $\mathrm{Mg}_{2} \mathrm{SiO}_{4}$ & 250 & 0.24 \\
\hline $\mathrm{MgAl}_{2} \mathrm{O}_{4}$ & 250 & 0.21 \\
\hline $\mathrm{Mg}-\mathrm{Li}$ & 250 & 4.49 \\
\hline $\mathrm{MnO}$ & 250 & 0.14 \\
\hline $\mathrm{Zn}(\mathrm{OH})_{2}$ & 250 & 1.79 \\
\hline $\mathrm{Mn}(\mathrm{OH})_{2}$ & 250 & 1.19 \\
\hline $\mathrm{MgO}$ & 300 & 2.03 \\
\hline $\mathrm{Mg}(\mathrm{OH})_{2}$ & 250 & 0.34 \\
\hline
\end{tabular}
imposed by the analytical system measuring the $\mathrm{CO}_{2}$ in the micro-reactor effluent and not the material.

The screening tests with $\mathrm{MgO}$ and $\mathrm{Mg}(\mathrm{OH})_{2}$ also indicated some promise for a $\mathrm{CO}_{2}$ sorbent material. However, on a stoichiometric basis, the observed capacities were significantly below their theoretical values $\left(110 \mathrm{wt} \%\right.$ based on $\mathrm{MgO}$ and $76 \%$ based on $\left.\mathrm{Mg}(\mathrm{OH})_{2}\right)$. The low capacity of these samples was assumed to be a result of low reactivity with $\mathrm{CO}_{2}$. Based on this 
assumption, a series of $\mathrm{MgO}$-based sorbents were prepared with the intention of making them significantly more reactive for $\mathrm{CO}_{2}$ adsorption.

The results of an HP-TGA screening test for one of these materials are shown in Figure 3-13. During the first 60 minutes of the test, the $\mathrm{MgO}$ sample was exposed to a $\mathrm{CO}_{2} / \mathrm{N}_{2}$ mixture with a $\mathrm{CO}_{2}$ partial pressure of 147 psig (total operating pressure $200 \mathrm{psig}$ ). The weight of the $\mathrm{MgO}$ was observed to increase rapidly, indicating that the $\mathrm{MgO}$ was reacting with the $\mathrm{CO}_{2}$ to form $\mathrm{MgCO}_{3}$. After 60 minutes, the $\mathrm{MgO}$ sample was heated to $500{ }^{\circ} \mathrm{C}$. When the $\mathrm{MgO}$ sample reached $500{ }^{\circ} \mathrm{C}$ (about 80 minutes into the test), the $\mathrm{MgO}$ sample began to lose weight, indicating regeneration of the $\mathrm{MgO}$ by decomposition of the $\mathrm{MgCO}_{3}$, which releases $\mathrm{CO}_{2}$ and causes a weight decrease. Because the gas composition had not been changed, the $\mathrm{MgO}$ sample was regenerating at a $\mathrm{CO}_{2}$ partial pressure of $147 \mathrm{psig}$. At about 160 minutes into the test, the $\mathrm{CO}_{2}$ flow was stopped and the sample was purged with pure $\mathrm{N}_{2}$. The $\mathrm{MgO}$ sample lost additional weight during this inert purge, returning to roughly the weight of the sample at the beginning of the test. With essentially no $\mathrm{CO}_{2}$ partial pressure in the regeneration gas, any remaining $\mathrm{MgCO}_{3}$ decomposed, releasing $\mathrm{CO}_{2}$ and regenerating $\mathrm{MgO}$.

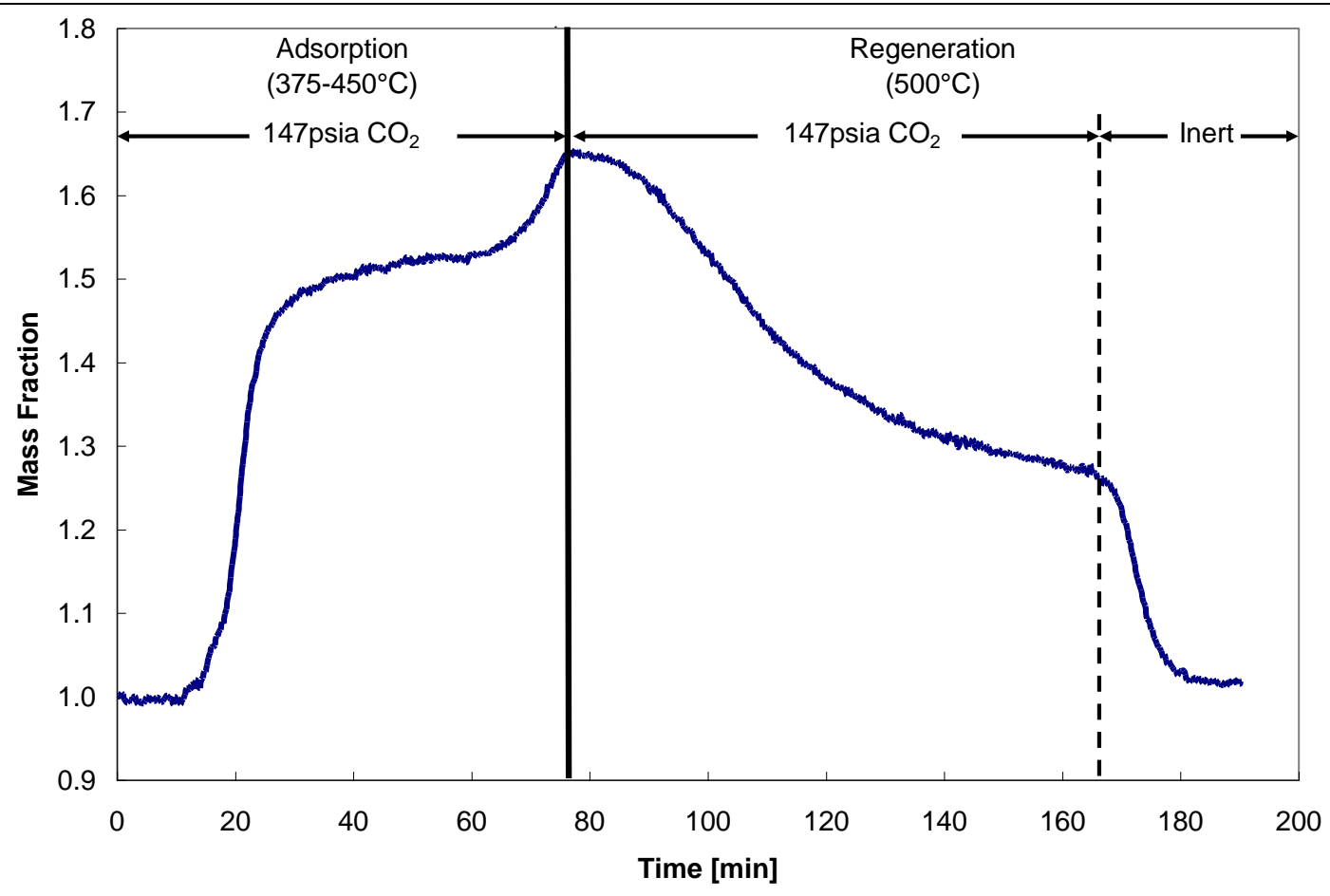

Figure 3-13. HP-TGA test of RTI-prepared "reactive" MgO sample 
Based on analysis of the information in Figure 3-13, this $\mathrm{MgO}$ sample had a $\mathrm{CO}_{2}$ capacity of roughly $56 \mathrm{wt} \%$. Furthermore, the dynamic $\mathrm{CO}_{2}$ capacity for regeneration producing a $\mathrm{CO}_{2}$ byproduct with $\mathrm{CO}_{2}$ pressure of 147 psig was about $30 \mathrm{wt} \%$. The $\mathrm{MgO}$ sample also seemed to be fully regenerable based on the return to essentially the same initial starting weight after regeneration with an inert purge.

\subsubsection{Promoter Screening and Evaluation}

Additional investigation into the physical and chemical properties of these "reactive" $\mathrm{MgO}$ samples identified that small amounts of additional compounds were introduced into the $\mathrm{MgO}$ during preparation. These compounds acted as promoters for the reaction between $\mathrm{MgO}$ and $\mathrm{CO}_{2}$. Additional investigation on promoter effects included chemical composition of the promoter, concentration of the promoter, and effect of the starting Mg compound. Analysis of the original active $\mathrm{MgO}$ materials indicated that the preparation method had introduced two components that could be active promoters. The results for testing with $\mathrm{MgO}$ materials made with specific amounts of these two promoters are shown in Figures 3-14 and 3-15.

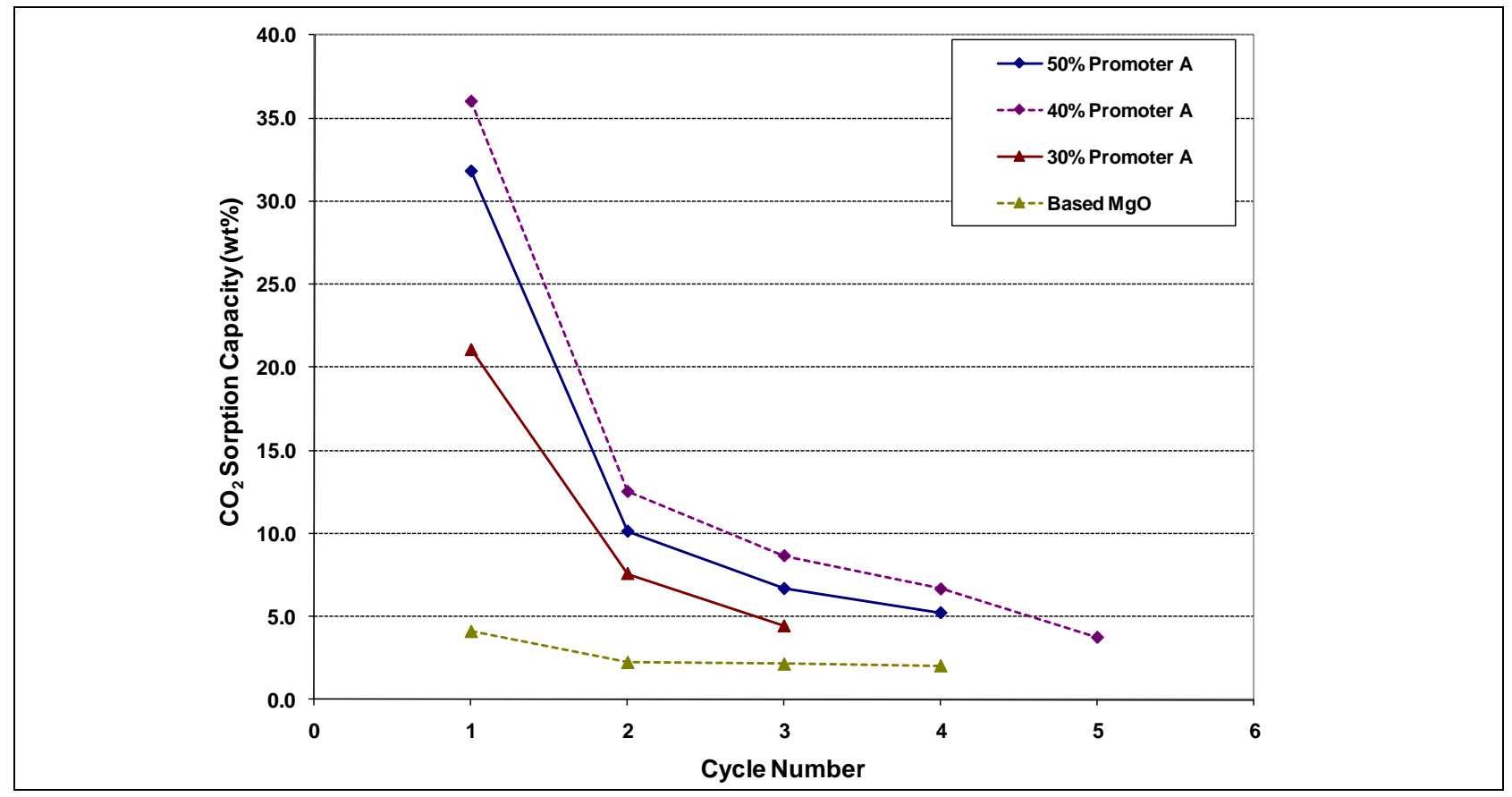

Figure 3-14. Parametric testing of Promoter A concentration on $\mathrm{CO}_{2}$ capture performance for promoted MgO 


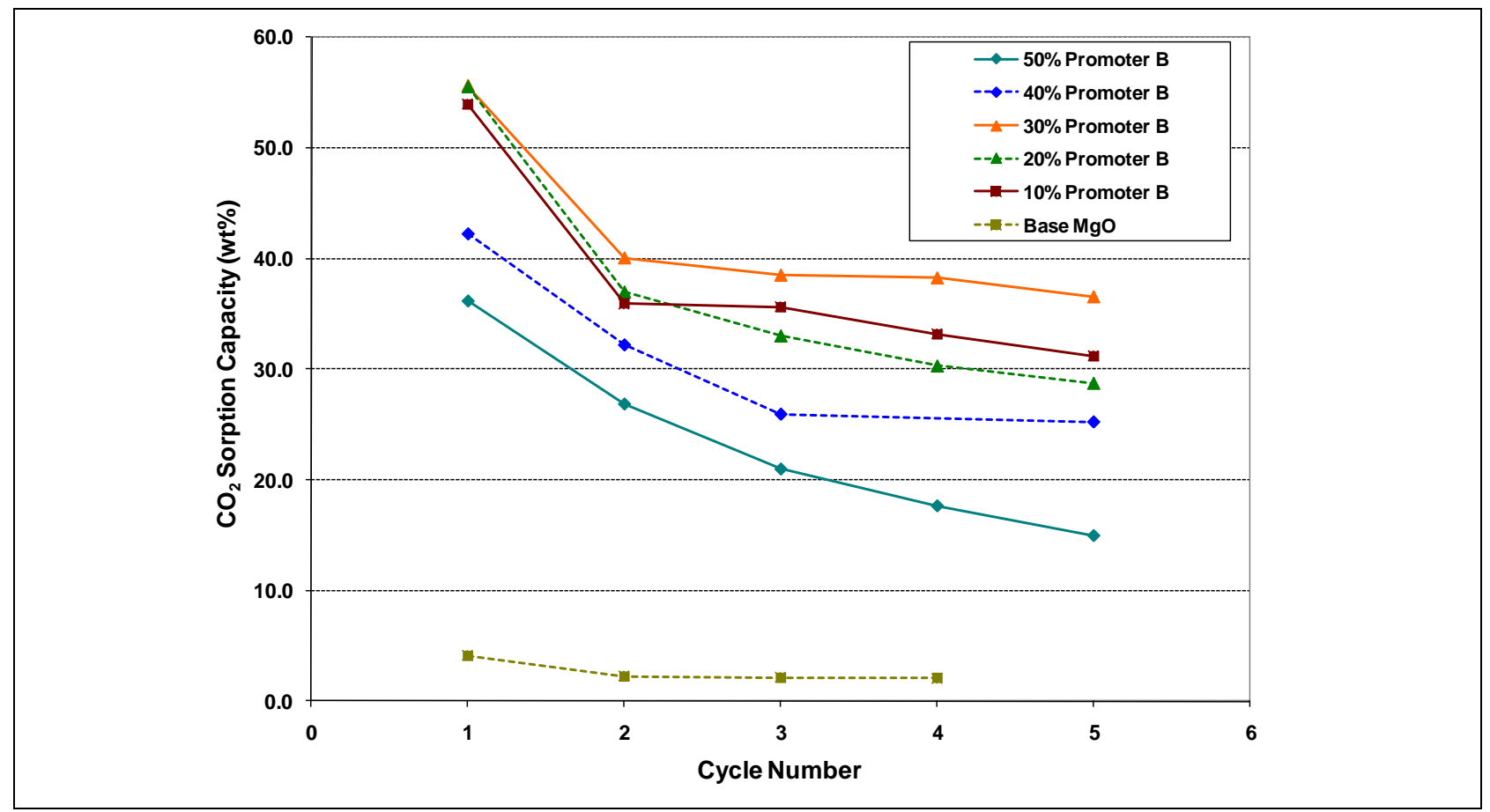

Figure 3-15. Parametric testing of Promoter $\mathrm{B}$ concentration for $\mathrm{CO}_{2}$ capture performance on promoted MgO

Figure 3-14 shows that Promoter A has the strongest promoting effect during the first cycle. However, as more $\mathrm{CO}_{2}$ capture and regeneration cycles are completed, the sorbent's $\mathrm{CO}_{2}$ capacity rapidly approaches capacities typical of the unpromoted material.

The results for $\mathrm{MgO}$ containing Promoter B, as shown in Figure 3-15, indicate a decrease in $\mathrm{CO}_{2}$ capture capacity with increasing numbers of $\mathrm{CO}_{2}$ capture and regeneration cycles; but, in most cases, the $\mathrm{CO}_{2}$ capture capacity appears to be stabilizing at a significantly higher $\mathrm{CO}_{2}$ value than the unpromoted $\mathrm{MgO}$ material. The $\mathrm{CO}_{2}$ capture capacity also achieves a maximum at about $70 \mathrm{wt} \% \mathrm{MgO}$ and $30 \mathrm{wt} \%$ Promoter B.

\subsubsection{Evaluation of Promoting Commercial MgO-based Materials}

A series of $\mathrm{MgO}$ samples with other potential promoters were prepared and tested. The results from these screening tests are shown in Figure 3-16. Based on these results, Promoters A, $\mathrm{B}, \mathrm{C}$, and $\mathrm{D}$ could be used to enhance the reactivity of $\mathrm{MgO}$ with $\mathrm{CO}_{2}$. 


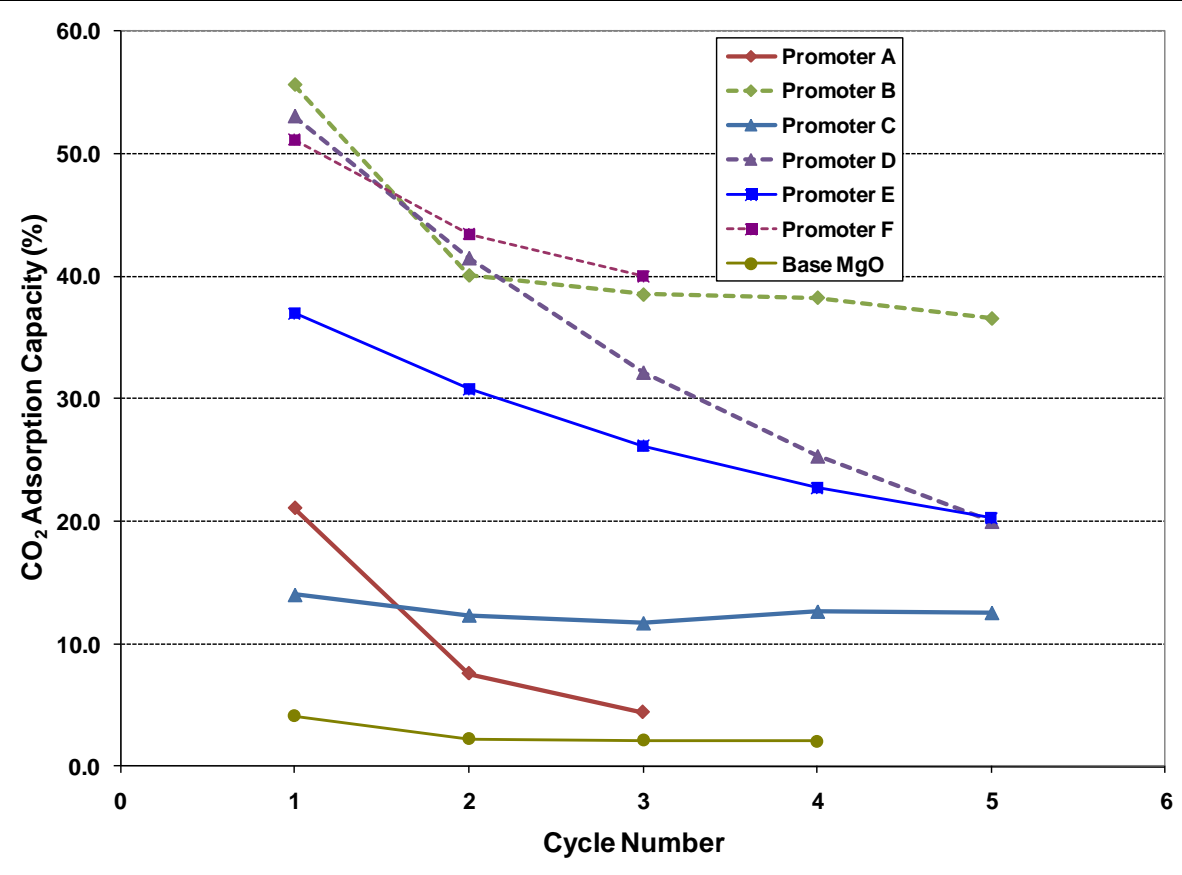

Figure 3-16. Parametric test results for $\mathrm{CO}_{2}$ capture for $\mathrm{MgO}$ samples with different promoters

Because the promoters had such a significant effect on the $\mathrm{CO}_{2}$ capacity of $\mathrm{MgO}$ materials prepared at RTI, the effect of adding these promoters to commercial Mg compounds that can readily be converted to $\mathrm{MgO}$ was investigated. Suitable $\mathrm{Mg}$ compounds include $\mathrm{MgO}$, $\mathrm{Mg}(\mathrm{OH})_{2}, \mathrm{MgCO}_{3}$, and magnesium hydrate carbonate $\left[\left(\mathrm{MgCO}_{3}\right)_{4} \cdot \mathrm{Mg}(\mathrm{OH})_{2} \cdot \mathrm{H}_{2} \mathrm{O}\right]$. The test results for $\mathrm{MgO}, \mathrm{Mg}(\mathrm{OH})_{2}$, and $\mathrm{MgCO}_{3}$ samples are shown in Figure 3-17 without any promoters. Figure 3-18 shows results of sorbent samples promoted with Promoter D. Figures 317 and 3-18 indicate that the promoter is the key ingredient required to activate the $\mathrm{MgO}$ material for $\mathrm{CO}_{2}$ capture.

Promoting commercial $\mathrm{MgO}$ samples demonstrated that commercial sorbent materials of $\mathrm{MgO}, \mathrm{Mg}(\mathrm{OH})_{2}$, and $\mathrm{MgCO}_{3}$ could achieve improved $\mathrm{CO}_{2}$ capture capacity when impregnated with suitable promoters. If promoting commercially available $\mathrm{MgO}$-based sorbent/catalyst was also successful, the $\mathrm{R} \& \mathrm{D}$ effort to develop a viable commercial $\mathrm{CO}_{2}$ sorbent could be significantly reduced. The commercial fluid catalytic cracking (FCC) additive used to control $\mathrm{SO}_{2}$ emissions from $\mathrm{FCC}$ regenerators, $\mathrm{DeSO}_{\mathrm{x}}$, which has all the fluidization, attrition resistance, and particle size distribution necessary, consists of a $\mathrm{MgO} / \mathrm{MgAl}_{2} \mathrm{O}_{4}$ mixture. A sample of $\mathrm{DeSO}_{\mathrm{x}}$ was obtained from the W. R. Grace Company. This catalyst has about $38 \mathrm{wt} \% \mathrm{MgO}$ based on the available composition information. Testing of the original $\mathrm{DeSO}_{\mathrm{x}}$ catalyst and promoted $\mathrm{DeSO}_{\mathrm{x}}$ catalyst were completed. The results, along with the results from pure and promoted $\mathrm{MgO}$, are presented in Figure 3-19, which shows that promoting the commercial 
DeSO $\mathrm{x}_{\mathrm{x}}$ catalyst did result in improved $\mathrm{CO}_{2}$ capacity of the material. Unfortunately, the improvement with promotion of the $\mathrm{DeSO}_{\mathrm{x}}$ catalyst was not as large as observed with pure $\mathrm{MgO}$, and the effect rapidly decreased with multiple cycles of operation.

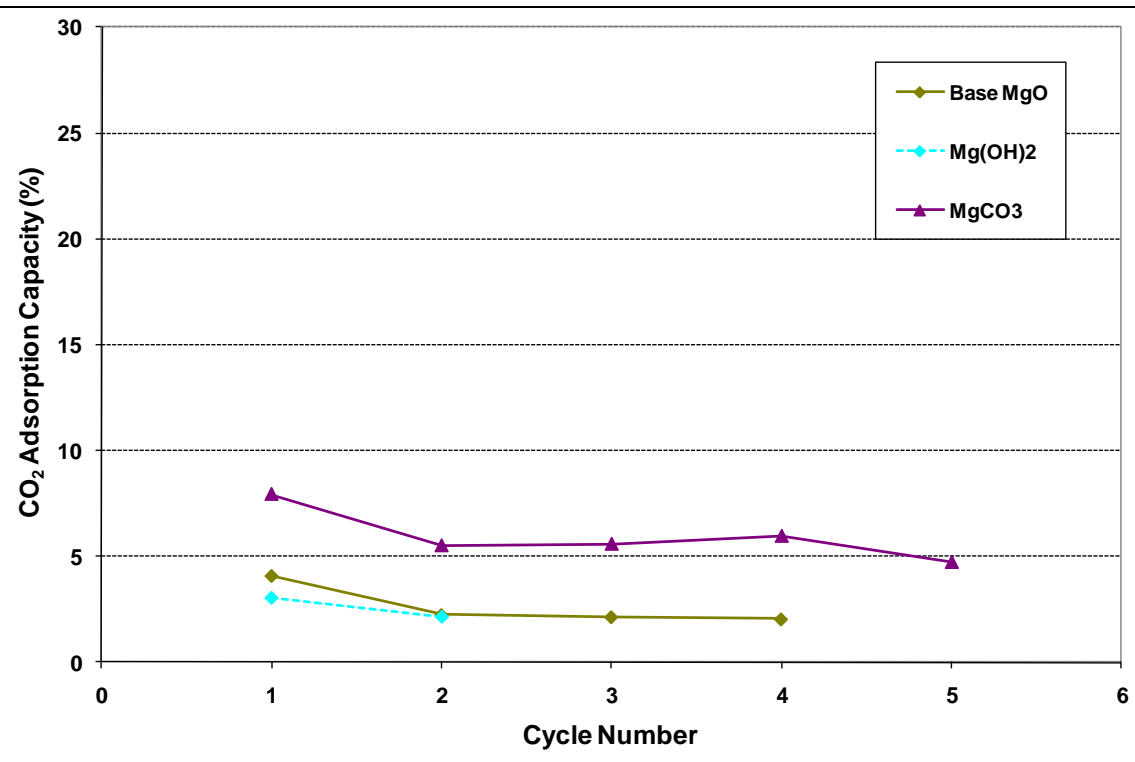

Figure 3-17. $\mathrm{CO}_{2}$ capture performance for commercial samples of $\mathrm{Mg}$ compounds

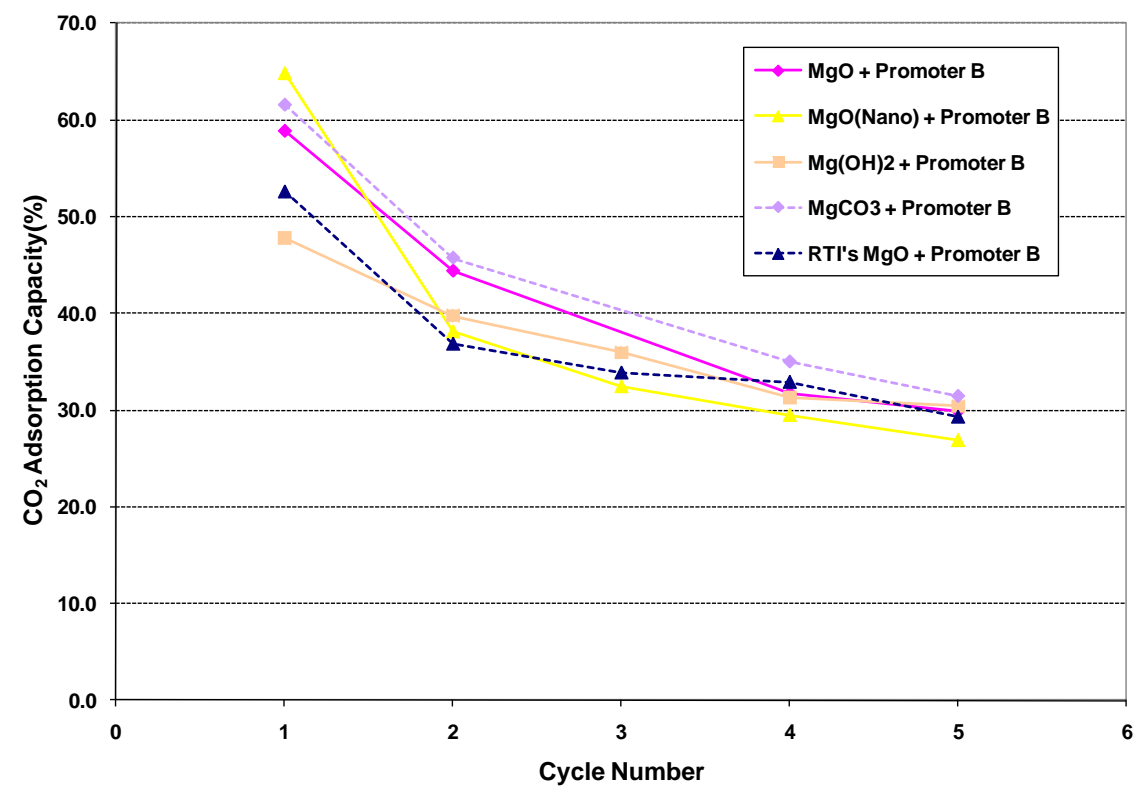

Figure 3-18. $\mathrm{CO}_{2}$ capture performance of commercial samples of $\mathrm{Mg}$ compounds promoted with Promoter D 


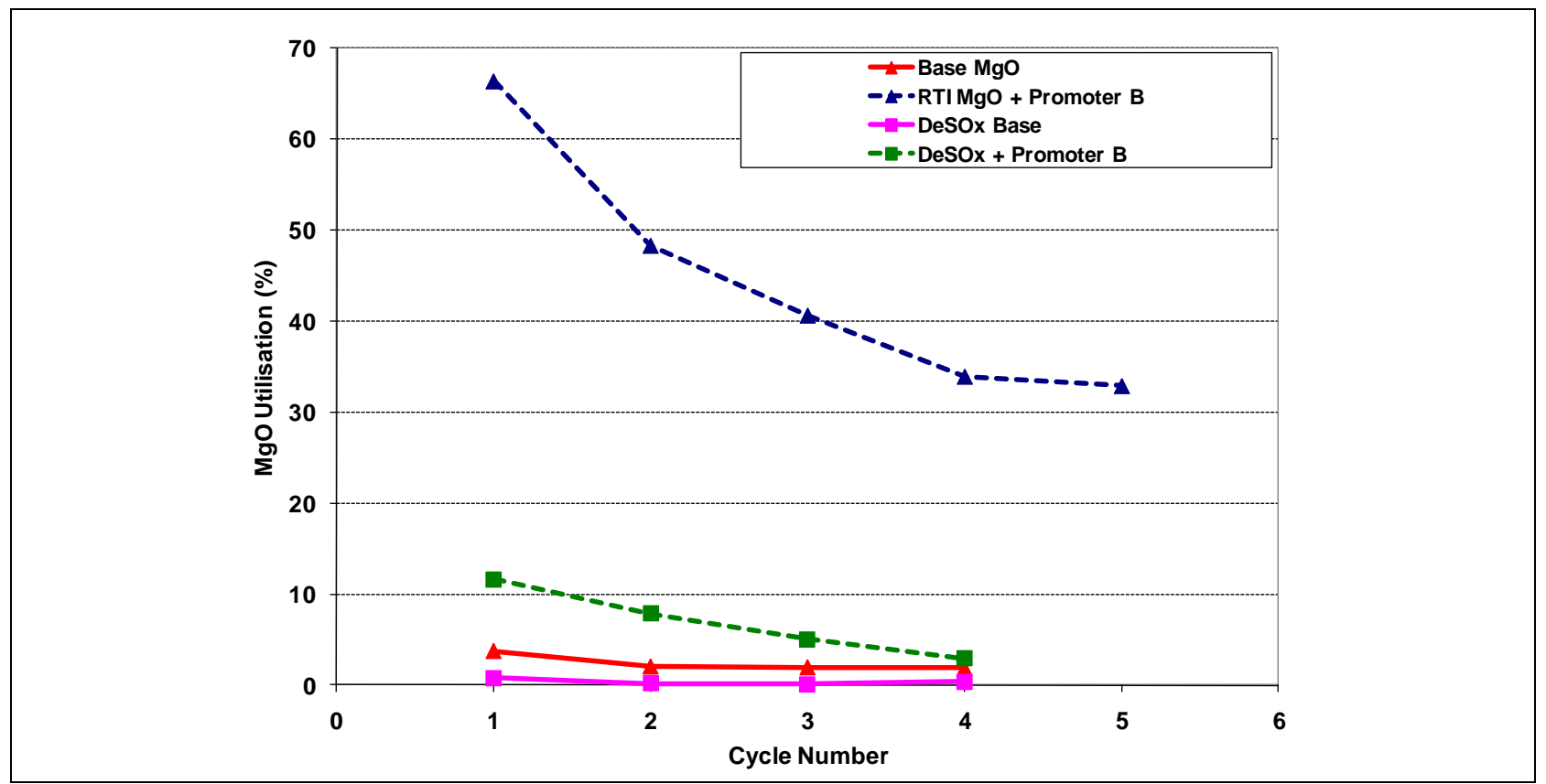

Figure 3-19. Comparison of $\mathrm{MgO}$ utilization for $\mathrm{DeSO}_{\mathrm{x}}$ catalyst with and without Promoter $\mathrm{B}$

Although the testing of promoted $\mathrm{DeSO}_{\mathrm{x}}$ catalyst did not achieve the high level of $\mathrm{CO}_{2}$ capture anticipated, this testing did show that strong commercial materials can be promoted and the key to effective sorbent development involves effectively optimizing and stabilizing the promoter effect.

\subsubsection{Sorbent Development}

With a strong understanding of the $\mathrm{CO}_{2}$ capacity associated with different promoter/MgO mixtures, the focus of sorbent development became preparation of a sorbent formulation with suitable physical and mechanical strength. Although one of the primary functions of the support material is to provide suitable physical characteristics to the sorbent formulation, this support material must also serve as an acceptable foundation for the promoted $\mathrm{MgO}$. The two key features that are required to make a material an acceptable foundation are to be chemically inert toward the active $\mathrm{CO}_{2}$ capture species ( $\mathrm{MgO}$ and promoters) and to provide structural support for the active species as the $\mathrm{MgO}$ is converted to $\mathrm{MgCO}_{3}$ during $\mathrm{CO}_{2}$ capture and back into $\mathrm{MgO}$ during regeneration. The latter requirement is critical to the long-term mechanical stability of the sorbent, while the former is more critical for chemical stability.

As an initial attempt at identifying suitable support materials, different candidate support materials were physically mixed with promoted $\mathrm{MgO}$ material. The results from testing these formulations in the AMR system are shown in Figure 3-20. These results indicate that magnesium aluminate and lithium aluminate are promising support materials. 


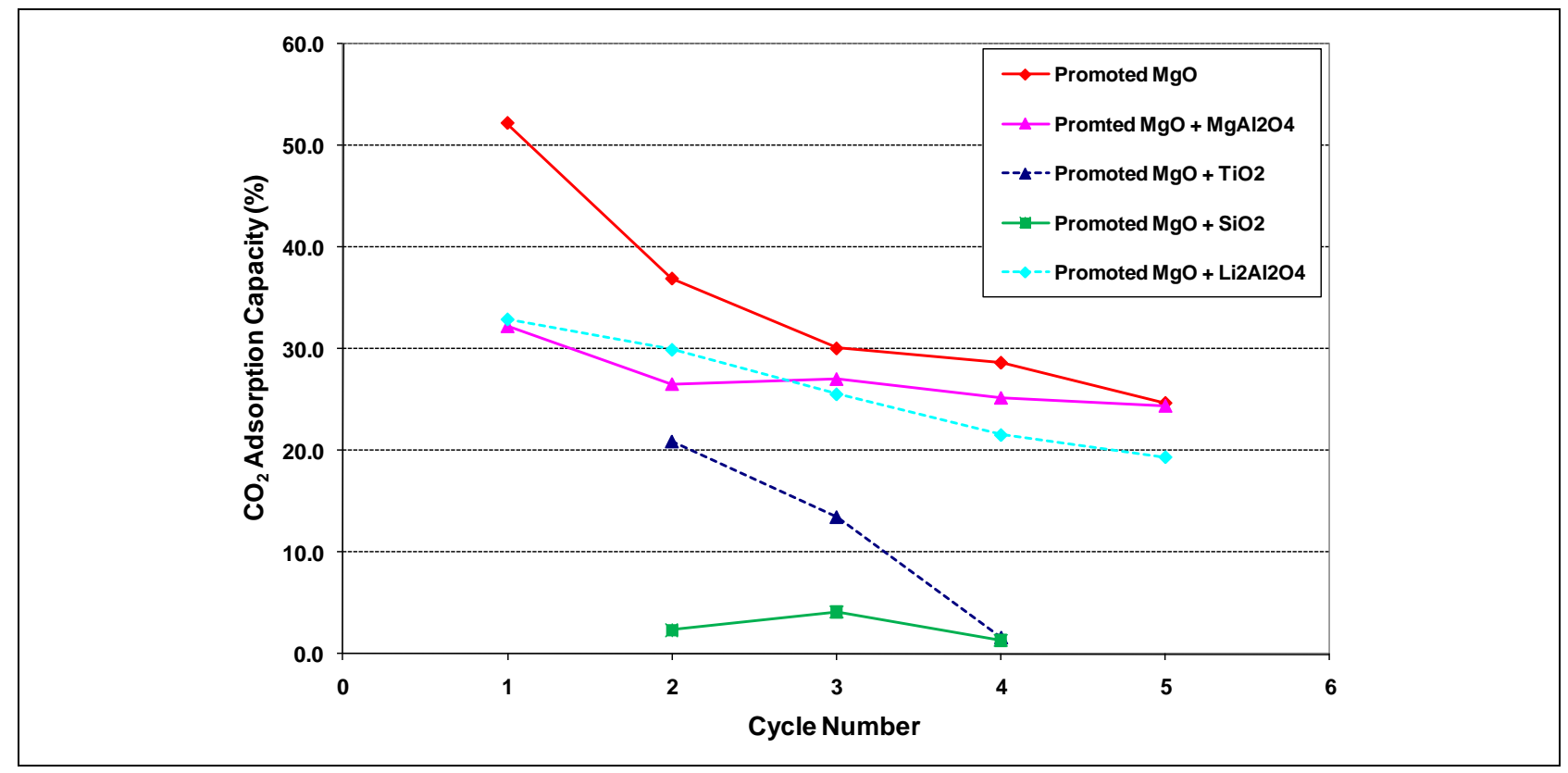

Figure 3-20. $\mathrm{CO}_{2}$ capacity performance for physical mixtures of promoted $\mathrm{MgO}$ and support materials

Testing physical mixtures of the promoted $\mathrm{MgO}$ and support materials is an excellent screening tool to identify potential chemical interactions between the support and promoted $\mathrm{MgO}$ material. Unfortunately, it does not support development of a sorbent formulation that provides a structural foundation for the chemical transformations occurring between the $\mathrm{CO}_{2}$ adsorption and regeneration cycles. Thus, support development was expanded to include incorporation of the support material as part of the sorbent formulation process. The first batch of sorbent formulation was prepared with sepiolite (a clay mineral that is a complex magnesium silicate, a typical formula for which is $\left.\mathrm{Mg}_{4} \mathrm{Si}_{6} \mathrm{O}_{15}(\mathrm{OH})_{2} \bullet 6 \mathrm{H}_{2} \mathrm{O}\right)$. This batch of materials was followed with a series of sorbent formulations based on alumina and bohemite.

The results from AMR testing of these two batches of sorbent formulations are shown in Figures 3-21 and 3-22. Both the results with sepiolite and alumina resulted in a significant decrease in $\mathrm{MgO}$ capacity. With bohemite, only limited loss of $\mathrm{CO}_{2}$ capacity was observed at a calcination 


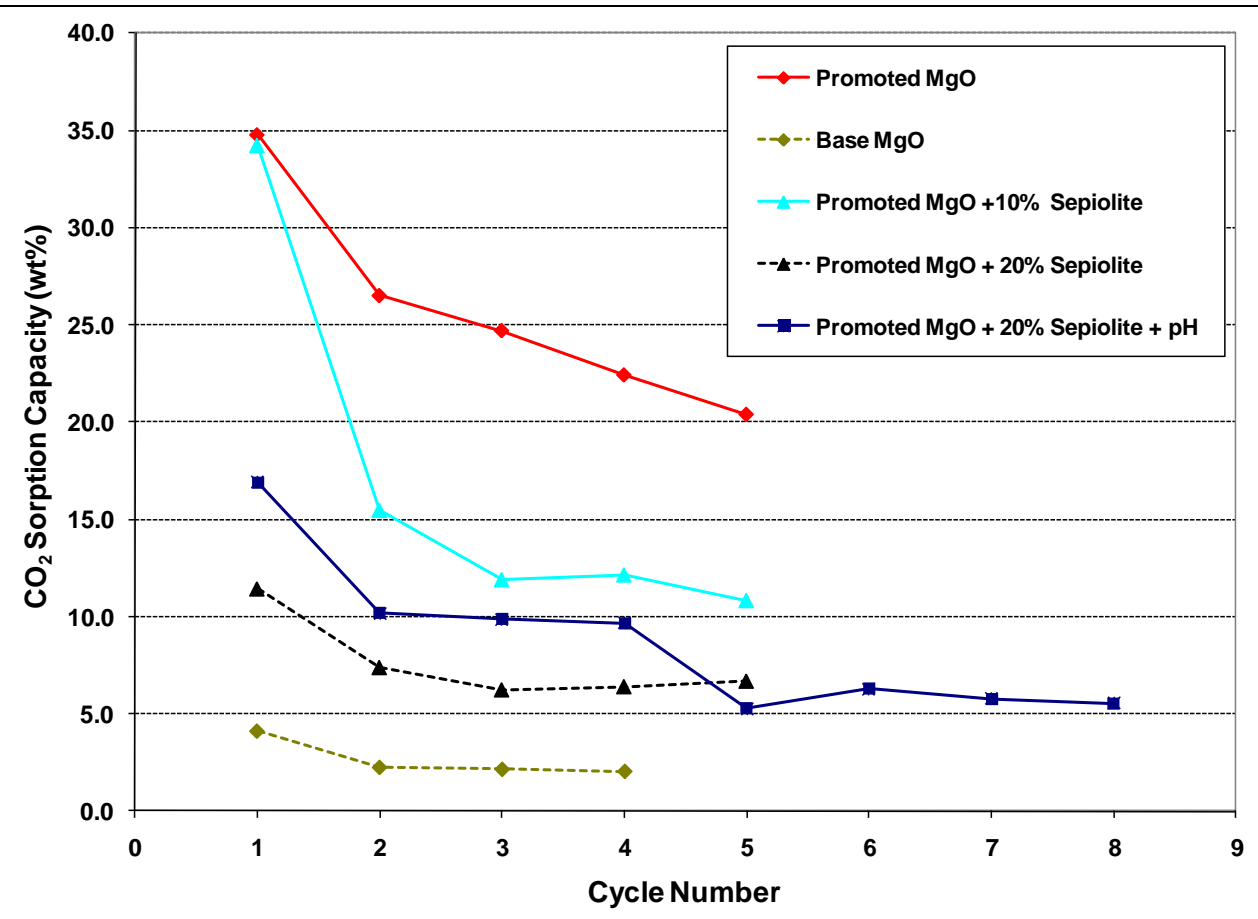

Figure 3-21. $\mathrm{CO}_{2}$ capture performance for samples with sepiolite being used as a support material

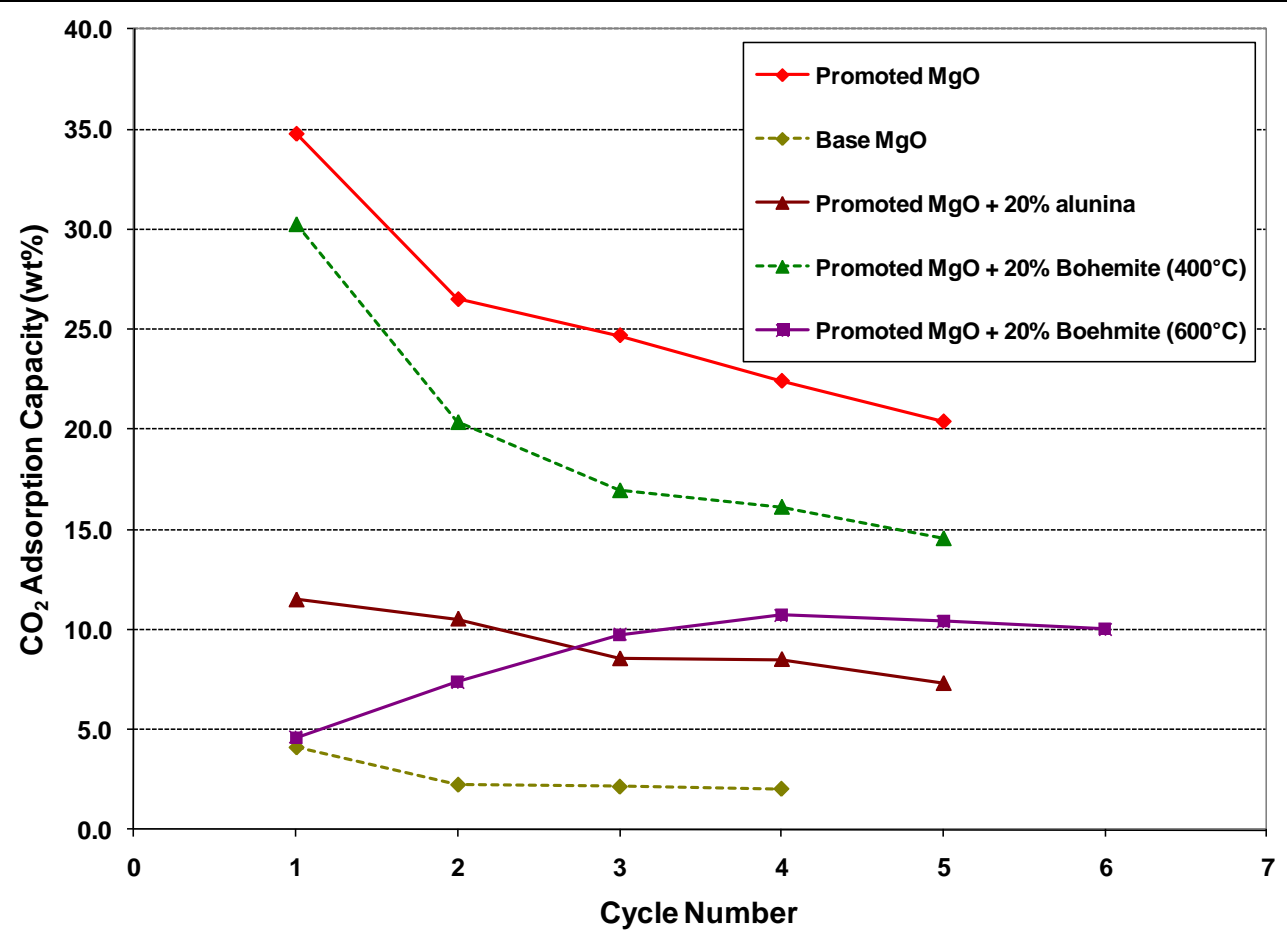

Figure 3-22. $\mathrm{CO}_{2}$ capture performance for samples with alumina and bohemite being used as a support material 
temperature of $<400{ }^{\circ} \mathrm{C}$. However, at higher calcination temperatures, the $\mathrm{CO}_{2}$ capacity decreased and became essentially identical to the alumina samples.

As shown in Figure 3-22, magnesium aluminate was identified as a promising support material based on physical mixtures of magnesium aluminate and promoted $\mathrm{MgO}$. The next step was to investigate preparation processes that incorporated magnesium aluminate during preparation of the $\mathrm{MgO}$. A series of samples were prepared by co-precipitation of $\mathrm{MgO}$ and alumina. This mixture of $\mathrm{MgO}$ and alumina was converted to magnesium aluminate during calcination.

In the first series of samples prepared, the sorbent was prepared in a one-step process and subsequently calcined at temperatures from $400{ }^{\circ} \mathrm{C}$ to $600{ }^{\circ} \mathrm{C}$. The $\mathrm{CO}_{2}$ adsorption capacity for this series of samples is shown in Figure 3-23. For these samples, the maximum $\mathrm{CO}_{2}$ capacity was observed at a calcination temperature of $400{ }^{\circ} \mathrm{C}$. Any further increase in the calcination temperature resulted in a decrease in $\mathrm{CO}_{2}$ capacity.

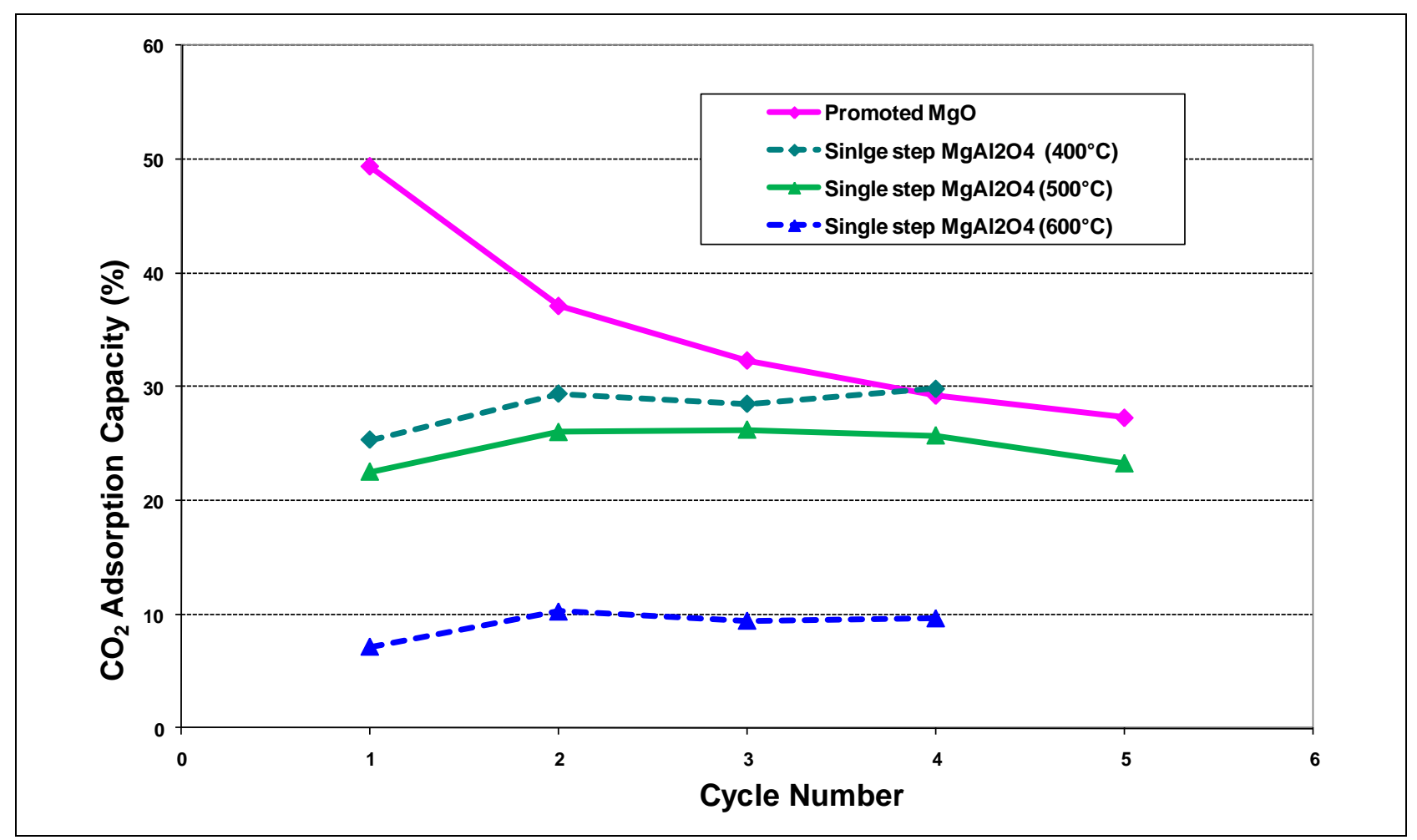

Figure 3-23. Comparison of $\mathrm{CO}_{2}$ adsorption capacity for single-step formulations with magnesium aluminate calcined at different temperatures 
In the next series of samples, the sorbent formulation was prepared, calcined, and subsequently promoted. The results for this second series of samples are shown in Figure 3-24. In contrast to the decrease in $\mathrm{CO}_{2}$ capacity observed with increasing calcination temperature seen in Figure 3-23, the $\mathrm{CO}_{2}$ capacity profiles show little or no effect of calcination temperature from $400{ }^{\circ} \mathrm{C}$ to $600{ }^{\circ} \mathrm{C}$. Another interesting feature of the $\mathrm{CO}_{2}$ capacity profiles for this series of sorbents is that, after the initial decrease in $\mathrm{CO}_{2}$ capacity in the first cycle, subsequent decreases in $\mathrm{CO}_{2}$ capacity were much smaller than observed for the base $\mathrm{MgO}$ promoted sample.

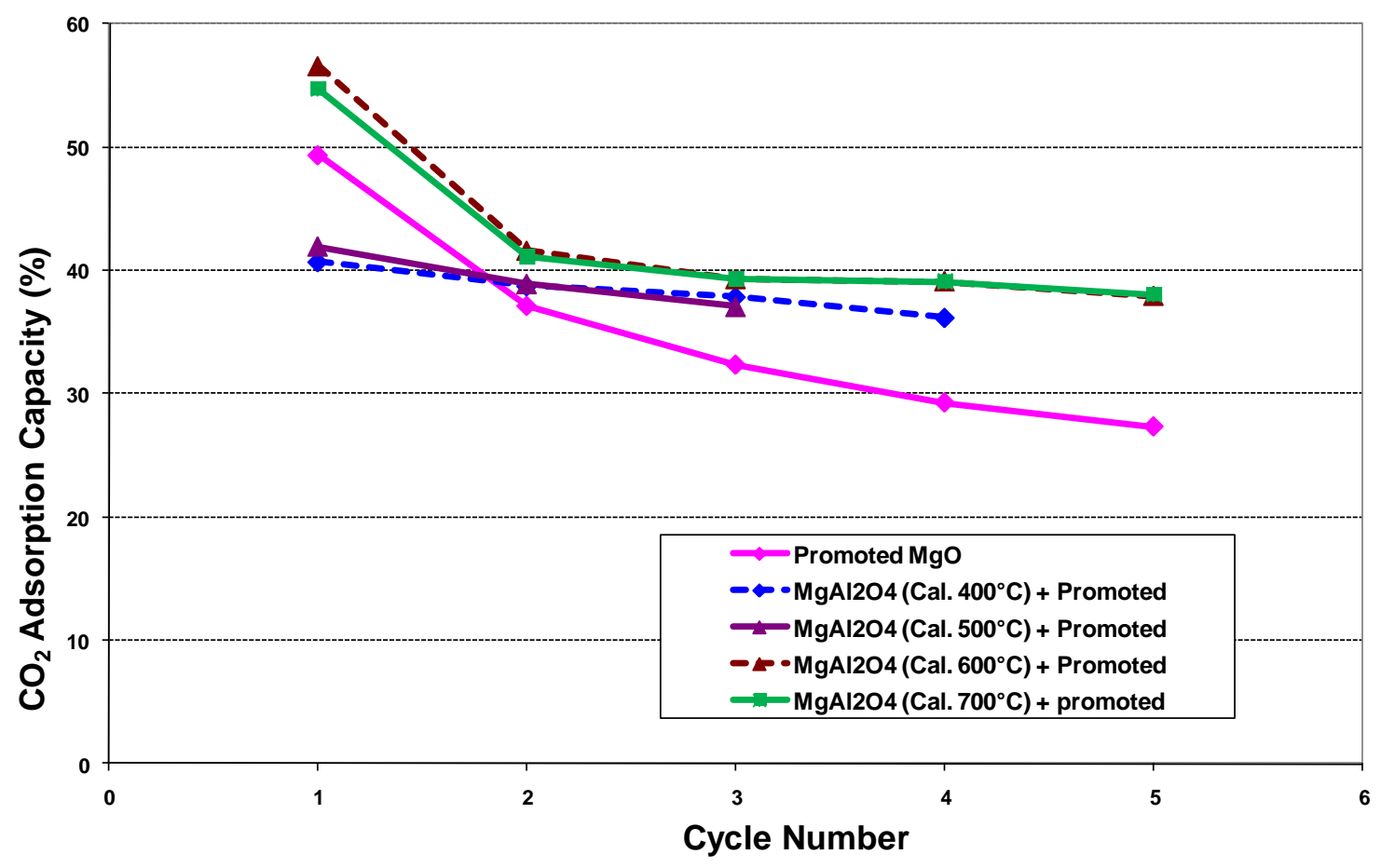

Figure 3-24. Comparison of $\mathrm{CO}_{2}$ adsorption capacity for formulations with magnesium aluminate calcined at different temperatures prior to being promoted

Because calcium aluminate should have properties very similar to magnesium aluminate, a series of samples were prepared in which calcium oxide and alumina precursors were converted to calcium aluminate during calcination. The results for these series of samples are shown in Figure 3-25. The calcium aluminate sample with the highest $\mathrm{CO}_{2}$ capacity was calcined at $400{ }^{\circ} \mathrm{C}$. As the calcination temperature was increased, the $\mathrm{CO}_{2}$ capacity for the calcium aluminate samples decreased, following the same trend observed for the magnesium aluminate samples. However, in general, the $\mathrm{CO}_{2}$ adsorption capacity of the sorbent samples with calcium aluminate had lower $\mathrm{CO}_{2}$ capacity than with magnesium aluminate. 


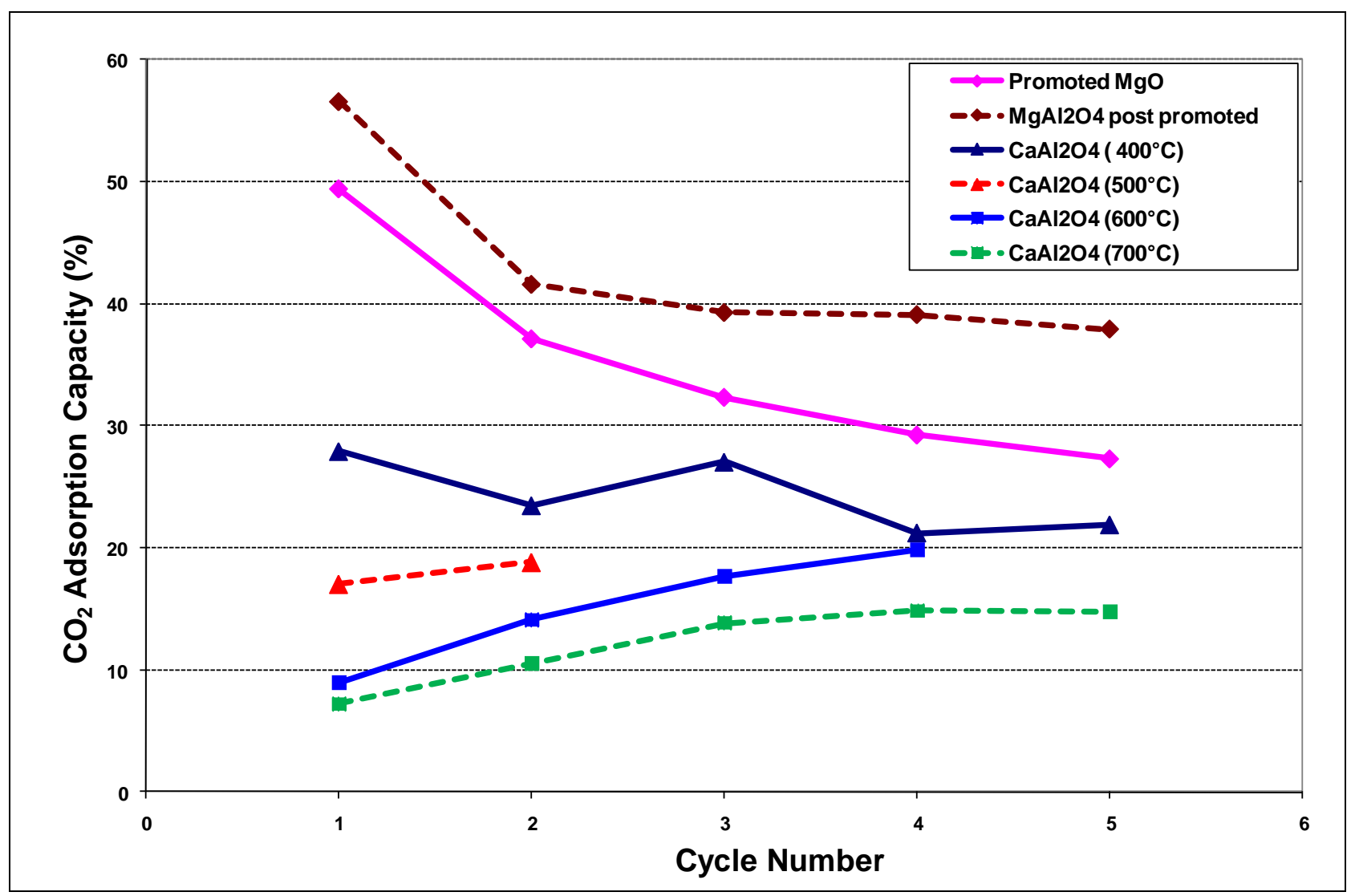

Figure 3-25. Comparison of $\mathrm{CO}_{2}$ adsorption capacity for calcium aluminate-based formulations calcined at temperatures between $400^{\circ} \mathrm{C}$ and $700^{\circ} \mathrm{C}$

\subsubsection{Syngas Testing}

After modifications to the micro-reactor system were completed, which allowed testing in simulated syngas mixtures, a test was conducted with syngas containing 10 vol\% steam. The results for this test, shown in Figure 3-26, indicate that the $\mathrm{CO}_{2}$ capacity of the sorbent decreased from roughly $40 \mathrm{wt} \%$ to essentially zero in just four adsorption/regeneration cycles. To identify which specific component was responsible for this rapid decay in $\mathrm{CO}_{2}$ capacity, several tests with $\mathrm{CO}_{2}$ /steam mixtures were conducted. The results from these tests are also shown in Figure 3-26. These results clearly show that the steam was responsible for this rapid decay in $\mathrm{CO}_{2}$ capacity and that the rate of decay was faster with higher steam concentrations. 


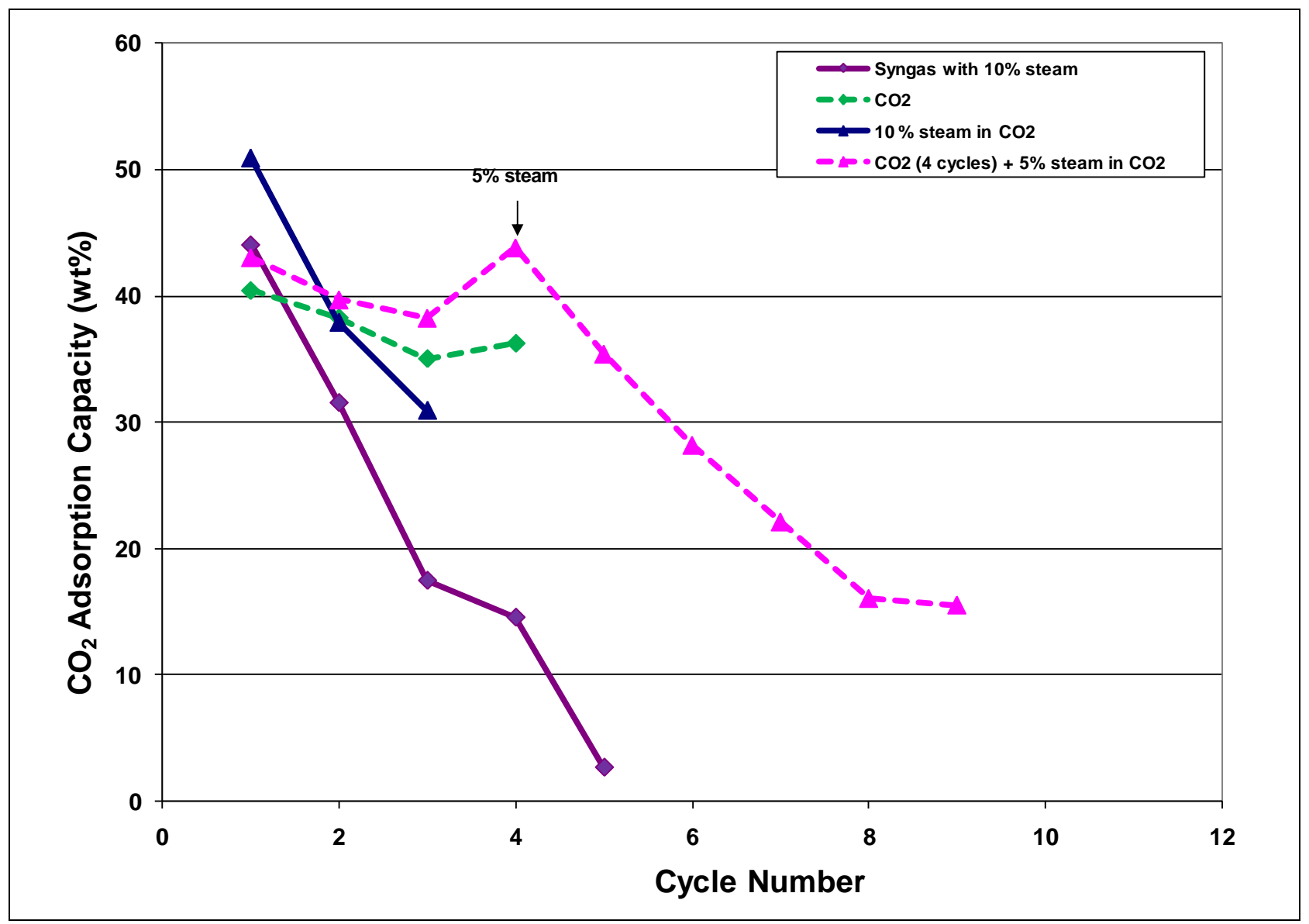

Figure 3-26. Effect of syngas and steam on $\mathrm{CO}_{2}$ adsorption capacity of $\mathrm{MgO}$ sorbent promoted with Promoter B

Analysis of the chemical composition of the samples generated during testing with steam provided the evidence necessary to show that the steam was reacting with the promoter. The list of promoters previously identified was revaluated to identify the promoters that were not anticipated to react with steam at typical operating conditions being used for the $\mathrm{CO}_{2}$ capture process. A promoted $\mathrm{MgO}$ sample was made with Promoter F, which had the anticipated steamresistant composition and achieved the highest $\mathrm{CO}_{2}$ capacity in the original promoter screening tests. The results from testing this promoted $\mathrm{MgO}$ sample with steam concentrations of up to $60 \mathrm{vol} \%$ are shown in Figure 3-27. Figure 3-27 shows that steam did not result in rapid decay of the $\mathrm{CO}_{2}$ capacity of this sorbent and, in fact, increased the $\mathrm{CO}_{2}$ capacity of the sorbent. For steam concentrations up to $40 \mathrm{vol} \%$, the $\mathrm{CO}_{2}$ capacity for this promoted $\mathrm{MgO}$ sample remained relatively constant from cycle to cycle. At a concentration of $60 \mathrm{vol} \%$ steam, the $\mathrm{CO}_{2}$ capacity was observed to decay for the final three cycles of the test, but this decay is significantly less than that observed for sorbent formulations made with Promoter B with as little as 5 vol\% steam. 


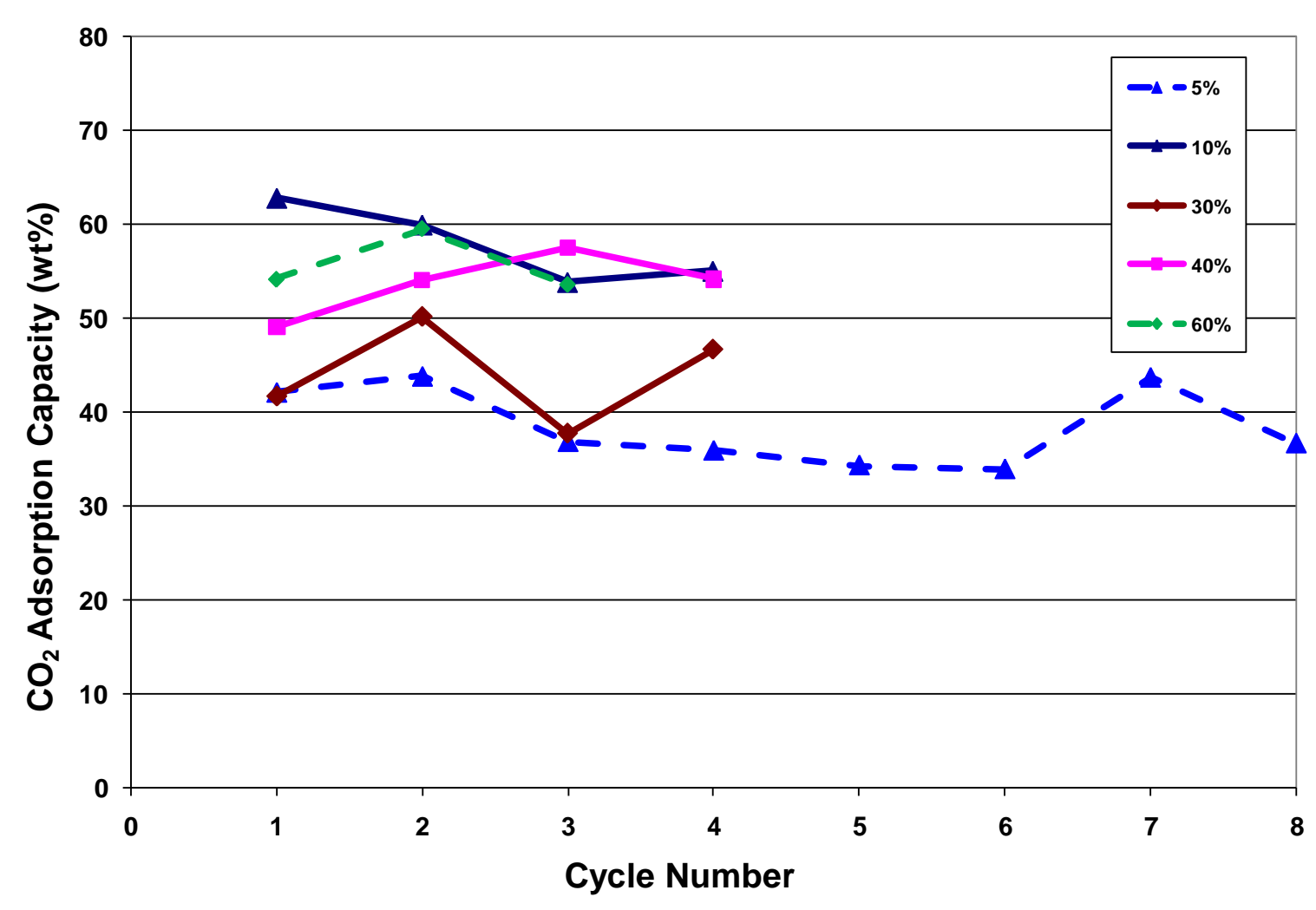

Figure 3-27. $\mathrm{CO}_{2}$ adsorption capacity at different steam concentrations for $\mathrm{MgO}$ promoted with Promoter F.

\subsubsection{Summary}

Initial testing of 5A and 13X zeolite materials demonstrated that these materials had critical properties necessary for operation of a $\mathrm{CO}_{2}$ recovery process from a dilute $\mathrm{CO}_{2}$ stream that produces a high-pressure high-purity $\mathrm{CO}_{2}$ product stream. These critical properties are

- High adsorption capacity at low temperature $\left(<100^{\circ} \mathrm{C}\right)$

- Low adsorption capacity at high temperature $\left(\sim 300^{\circ} \mathrm{C}\right)$

- Minor competitive adsorption of water vapor at both high and low temperature

- Minimum $\mathrm{CO}_{2}$ partial pressure of approximately 14.6 psi in dilute $\mathrm{CO}_{2}$ stream.

For 5A zeolites, no specific improvements in $\mathrm{CO}_{2}$ adsorption capacity were observed with ion exchange, but ion exchange of the $13 \mathrm{X}$ zeolites did show promise for improved $\mathrm{CO}_{2}$ adsorption performance.

Attempts to identify operating conditions for regeneration of the lithium silicate sorbent that would produce a product stream with about $14.6 \mathrm{psi}$ of $\mathrm{CO}_{2}$ partial pressure were not 
successful. These regeneration studies indicated that the typical effluent $\mathrm{CO}_{2}$ concentration was $<1.5$ vol\% ( $0.15 \mathrm{psi})$. The only conditions under which higher $\mathrm{CO}_{2}$ concentrations were observed was at temperatures of $>700{ }^{\circ} \mathrm{C}$. Because the $\mathrm{CO}_{2}$ concentration in the lithium silicate regeneration effluent was too low for successful use of the $\mathrm{CO}_{2}$ recovery process, these $\mathrm{R} \& \mathrm{D}$ activities were discontinued.

Based on the lessons learned during the screening of the lithium silicate sorbent, a new screening approach was implemented. This method identified several candidate materials. One of these materials is $\mathrm{MgO}$. Although the theoretical capacity of $\mathrm{MgO}$ is high ( $\sim 110 \mathrm{wt} \%$ based on $\mathrm{MgO}$ ), the observed $\mathrm{CO}_{2}$ capacity of commercially available $\mathrm{MgO}$ is $<10 \mathrm{wt} \%$. This discrepancy was believed to be the result of low reactivity of the $\mathrm{MgO}$ with $\mathrm{CO}_{2}$. Through attempts to improve the $\mathrm{CO}_{2}$ reactivity of $\mathrm{MgO}$, a promoter material was identified that could achieve 20 wt $\%$ to $>60 \mathrm{wt} \% \mathrm{CO}_{2}$ adsorption capacity with $\mathrm{MgO}$. Screening of other potential promoter agents identified at least four other materials. Development of the sorbent coupled with parametric testing has shown that

- Commercially available $\mathrm{MgO}$ precursors $\left(\mathrm{MgO}, \mathrm{Mg}(\mathrm{OH})_{2}, \mathrm{MgCO}_{3}\right)$ can be converted into $\mathrm{CO}_{2}$ sorbents through addition of a promoter

- Magnesium aluminate is a good support that provides a stable foundation for the chemical transformations of $\mathrm{CO}_{2}$ capture and regeneration and low reactivity with the active components

- Three of the six identified promoters have been demonstrated to be stable in syngas mixtures containing steam.

These results demonstrate the potential for developing an effective $\mathrm{CO}_{2}$ sorbent for $\mathrm{CO}_{2}$ capture at temperatures above $300{ }^{\circ} \mathrm{C}$. In the next section, the testing focus shifts from material development to process development with the goal of demonstrating the technical feasibility of using $\mathrm{MgO}$-based $\mathrm{CO}_{2}$ capture sorbent for $\mathrm{CO}_{2}$ capture in IGCC systems to achieve $>90 \% \mathrm{CO}_{2}$ capture and high overall thermal efficiency and to minimize the increase in cost of electricity resulting from implementation of $\mathrm{CO}_{2}$ capture and sequestration.

\subsection{Process Development}

\subsubsection{Experimental Testing Supporting Process Development Feasibility}

Based on the progress made with sorbent development, described in the previous sections, efforts to optimize integration of a regenerable sorbent-based warm $\mathrm{CO}_{2}$ capture process in a thermally efficient and economically viable manner within an IGCC plant were initiated. To support this evaluation, micro-reactor testing was begun to explore the different 
operating conditions to demonstrate the technical feasibility of these different process configurations.

The first series of tests investigated the effectiveness of regenerable $\mathrm{CO}_{2}$ sorbents as a function of the partial pressure of $\mathrm{CO}_{2}$. Figure 3-28 shows the results from this series of tests at adsorption temperatures of $325^{\circ} \mathrm{C}$ and $375^{\circ} \mathrm{C}$. In Figure 3-28, the $\mathrm{CO}_{2}$ capacity begins to significantly increase only at $\mathrm{CO}_{2}$ partial pressures of $>100$ psi. As expected, higher adsorption temperatures (due to faster kinetics) result in higher $\mathrm{CO}_{2}$ capacity.

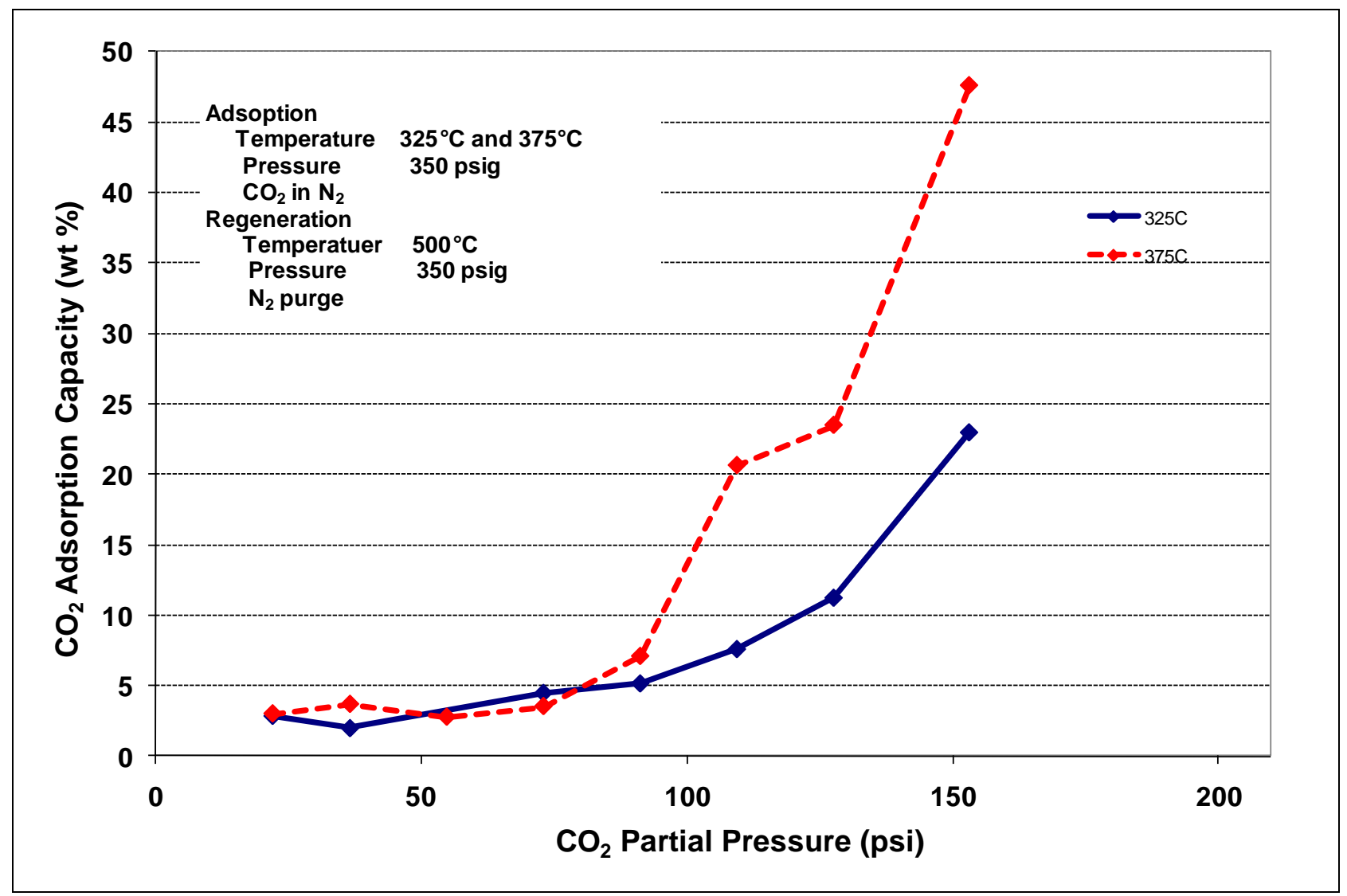

Figure 3-28. Effect of $\mathrm{CO}_{2}$ partial pressure on $\mathrm{CO}_{2}$ adsorption capacity

The next series of tests focused on exploring regeneration temperatures. During testing, the regeneration temperature was sequentially lowered from $500{ }^{\circ} \mathrm{C}$ to $375^{\circ} \mathrm{C}$ in increments of $25^{\circ} \mathrm{C}$. As shown in Figure 3-29, stable consistent performance is maintained when the sorbent is regenerated between $400{ }^{\circ} \mathrm{C}$ and $475^{\circ} \mathrm{C}$. At regeneration temperatures $>500{ }^{\circ} \mathrm{C}$ and $<400{ }^{\circ} \mathrm{C}$, the $\mathrm{CO}_{2}$ capacity of the sorbent drops rapidly during the first two to three cycles, but appears to become more stable in subsequent cycles. 


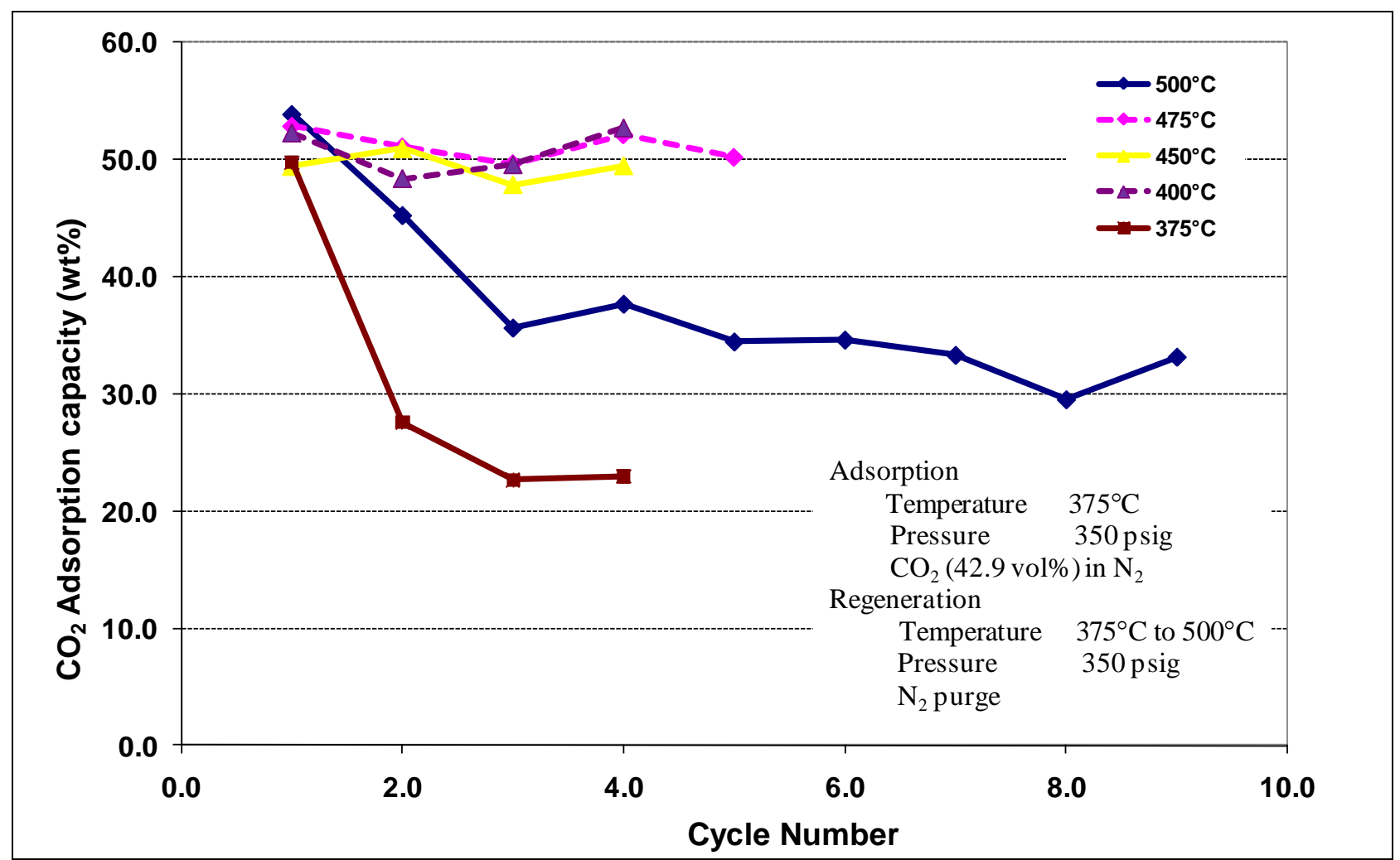

Figure 3-29. Effect of regeneration temperature on $\mathrm{CO}_{2}$ adsorption capacity

The sorbent was also tested at different space velocities from 750 to $2,000 \mathrm{~h}^{-1}$ at STP. The interesting result from this testing was that space velocity had little or no effect on the sorbent capacity, as shown in Figure 3-30.

A mixture of the sorbent and water gas shift (WGS) catalyst (8:1 sorbent to WGS catalyst) was tested to investigate potential benefits that could be derived from combining WGS and $\mathrm{CO}_{2}$ capture. These potential benefits included a reduction in the steam needed by using $\mathrm{CO}_{2}$ removal to help drive the shift reaction toward greater $\mathrm{H}_{2}$ and $\mathrm{CO}_{2}$ production and recovery of the exothermic WGS reaction enthalpy with the $\mathrm{CO}_{2}$ adsorption enthalpy. The results, shown in Figure 3-31, indicate that this mixed bed was able to effectively convert $\mathrm{CO}$ into $\mathrm{CO}_{2}$ and remove this $\mathrm{CO}_{2}$. 


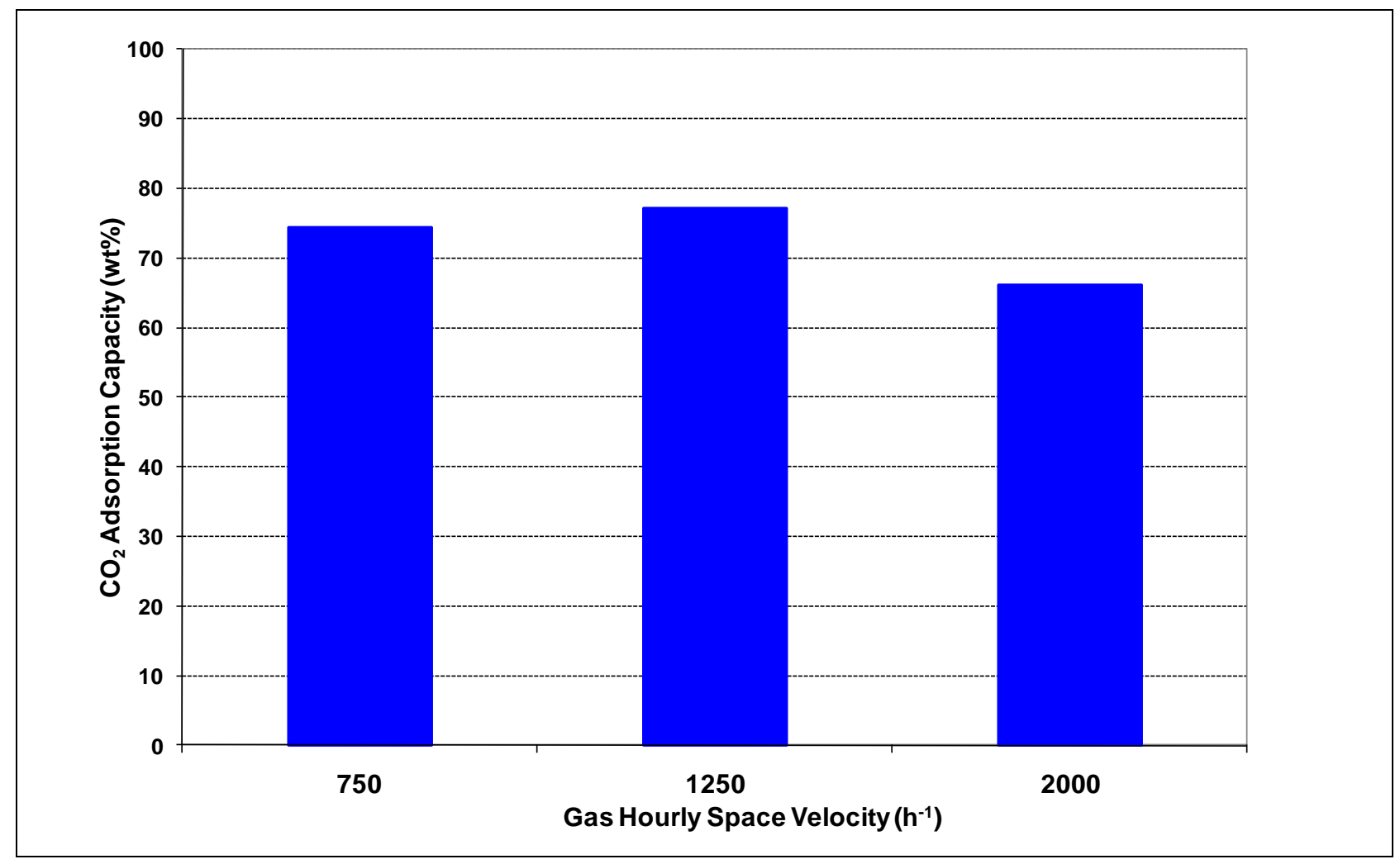

Figure 3-30. Effects of space velocity on $\mathrm{CO}_{2}$ adsorption capacity

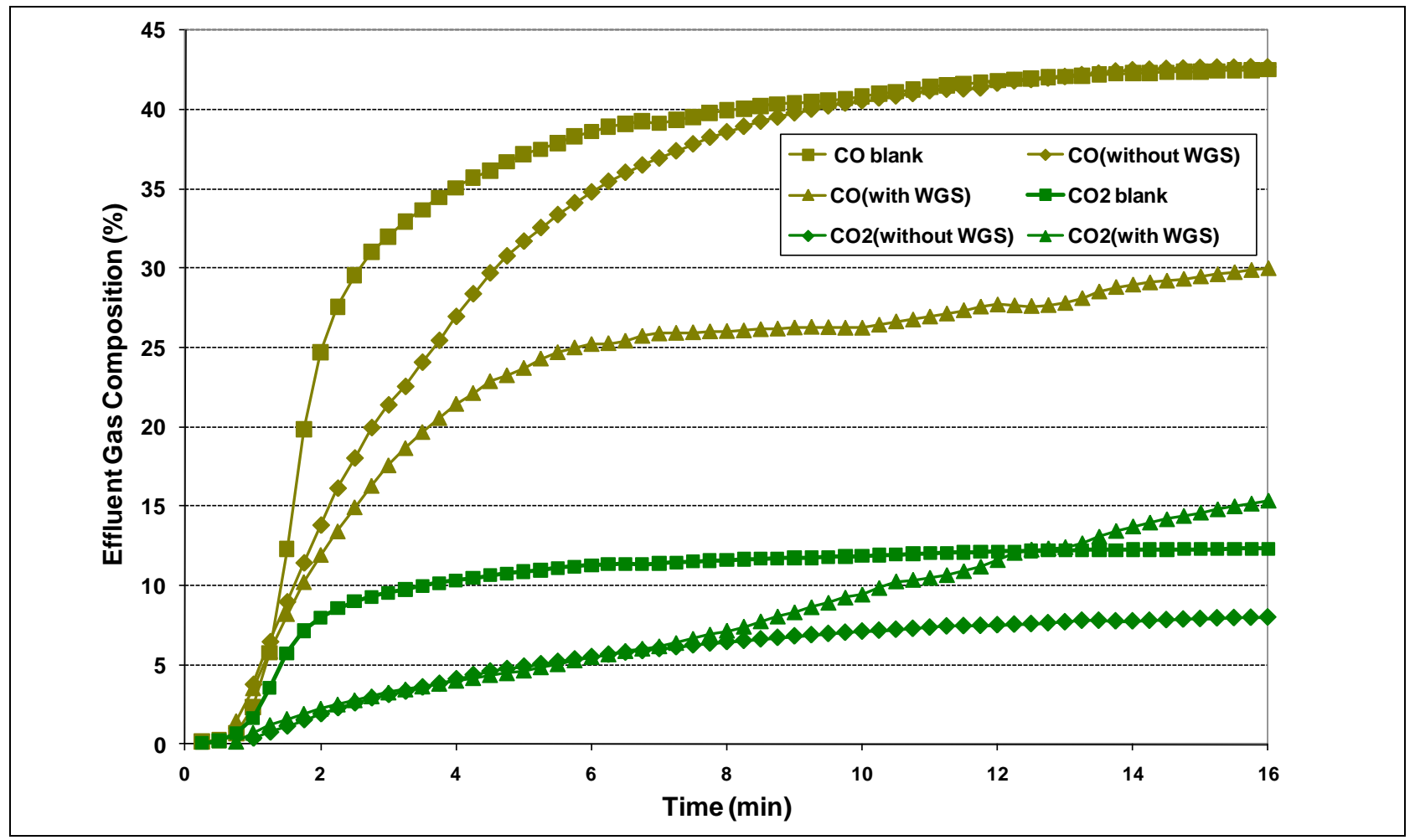

Figure 3-31. Effluent gas compositions for testing with and without WGS catalyst 
Because most of the previous testing had been completed based on thermal swing regenerations, a series of tests were completed to demonstrate that the promoted $\mathrm{MgO}$ sorbents could also be effectively regenerated with a pressure swing. The temperature for this regeneration was selected to be lower than the adsorption temperature to facilitate using the heat release during adsorption to drive the endothermic regeneration reaction. Figure 3-32 shows that the promoted $\mathrm{MgO}$ sorbents developed can be regenerated with a pressure swing and with a regeneration operating temperature less than $\mathrm{CO}_{2}$ adsorption. The cycle-to-cycle $\mathrm{CO}_{2}$ capacity during the tests using pressure swing regeneration was almost identical to the results obtained with thermal swing regeneration.

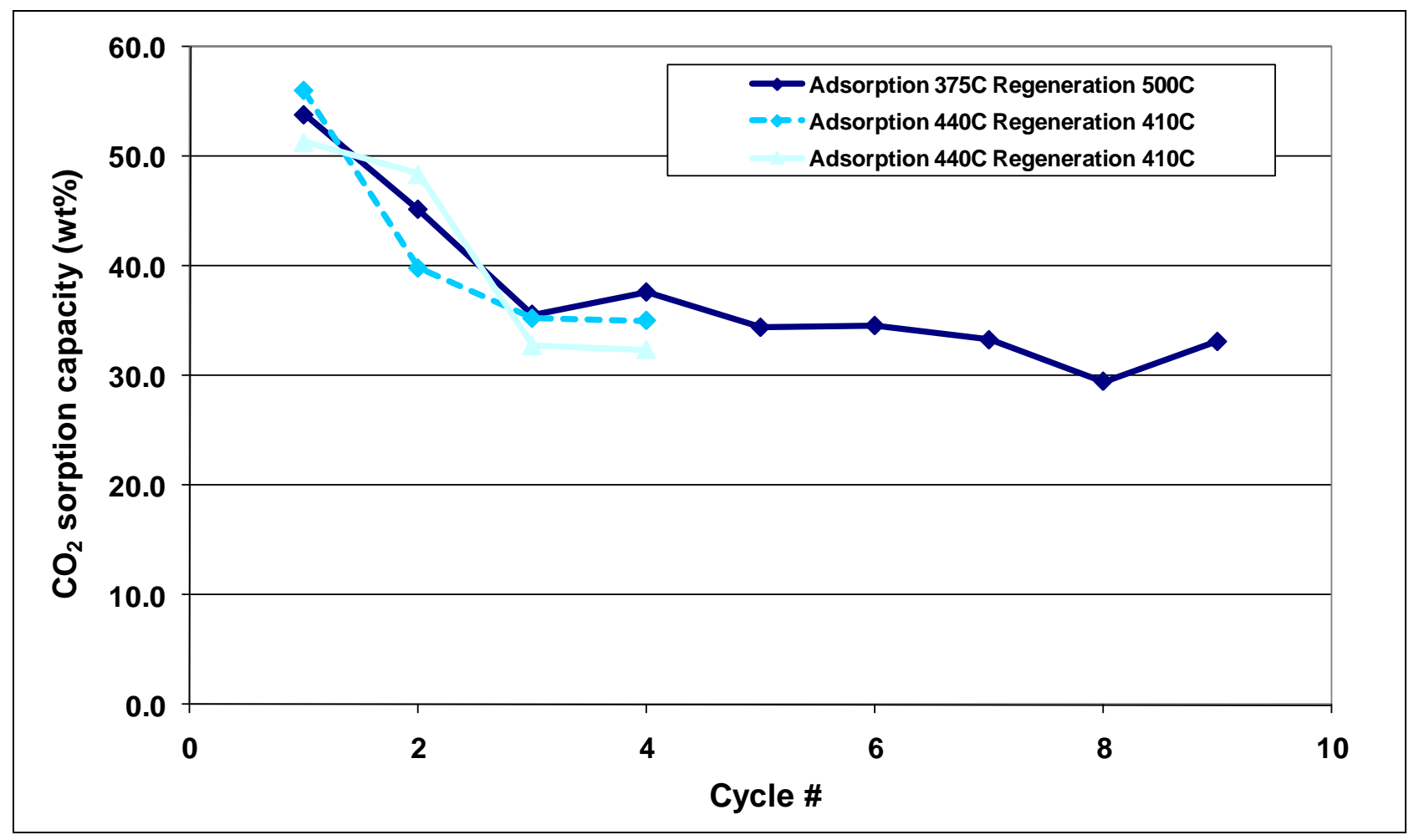

Figure 3-32. Test of new operating cycle for new process configuration

Because a key DOE programmatic goal is to achieve $90 \% \mathrm{CO}_{2}$ capture, a final series of experiments were conducted to demonstrate that a regenerable sorbent-based process using promoted $\mathrm{MgO}$ sorbent could effectively capture $90 \%$ of the $\mathrm{CO}_{2}$ in the feed stream. Because all reactor systems have an inherent volume, a blank test was conducted to establish the $\mathrm{CO}_{2}$ effluent profile for the reactor system without any $\mathrm{CO}_{2}$ adsorption. Subsequently, parametric testing at different $\mathrm{CO}_{2}$ partial pressures and adsorption temperatures was completed. Figure 333 shows the results at a $\mathrm{CO}_{2}$ partial pressure of $225 \mathrm{psi}$ and at three temperatures $(300,350$ and $400{ }^{\circ} \mathrm{C}$ ). As shown in Figure 3-33, the promoted $\mathrm{MgO}$ sorbent was able to reduce the effluent $\mathrm{CO}_{2}$ concentration to $<1 \mathrm{vol} \% \mathrm{CO}_{2}$ (detection limit for the equipment used in this particular test). 
The length of time that the sorbent can achieve this high $\mathrm{CO}_{2}$ capture decreased as the adsorption temperature increased. This high $\mathrm{CO}_{2}$ capture was also observed at 150,300, and $325 \mathrm{psi}$ of $\mathrm{CO}_{2}$ partial pressure. Figure 3-34 shows calculated $\mathrm{CO}_{2}$ adsorption capacities for this high $\mathrm{CO}_{2}$ capture at different adsorption temperatures and $\mathrm{CO}_{2}$ partial pressures. Calculated $\mathrm{CO}_{2}$ adsorption capacities associated with the high $\mathrm{CO}_{2}$ capture ranged from almost no adsorption to about $60 \mathrm{wt} \%$. As part of this additional testing, a different analytical system was used to monitor the effluent $\mathrm{CO}_{2}$ concentration to significantly lower the detection limit. With this new analytical system, the effluent concentration at the conditions demonstrating $>90 \% \mathrm{CO}_{2}$ capture was $<100$ ppmv.

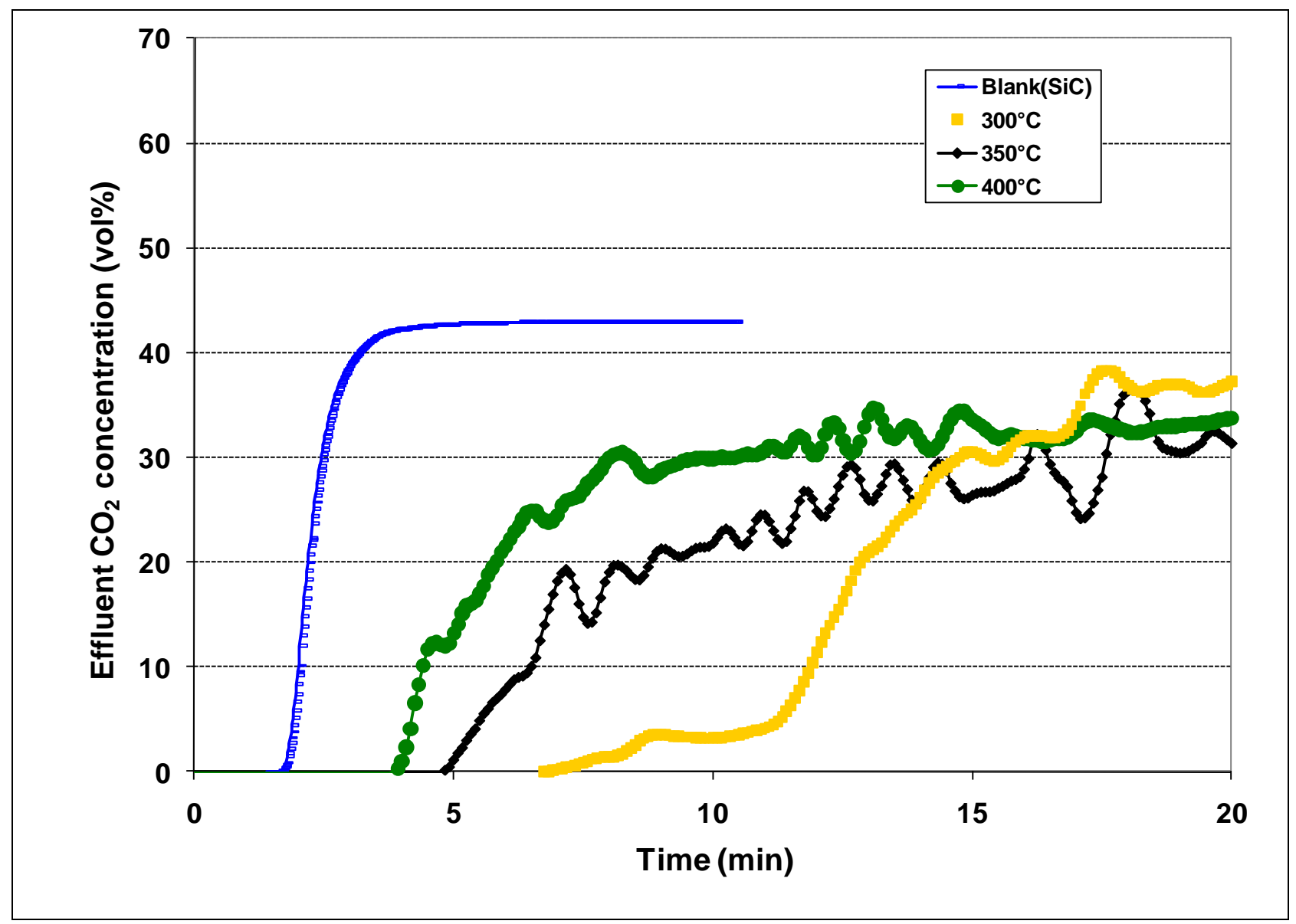

Figure 3-33. Temperature effects on MgO-based sorbents to achieve extremely low effluent $\mathrm{CO}_{2}$ concentrations at $225 \mathrm{psi}$ of $\mathrm{CO}_{2}$ partial pressure 


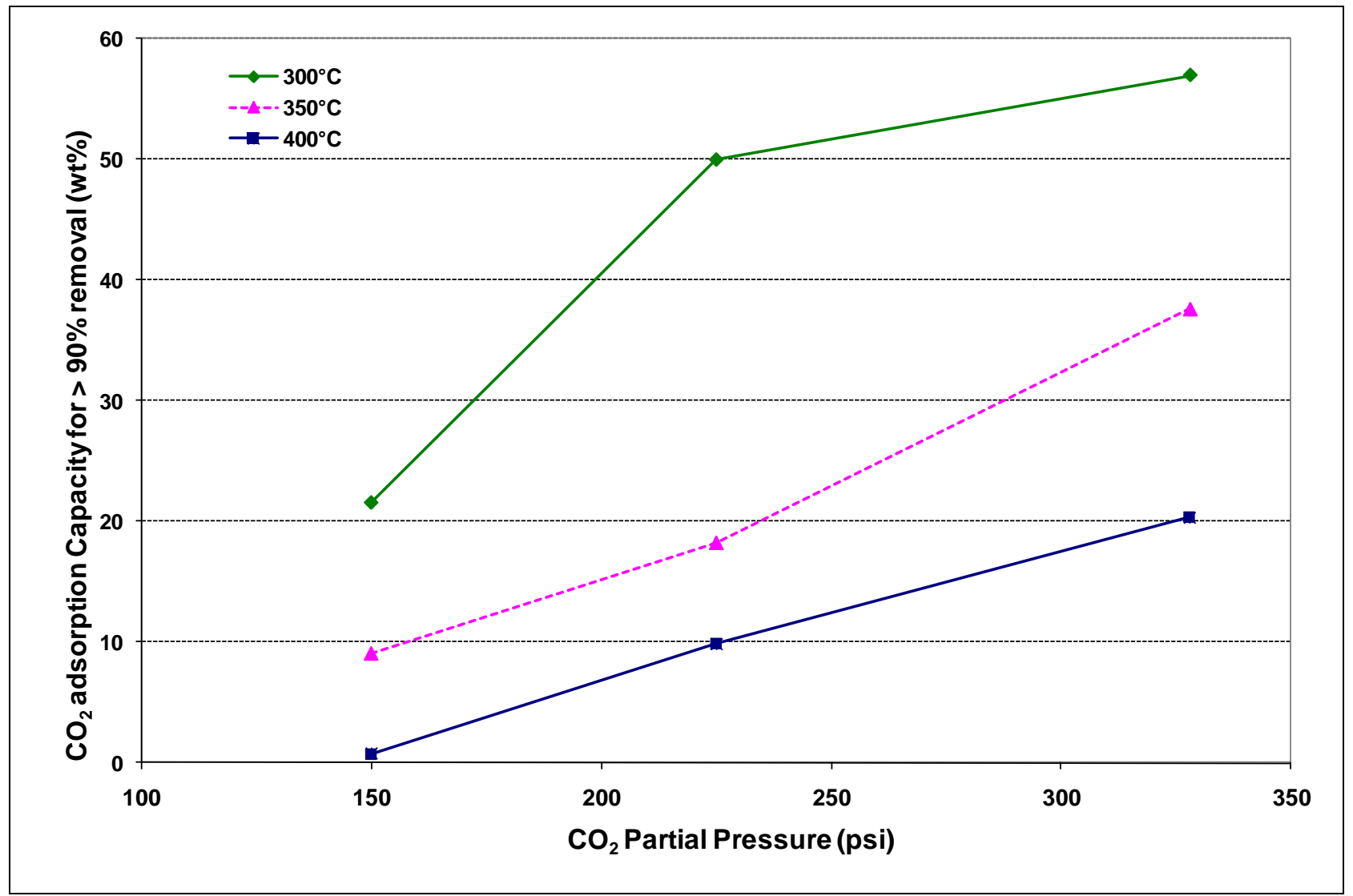

Figure 3-34. Calculated $\mathrm{CO}_{2}$ adsorption capacities near $100 \% \mathrm{CO}_{2}$ capture for parametric testing of adsorption temperature and $\mathrm{CO}_{2}$ partial pressure

\subsubsection{Process Simulation}

With the assistance of Noblis performing process simulation and analysis, RTI and Noblis evaluated a number of different process configurations. The simplified block flow diagram (BFD) of the generic IGCC system is shown in Figure 3-35. For this analysis, the goal was to evaluate and compare the thermal performance of different process configurations for the $\mathrm{CO}_{2}$ capture and processing system. To fulfill this goal, the systems in the balance of the IGCC plant remained constant, while different process configurations for the $\mathrm{CO}_{2}$ capture and processing system were evaluated. The specific processing required in the $\mathrm{CO}_{2}$ capture and processing system included $\mathrm{CO}$ conversion to $\mathrm{H}_{2}$ and $\mathrm{CO}_{2}$, separation of the $\mathrm{CO}_{2}$ from the $\mathrm{H}_{2}-$ rich syngas ( $>90 \% \mathrm{CO}_{2}$ capture), compression and conditioning of the $\mathrm{CO}_{2}$ product for sequestration, and additional conditioning of the $\mathrm{H}_{2}$-rich syngas. For the base case, the $\mathrm{CO}_{2}$ capture and processing system included a water gas shift train, a cooling train, a Selexol separation process for the $\mathrm{CO}_{2}$, and a compression train for the $\mathrm{CO}_{2}$. The comparison case for the emerging technologies used Eltron's high-temperature $\mathrm{H}_{2}$ membrane to separate the $\mathrm{CO}_{2}$ from the $\mathrm{H}_{2}$-rich syngas. 


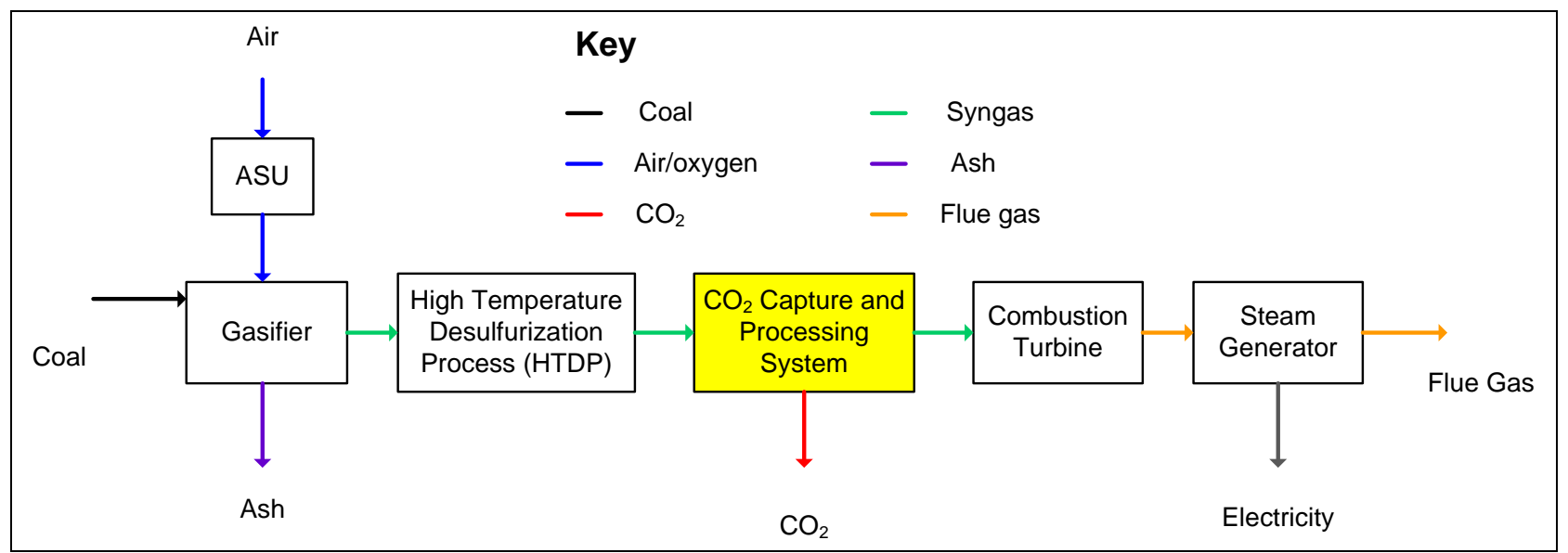

Figure 3-35. Block flow diagram of generic IGCC system

RTI evaluated a number of different configurations for the $\mathrm{CO}_{2}$ capture and processing system that attempted to exploit the high-pressure regeneration, potential process intensification combining the $\mathrm{CO}_{2}$ capture and the water gas shift reaction, and effective heat integration in the IGCC system. The most challenging was the heat integration. Because of the large amount of $\mathrm{CO}_{2}$ involved, the key challenge encountered during heat integration process was not the quantity of heat, but the ability to use this heat for increasing net power generation. For the different configurations evaluated, the overall thermal efficiencies were comparable or slightly better than conventional $\mathrm{CO}_{2}$ capture technologies. However, the overall efficiency improvements for these sorbent-based processes did not demonstrate the same level of thermal efficiency improvement that exists with other emerging technologies. Because the experimental results have demonstrated technical feasibility, RTI plans to continue to investigate and optimize thermal integration options for this technology. 



\section{SECTION 4 \\ CONCLUSIONS}

The overall objective for the Phase II work was to complete R\&D supporting commercial deployment of the warm syngas cleaning technology platform for chemical/fuels production. The specific work to be accomplished in this phase is listed below:

- Provide technical support to facilitate successful scale-up of the warm syngas desulfurization process for a demonstration plant.

- Develop a warm syngas cleaning platform that will produce an effluent syngas product suitable for chemical/fuels production with the specification provided in Table4-1.

- Develop a warm syngas $\mathrm{CO}_{2}$ capture

Table 4-1. Warm Syngas Cleanup'DOE Performance Goals

\begin{tabular}{cc}
\hline Contaminant & $\begin{array}{c}\text { Maximum after } \\
\text { Cleanup }\end{array}$ \\
\hline $\mathrm{S}$ (total) & $50 \mathrm{ppb}$ \\
$\mathrm{NH}_{3}$ & $10 \mathrm{ppm}$ \\
$\mathrm{HCl}$ & $10 \mathrm{ppb}$ \\
$\mathrm{Hg}$ & $5 \mathrm{ppbw}$ \\
$\mathrm{Se}$ & $0.2 \mathrm{ppm}$ \\
$\mathrm{As}$ & $5 \mathrm{ppb}$ \\
$\mathrm{P}$ & $20 \mathrm{ppb}$ \\
$\mathrm{CO}_{2}$ & $>90 \%$ \\
\hline
\end{tabular}

${ }^{1}$ At pressure $\geq 600 \mathrm{psi}$; temperatures $\geq 400^{\circ} \mathrm{F}$ technology for both power and chemical production with a goal of $90 \% \mathrm{CO}_{2}$ removal and producing a sequestration-ready $\mathrm{CO}_{2}$ stream.

The first task has been added to the scope of work of DOE/NETL cooperative agreement DE-FE0000489 because these activities are critical to the successful design, construction, and operation of the precommercial syngas cleaning system.

\subsection{Multicontaminant Technologies for Warm Syngas Cleanup Platform}

Although the Eastman field test was specifically focused on $\mathrm{Hg}$ and As sorbents, this field test was the foundation from which the project was expected to continue and expand the multicontaminant technology development. To this end, the sorbents exposed during the Eastman field test were carefully analyzed to extract as much information about contaminant removal by these sorbents as possible. Through these analyses, multi-component capacity of Commercial Sorbent A was demonstrated. The observation of the trends for As capture by the different sorbent beds has provided evidence that more than one chemical species of As is present in the syngas. These other As species also have interacted differently with the sorbents, resulting in different removal capacities. 
The Hg removal by Commercial Sorbent A during the Eastman field test was thoroughly investigated. The results of this investigation demonstrated that the Se capture by Commercial Sorbent A provided the sorbent with the potential to capture $\mathrm{Hg}$. Additional testing of the Sebased sorbent has shown that Se has the potential for very high $\mathrm{Hg}$ capacities at higher temperatures, but these higher operating temperatures result in the loss of Se through vaporization. Experimentation with combination of multi-functional sorbents has shown promise in providing higher $\mathrm{Hg}$ removal capacities and limiting Se loss. Additional research will be necessary to fully develop and apply these multi-functional sorbent beds to optimize $\mathrm{Hg}$ capacity and removal.

Sorbent development for As, Se, and P was able to identify a number of candidate sorbents that demonstrated $>3.0 \mathrm{wt} \%$ capacity for these contaminants. With the primary selection process focusing on commercial materials and materials with the ability to remove multiple contaminants, the list of promising candidate sorbents is demonstration of successful acceleration of development and commercialization of these technologies.

Efforts to start testing for potential sorbents for $\mathrm{Cd}$ were hindered by the challenge of generating a consistent and known concentration of $\mathrm{Cd}$ vapor in a simulated syngas mixture. Even when the temperature of the $\mathrm{Cd}$ generator was maintained just $10{ }^{\circ} \mathrm{C}$ below its melting point, the effluent $\mathrm{Cd}$ vapor concentration was significantly less than thermodynamic predictions. This, coupled with the evidence from the Eastman field test that demonstrated a near-zero $\mathrm{Cd}$ concentration in actual coal-derived syngas, suggests that $\mathrm{Cd}$ may not be a serious contaminant in actual coal-derived syngas. These results warrant considering whether additional research in $\mathrm{Cd}$ removal technologies is necessary.

\section{2 $\mathrm{CO}_{2}$ Technology for Warm Syngas Cleanup Platform}

One of the key objectives for developing the $\mathrm{CO}_{2}$ capture technology under this project was to implement a modified version of our original screening process to identify materials that had the potential to regenerate at higher $\mathrm{CO}_{2}$ partial pressures. The primary reason for this objective was to significantly reduce the amount of diluents necessary for sorbent regeneration, but this goal also presented a major opportunity for generating a high-pressure $\mathrm{CO}_{2}$ by-product that could significantly reduce the parasitic energy demand for $\mathrm{CO}_{2}$ compression. With this modified screening protocol, we were able to successfully demonstrate the ability to generate a high-pressure $\mathrm{CO}_{2}$ product for both $\mathrm{MgO}$-based materials and zeolite materials.

With two promising sorbent candidates, our next challenges were to develop a process to effectively exploit the promise of these two materials and to develop an acceptable formulation 
for commercial production. For the zeolite sorbents, a key component of the process was to demonstrate that lithium silicate could produce a stream from which the zeolite material could effectively capture the $\mathrm{CO}_{2}$. Unfortunately, efforts to demonstrate that the lithium silicate could produce a suitable product stream for $\mathrm{CO}_{2}$ recovery with zeolites were not successful. At this point, all research efforts were reallocated to development of the $\mathrm{MgO}$ sorbent.

Although $\mathrm{MgO}$ has significant potential for $\mathrm{CO}_{2}$ capture based on favorable thermodynamic equilibrium, actual experimental results with commercially available $\mathrm{MgO}$ based materials did not support the thermodynamic results. Through efforts to increase the reactivity of the $\mathrm{MgO}$ for $\mathrm{CO}_{2}$, we identified a total of six promoter mixtures that significantly increased the $\mathrm{CO}_{2}$ capacity of $\mathrm{MgO}$ materials from $<5 \mathrm{wt} \%$ to a range of 40 to $60 \mathrm{wt} \%$. During testing with syngas, the most detrimental effect was associated with steam. Two of these promoters have been demonstrated to work in syngas mixtures with 10 vol\% steam. The most promising promoter demonstrated that, up to a steam concentration of $60 \mathrm{vol} \%$, the steam resulted in only a moderate increase in the $\mathrm{CO}_{2}$ adsorption capacity.

As part of facilitating sorbent development, it was demonstrated that readily available commercial samples of $\mathrm{MgO}$ materials could be promoted with a significant increase in $\mathrm{CO}_{2}$ adsorption capacity. This promotion was effective even with a commercial FCC catalyst material called $\mathrm{DeSO}_{\mathrm{x}}$, which had typical attrition resistance, particle size distribution, and fluidization properties suitable for fluid bed applications.

Based on the significant amount of $\mathrm{CO}_{2}$ adsorbed by $\mathrm{MgO}$, sorbent development focused on identifying a material that could provide the structural support for the repetitive transformation between $\mathrm{MgO}$ and $\mathrm{MgCO}_{3}$ and would be essentially inert toward $\mathrm{MgO}$ and the various promoters. A number of different materials were screened, with magnesium aluminate being the most promising. In several preparations, calcination temperatures above $400{ }^{\circ} \mathrm{C}$ resulted in a significant reduction in $\mathrm{CO}_{2}$ adsorption capacity. One preparation method in which promoters were added as the final preparation step demonstrated $\mathrm{CO}_{2}$ adsorption capacity that was not adversely affected by calcination temperature and had reasonable cycle-to-cycle stability.

The final challenge was to incorporate the development completed for the $\mathrm{MgO}$-based sorbent into a process with acceptable thermal integration in an IGCC system. The thermal integration for this process was probably the most challenging aspect of the project. Although a number of novel and creative approaches were considered, the net improvement in the overall thermal efficiency of the IGCC system was less than that for other emerging $\mathrm{CO}_{2}$ capture 
technologies being developed for IGCC systems. The key challenge encountered during our thermal integration process was not the quantity of heat, but the ability to use this heat for increasing net power generation. Because optimizing thermal integration is a challenge faced by all $\mathrm{CO}_{2}$ capture technologies, we are continuing to examine approaches that can effectively result in an optimal integrated system with high thermal efficiency. 